Portland State University

PDXScholar

Winter 4-3-2015

\title{
A Metal-Free Approach to Biaryl Compounds: Carbon-Carbon Bond Formation from Diaryliodonium Salts and Aryl Triolborates
}

Kuruppu Lilanthi Jayatissa

Portland State University

Follow this and additional works at: https://pdxscholar.library.pdx.edu/open_access_etds

Part of the Catalysis and Reaction Engineering Commons Let us know how access to this document benefits you.

\section{Recommended Citation}

Jayatissa, Kuruppu Lilanthi, "A Metal-Free Approach to Biaryl Compounds: Carbon-Carbon Bond Formation from Diaryliodonium Salts and Aryl Triolborates" (2015). Dissertations and Theses. Paper 2229.

https://doi.org/10.15760/etd.2226

This Thesis is brought to you for free and open access. It has been accepted for inclusion in Dissertations and Theses by an authorized administrator of PDXScholar. Please contact us if we can make this document more accessible: pdxscholar@pdx.edu. 


\title{
A Metal-Free Approach to Biaryl Compounds: Carbon-Carbon Bond Formation from
} Diaryliodonium Salts and Aryl Triolborates.

$$
\text { by }
$$

Kuruppu Lilanthi Jayatissa

\begin{abstract}
A thesis submitted in partial fulfillment of the requirement for the degree of
\end{abstract}

\author{
Master of Science \\ in \\ Chemistry
}

\section{Thesis Committee: David Stuart, Chair Robert Strongin Theresa McCormick}

Portland State University 2015 


\begin{abstract}
Biaryl moieties are important structural motifs in many industries, including pharmaceutical, agrochemical, energy and technology. The development of novel and efficient methods to synthesize these carbon-carbon bonds is at the forefront of synthetic methodology. Since Ullmann's first report of stoichiometric $\mathrm{Cu}$-mediated homo-coupling of aryl halides, there has been a dramatic evolution in transition metal catalyzed biaryl cross-coupling reactions.
\end{abstract}

Our work focuses on the discovery and development of an unprecedented reagent combination for metal-free cross-coupling. It is hypothesized that direct carbon-carbon bond formation occurs via a triaryl- $\lambda^{3}$-iodane and that electrophile/nucleophile pairing is critical for success in the reaction. Proof-of-concept for this approach focused on the reaction between bromo 4-trifluoromethylphenyl(trimethoxybenzene)- $\lambda^{3}$-iodane and potassium 3-fluorophenyltriolborate. The spectator ligand and counter ions are important parameters for both reactivity and selectivity of the aryl group transfer in this reaction. Moderate to good yields of biaryl products are obtained by this method. Experimental evidence supports the assertion of a metal-free cross-coupling reaction. 


\section{Dedication}

To my parents and loving husband, who always have faith in me: I'm sorry I was away so much and I hope you know how thankful I am for everything. 


\section{Acknowledgements}

I would like to express my deepest appreciation and gratitude to the entire Stuart research group: mostly to Dr. David Stuart for his support and kindness; for always being patient with me and teaching how to become a great scientist. For believing in my project and pushing me to bring it to where it is today. Sunil Sundalam for being a great friend and lab colleague throughout the two years and for helping with my NMR and Mass spectroscopic data. Thomas Seidl for editing my thesis and for encouraging me to try out new ideas. Undergraduate student Mark Wilkinson for his assistance in optimizing the general reaction. Tricia Clement for helping me prepare starting materials in the last few weeks when things were getting rough. Last but not least my beloved undergraduates Olga Britantchouck and Chandler Barton for all the help with melting points, Infrared spectroscopy and Mass spectroscopy.

I also owe a debt of gratitude to non-group members: Rob Jensen and Kelsie Kendrick for teaching me NMR spectroscopy and Portland State University and ACS PRF for providing funding.

Finally, a special thanks to my committee members, Dr. Robert Strongin and Dr. Theresa McCormick, for setting aside time in their busy schedules to review my thesis. 


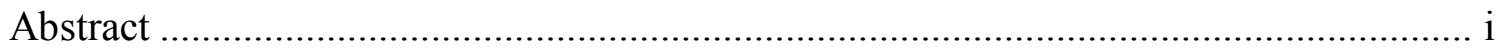

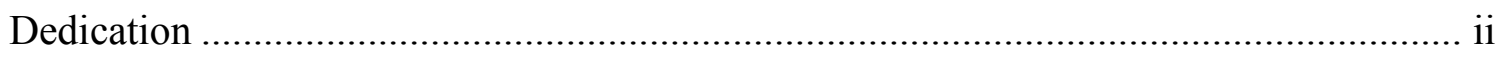

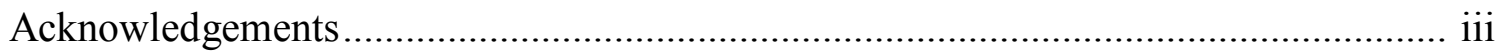

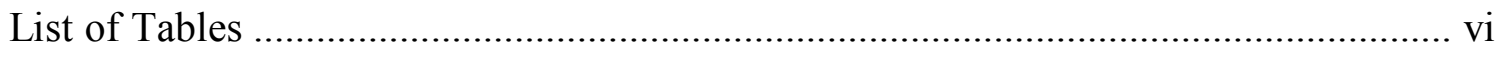

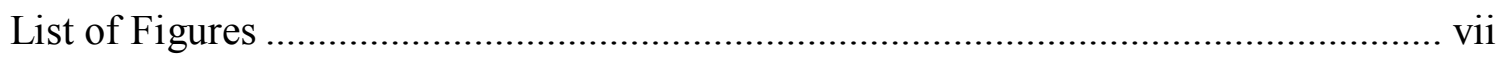

List of Abbreviations .......................................................................................... viii

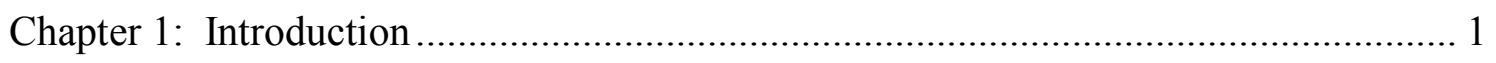

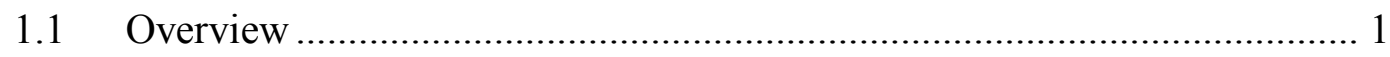

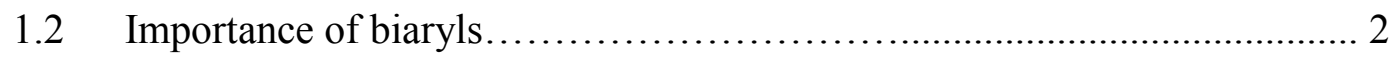

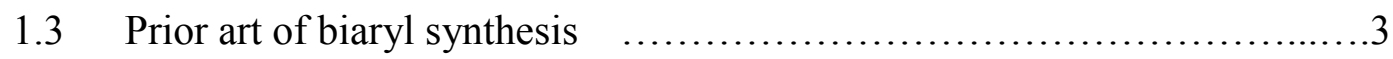

1.3.1 Use of stoichiometric metal in the synthesis of biaryls: Ullmann

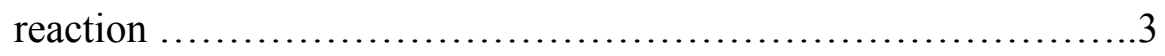

1.3.2 Prior art of carbon carbon cross coupling via metal catalyzed reactions..............................................

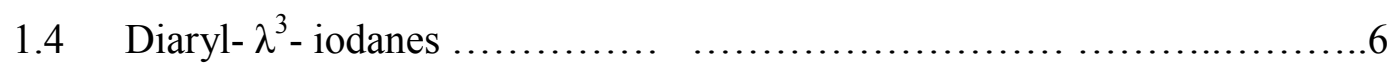

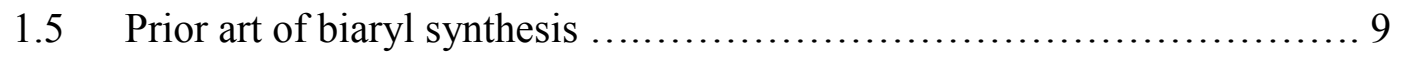

1.6 Triolborates- Cyclic stable complexes of boronic acids................. 10

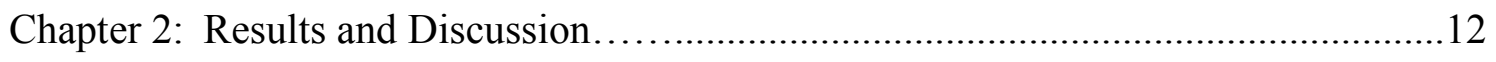

2.1 Reaction discovery and development ............................... 12

2.2 Reaction of diaryl- $\lambda^{3}$-iodanes with highly reactive nucleophiles...........12

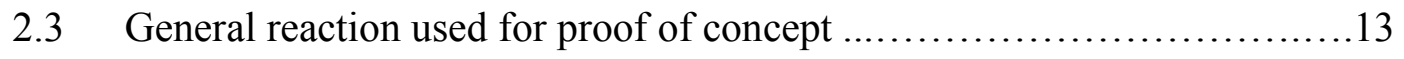


2.4 Nucleophilicity of the triolborates ............................... 16

2.5 Development and optimization of the general reaction ...................19

2.6 Scoping of the reaction with multiple substrates ...................... 22

2.7 Mechanistic hypotheses for the formation of biaryl compounds............25

2.8 Results observed with metal catalysts .............................26

2.9 Our proposed mechanism for the metal free synthesis of biaryls.........29

2.10 Isolation of the proposed salt metathesis product...................... 30

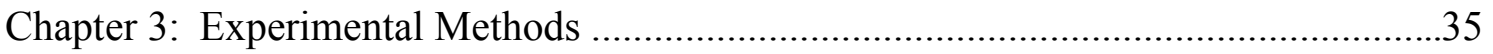

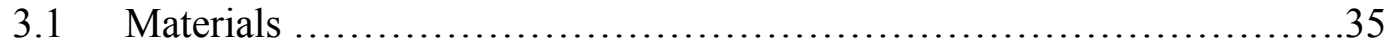

3.2 Methods and instrumentation......................................... 35

$3.3 \quad$ Reaction schemes.................................................

3.3.1 Synthesis of diaryl- $\lambda^{3}$-iodane............................. 36

3.3.2 Synthesis of cyclic triolborates................................

3.3.3 Synthesis of biarlys........................................40

3.3.4 Synthesis of metathesis intermediate.........................40

3.3.5 Synthesis of biaryls via Grignard and organolithiums............41

3.4 Characterization data..............................................42

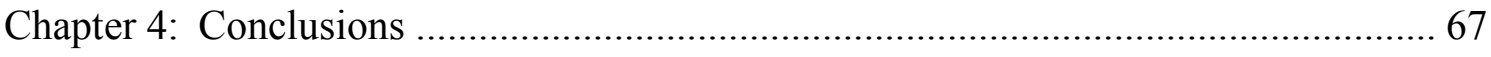

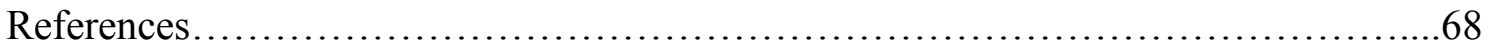

Appendix ${ }^{1} \mathrm{H},{ }^{13} \mathrm{C}$, and ${ }^{19} \mathrm{~F}$ NMR spectra of new compounds....................................72 


\section{List of Tables}

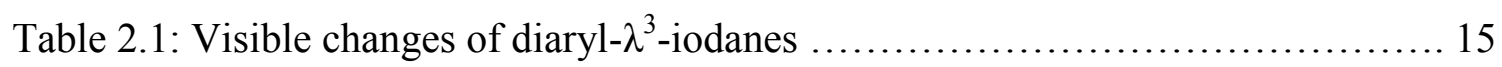

Table 2.2: Nucleophilicity of the triolborates ...................................17

Table 2.3: Optimization table of triolborate counter ion .......................... 18

Table 2.4: Stability of different triolborate counter ions ...........................19

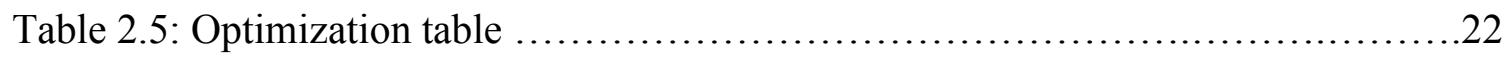

Table 2.6: ICP-MS data for the starting materials ...............................27

Table 2.7: Using the general reaction to explore the effect of metal catalysts ...........28

Table 2.8: Reaction used to probe the effect of metal catalysts ......................29 


\section{List of Figures}

Figure 1.1: Structures of important biaryl compounds (highlighted in red)...............2

Figure 1.2: Catalytic cycle for general palladium catalyzed cross-coupling reactions .....4

Figure 1.3: Carbon cross coupling via aryl halides with transition metal catalysts........5

Figure 1.4: Metal catalyst intermediate vs. diaryl- $\lambda^{3}$ - iodane intermediate ...............6

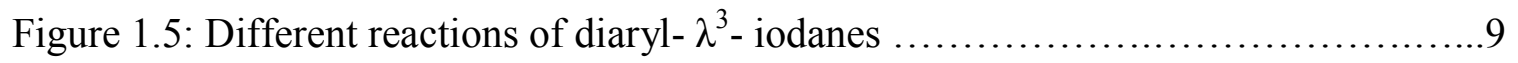

Figure 1.6: Ranking organoboron compounds in comparison with related nucleophiles..11

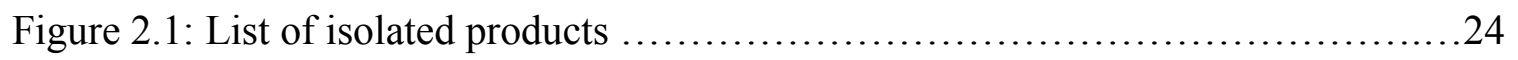

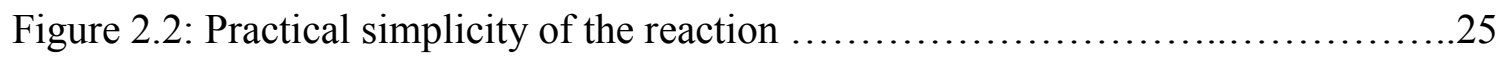

Figure 2.3: Berry-pseudo rotation of the T-shaped reaction intermediate $\ldots \ldots \ldots \ldots . . . .30$

Figure 2.4: ${ }^{1} \mathrm{H}$ NMR spectra confirmed the formation of the salt metathesis product ....32

Figure 2.5: ${ }^{19} \mathrm{~F}$ NMR spectra confirmed the disappearance of the triflate peak...........32

Figure 2.6: Proposed mechanism of the reaction............................... 33 
$\mathrm{AcOH}-$ Acetic acid

Ar - Aryl group

$\mathrm{ArNH}_{2}$ - Aryl amine

ArOH - Aryl alcohol

$\mathrm{CDCl}_{3}-$ Chloroform-D

DCE - Dichloroethane

DCM - Dichloromethane

DMSO - Dimethyl sulfoxide

EDG - Electron donating group

EWG- Electron withdrawing group

HFIP - Hexafluoro-2-propanol

HRMS - High resolution mass spectra

$\mathrm{H}_{2} \mathrm{O}$ - Water

ICP-MS - Inductively coupled plasma mass spectrometry

$\mathrm{KBr}$ - Potassium bromide

KF - Potassium fluoride

m-CPBA - Meta-Chloroperoxybenzoic acid

$\mathrm{MeCN}$ - Acetonitrile

MES - Mesitylene

2-Me THF - 2-Methyltetrahydrofuran

$\mathrm{NaBF}_{4}$ - Sodium tetrafluoroborate

$\mathrm{NaCN}$ - Sodium cyanide 


\author{
$\mathrm{NH}_{3}-$ Ammonia \\ NMR - Nuclear Magnetic Resonance spectroscopy \\ $\mathrm{NaOH}$ - Sodium hydroxide \\ $\mathrm{NaOt}-\mathrm{Bu}$ - Sodium tert-butoxide \\ NaOTf- Sodium triflate \\ $\mathrm{Nu}$ - Nucleophile \\ R - Substituent \\ $\mathrm{RMgBr}$ - Grignard reagent \\ SET - Single electron transfer \\ TFE - 2,2,2-trifluoroethanol \\ THF - Tetrahydrofuran \\ TLC - Thin Layer Chromatography \\ TMB - Trimethoxybenzene \\ TMS - Tetramethylsilane \\ TMSO - Trimethylsilyl \\ $\mathrm{TfOH}$ - Triflic acid
}




\section{Chapter 1: Introduction}

\subsection{Overview}

Carbon-carbon and carbon-hetaroatom bond formation is a central process in many industries, including pharmaceutical, agrochemical, energy and technology. ${ }^{1,2}$ Hence there is a need to develop simple and synthetically useful methods to form these bonds. ${ }^{3}$ This thesis focuses on the formation of biaryls and specifically a new reagent combination for the construction of these compounds: diaryliodonium salts and potassium aryl triolborates. This metal free approach to biaryl compounds aims to address the economic and environmental sustainability concerns of contemporary transition metal catalyzed strategies. The unprecedented reagent combination we have discovered to accomplish this transformation provides a new pathway to the formation of biaryl bonds.

Chapter 1 provides an introduction to biaryls and prior history of synthetic methods for the formation of these moieties. The general chemistry of diaryliodonium salts (also referred to here as diaryl- $\lambda^{3}$-iodanes) and cyclic triolborates are also discussed in this chapter. Chapter 2 discusses the results of the discovery and development of this metalfree method to produce biaryl compounds. The Results and Discussion chapter will also provide data to demonstrate establishment of reactivity and optimization of the general reaction, followed by the scope of this new reactivity. A mechanistic hypothesis for the observed reactivity is discussed and experiments to corroborate the hypothesis are presented. Chapter 3 will outline detailed experimental procedures and characterization 
data for all the compounds and copies of ${ }^{1} \mathrm{H},{ }^{13} \mathrm{C}$ and ${ }^{19} \mathrm{~F}$ NMR spectra for all new compounds are also provided as Appendix.

\subsection{Importance of biaryl compounds}

Biaryls are molecules with two aryl rings connected by a single sigma bond ${ }^{4}$ and this axis is known as the biaryl axis. Synthesis of carbon-carbon bonds between arenes is significant to many industries. Biaryl motifs are important in pharmaceuticals, agrochemicals, energy and functional materials (Figure 1.1). ${ }^{5}$ Thus the development of new and sustainable methods for the formation of biaryl bonds is of critical importance to the low-cost and environmentally benign production of these important compounds.<smiles>CCOC(=O)Cc1ccc(-c2ccccc2)cc1</smiles>

Antiarthritic Anti-inflammatory Drug<smiles>Cc1ccc(NC(=O)c2ccc(CN3CCN(C)CC3)cc2)cc1Nc1nccc(-c2cccnc2)n1</smiles><smiles>CC(C)c1nc(N(C)S(C)(=O)=O)nc(-c2ccc(F)cc2)c1/C=C/C(O)CC(O)CC(=O)O</smiles>

Rosuvastatin Treats Cholesterol<smiles>Cn1cc(C(=O)Nc2ccc(F)cc2-c2ccc(Cl)c(Cl)c2)c(C(F)F)n1</smiles><smiles>CCc1ccc(-c2ccc(-c3ccc(-c4ccc(C(C)(C)C)s4)s3)s2)s1</smiles>

Polythiophene Conducting polymer

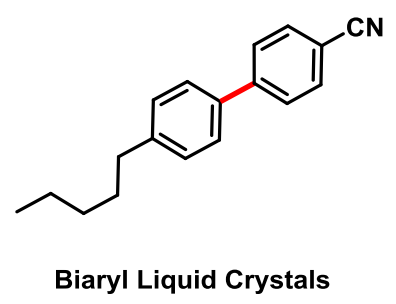

Figure 1.1: Structures of important biaryl compounds (bonds highlighted in red) 


\subsection{Prior art of biaryl synthesis}

1.3.1. Use of stoichiometric metal in the synthesis of biaryls: Ullmann reaction $(1901)^{4}$

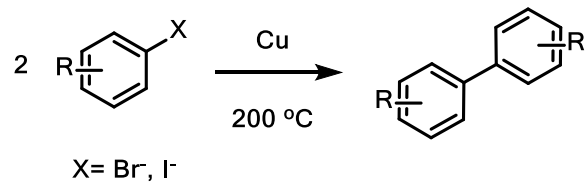

Scheme1.1: Ullmann reaction

Fritz Ullmann reported the first example of biaryl synthesis through the homocoupling of two aryl halides in 1901. In this reaction two equivalents of an aryl halide and one equivalent copper was reacted at $200{ }^{\circ} \mathrm{C}$ to produce biaryls and the corresponding copper halide. After this discovery many methodologies have been developed to form biaryl bonds via metal catalyzed routes. Kumada, Negishi, Stille, Hiyama and Suzuki are a few examples of cross coupling reactions of halides and aryl organometallics via transition-metal catalysis.

\subsubsection{Prior art of carbon carbon cross-coupling via metal catalyzed reactions}

Transition metals such as $\mathrm{Ni}(0)$ and $\mathrm{Pd}(0)$ are primarily used to catalyze cross coupling reactions. ${ }^{6}$ The general catalytic cycle for the palladium catalyzed crosscoupling of aryl electrophiles and nucleophilic organometallic compounds involves oxidative addition, transmetalation and reductive elimination (Figure 1.2). In the oxidative addition step the organo halide reacts with the palladium catalyst to form a palladium-aryl bond. In transmetalation the organometallic coupling partner transfers a 
nucleophilic group to the catalyst. Finally the palladium catalyst reductively eliminates the aryl-nucleophile bond and regenerates the metal catalyst.

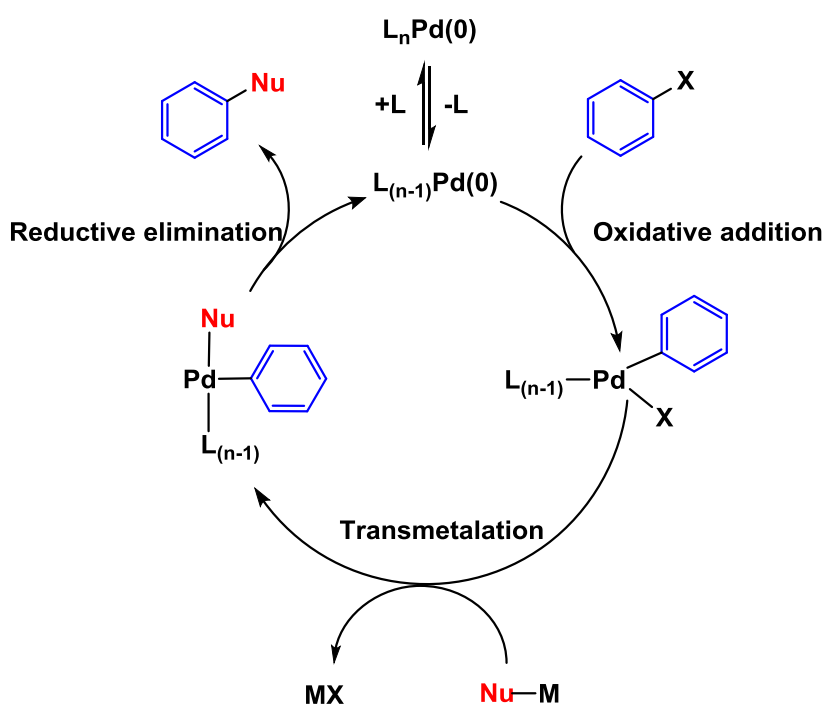

Figure 1.2: Catalytic cycle for general palladium catalyzed cross-coupling reactions Many reactions have been developed over the years to form carbon carbon bonds in biaryls via aryl halides with the use of transition metal catalysts. One of the largest differences among the various methods is the type of organometallic compound used and this can have a significant influence on the reactivity and the functional group tolerance of the reaction (Figure 1.3). Kumada ${ }^{7}$ coupling reactions between an aryl halide and a Grignard reagent is one method to successfully cross-coupled biaryl products. Grignard reagents are not functional group tolerant and will react with moisture so these reactions need to be carried out under oxygen-free and moisture-free conditions. Negishi ${ }^{8}$ reacted organo zinc chloride, with an organo halide (iodide or bromide) in THF with catalytic amounts of a Pd-phosphine complex to give carbon-carbon coupling products in high yield. Organozinc reagents are less reactive than Grignard reagents, therefore are more functional group tolerant. Stille ${ }^{9}$ found that organotin compounds readily react with 
organohalides in the presence of a palladium catalyst and ligands (phosphine) and yield carbon-carbon coupling products. Tin is a highly toxic metal thus is not used industrially. Hiyama ${ }^{10}$ reported that organic halides and organosilicon compounds produce the desired coupling products in the presence of a palladium catalyst and a fluorine source. Common fluoride sources include potassium fluoride $(\mathrm{KF})$, cesium fluoride (CsF) and tris(diethylamino)sulfonium difluorotri- methylsilicate (TASF). The Suzuki ${ }^{11}$ reaction is one of the most versatile reactions for the selective synthesis of carbon-carbon bonds. It is widely utilized in the formation of biaryls. ${ }^{12}$ In these reactions Suzuki focused on the use of organoboronic acids for a number of reasons, including their thermal stability and inertness to water and oxygen. These features therefore allow handling without special precautions. ${ }^{13}$ Organoboron nucleophiles were reacted with the eletrophilic organic halides in the presence of palladium catalyst and base to produce good yields of carboncarbon coupling products. This reaction is done under mild conditions and byproducts formed are non toxic. In the development of the Suzuki reaction conditions a wide range of palladium metal complexes have been created and used as catalysts. ${ }^{14}$ Low catalyst loading of palladium complexes are often used in these reactions.

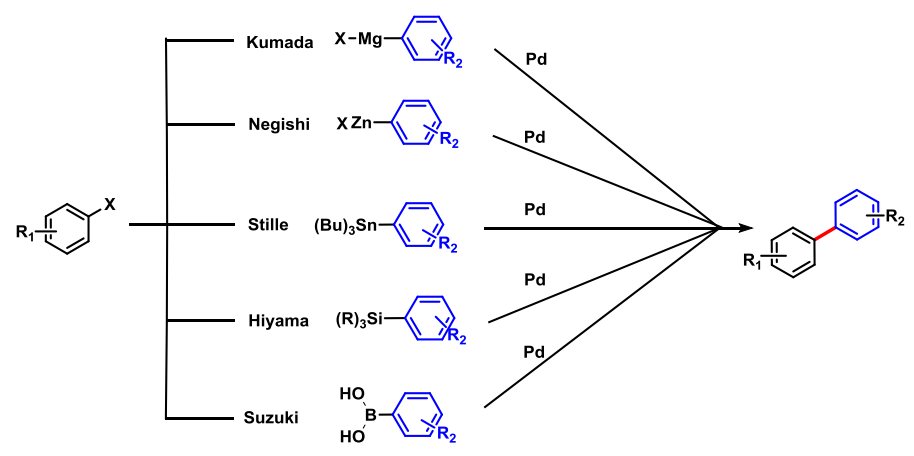

Figure 1.3: Carbon-carbon cross coupling via aryl halides with transition metal (Pd) catalysts 


\subsection{Diaryl- $\lambda^{3}$-iodanes}

Hypervalent iodine compounds belong to two general structural types: iodine (III) (also refer to as $\lambda^{3}$-iodanes) and iodine (V) (also refer to as $\lambda^{5}$-iodanes). The $\lambda^{3}$-iodanes have geometry of distorted trigonal bipyramid while the $\lambda^{5}$-iodanes are octahedral. ${ }^{22}$ In diaryl- $\lambda^{3}$-iodanes the axial position is occupied by the counter ion and one of the aryl groups. The least electronegative aryl group and both electron pairs reside in equatorial positions. Bonding in these compounds use non-hybridized 5p orbital of iodine forming a three-center, four-electron $(3 \mathrm{c}-4 \mathrm{e})$ bond which is longer and weaker, therefore gives rise to high electrophilicity of iodine in diaryl- $\lambda^{3}$-iodanes. The chemistry of iodonium salts has developed immensely in the recent years and new methods for the formation of carbon-carbon and carbon-hetaroatom bonds have been developed. Both radical and ionic reactions have been developed with diaryliodonium salts. The ionic reactivity of diaryl$\lambda^{3}$-iodanes with carbon and hetaroatom nucleophiles is believed to occur via a substitution of the " $\mathrm{X}$ " with a nucleophile to produce T-shaped iodine intermediate. This intermediate is isostructural with $\mathrm{C}-\mathrm{Nu}$ bond-forming palladium intermediate in the general catalytic cycle of palladium-catalyzed arylation reactions (Figure 1.4).

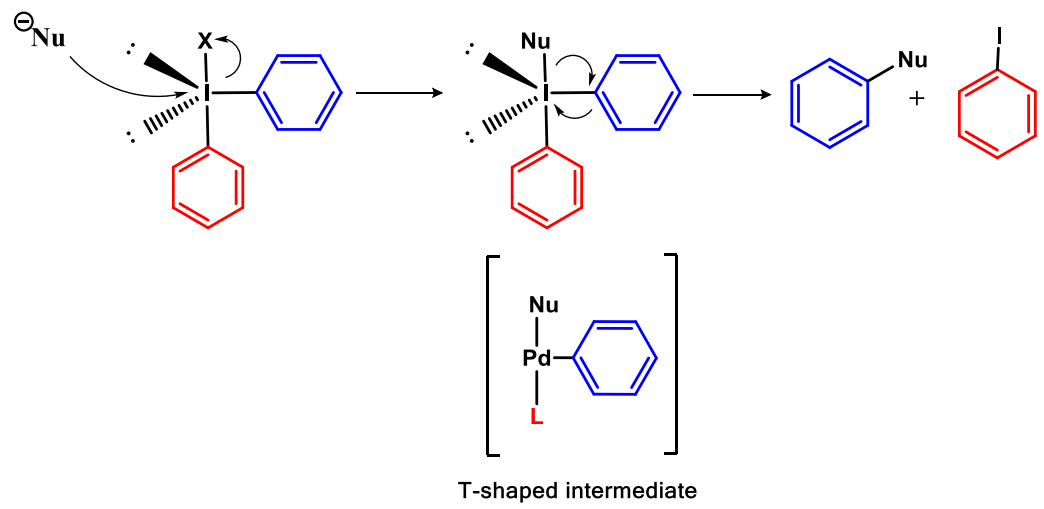

Figure 1.4: Metal catalyst intermediate vs. diaryl- $\lambda^{3}$ - iodane intermediate 
Diaryl- $\lambda^{3}$-iodane compounds have many unique properties that are synthetically useful and have received considerable attention in organic synthesis. ${ }^{15}$ These compounds are bench stable, non-toxic, mild and selective reagents ${ }^{16}$ used in many organic reactions, such as heterocycle arylation, ${ }^{17,18}$ metal-catalyzed cross-coupling reactions ${ }^{19,20}$ and polymerization reactions. ${ }^{21}$ In 1894 Hartmann and Meyer reported the first synthesis of the diaryl iodonium salts. ${ }^{22}$ This early synthesis was conducted by condensation of other hypervalent iodine compounds. Iodosylarenes $(\mathrm{ArI}=\mathrm{O})$ are examples of such compounds used. These reaction procedures were low yielding and time consuming hence synthetic methods of diaryl- $\lambda^{3}$-iodanes were not developed for decades.

In the 1950's and 1960's Beringer and co-workers improved synthetic routes for the formation of many iodonium salts and established a broad range of reactivity for these compounds. ${ }^{23}$ Modern synthesis of diaryl- $\lambda^{3}$-iodanes typically involves two or three steps but in many cases can be carried out in a single flask. ${ }^{24}$ In one case an aryl iodide is oxidized to iodine(III), followed by ligand exchange with a simple arene (Scheme 1.2, method 1). In a second approach, hypervalent iodine compounds react with an aryl organometallic reagent, such as a boronic acid, to synthesize an iodonium salt (Scheme 1.2, method 2). Diaryliodanes with auxiliaries such as trimethoxybenzene cannot be synthesized by a one pot method; therefore a multi step route is used (Scheme 1.2, method 3). Diaryl- $\lambda^{3}$-iodanes can be synthesized with many counter ions such as $\mathrm{Br}^{-}$, $\mathrm{OTs}^{-}, \mathrm{TFA}^{-}, \mathrm{Cl}^{-}, \mathrm{BF}_{4}^{-}$and OTf. In each of these reactions the different counter ions can be introduced via an ion exchange between the diaryliodonium salt and a saturated salt solution of the desired ion. 


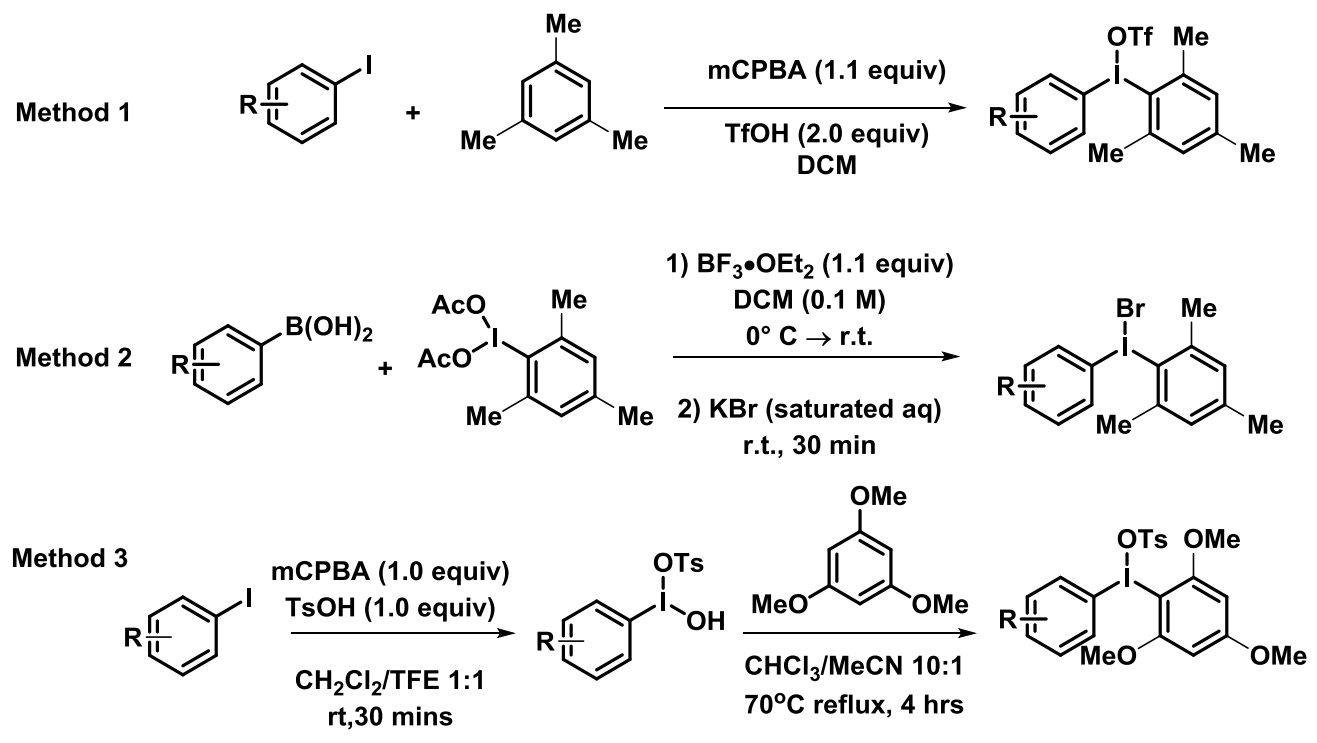

Scheme 1.2: General routes to diaryl iodonium salt synthesis ${ }^{25,26,27}$

Diaryl- $\lambda^{3}$-iodanes undergo a variety of reactions to give many useful products in organic chemistry (Figure 1.5). Unsymmetrical iodanes are useful in selective coupling reactions. Carbon heteroatom bond formation $(\mathrm{C}-\mathrm{O}, \mathrm{C}-\mathrm{N}, \mathrm{C}-\mathrm{F})$ via diaryl iodonium salts has been studied and developed over the years (Figure 1.5, highlighted in green). This is done by the activation of a nucleophile using a base followed by the reaction with diaryl iodonium salts. Development of reliable methods to synthesize carbon carbon bonds from iodonium salts is still under developed. 


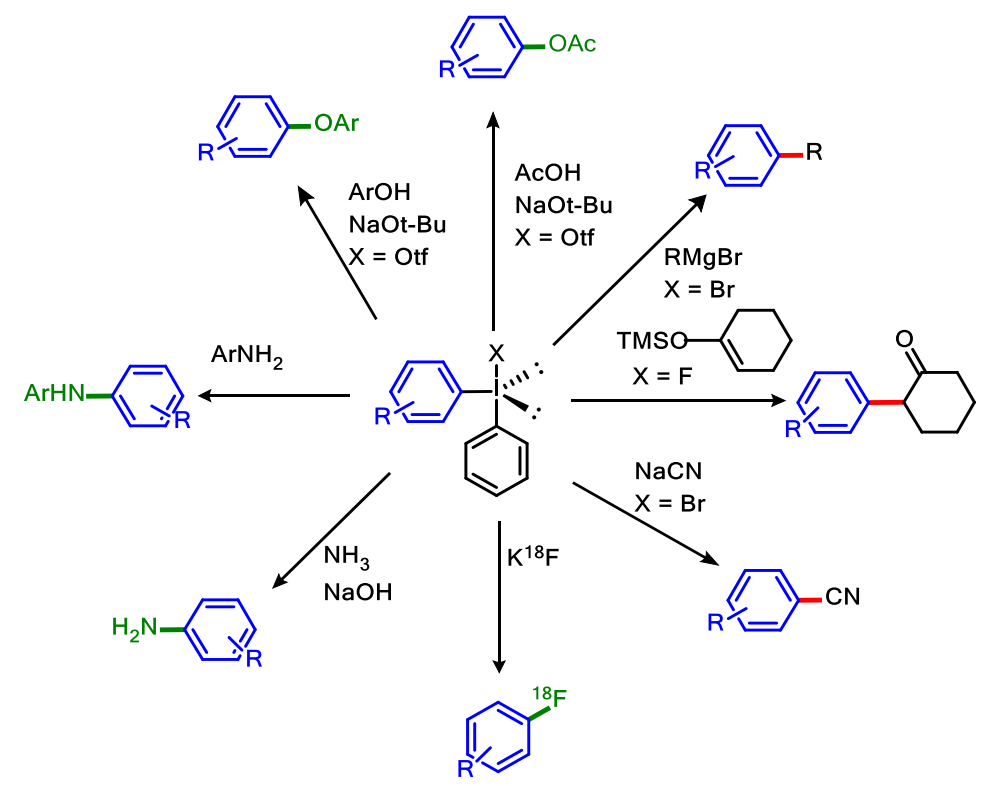

Figure 1.5: Different reactions of diaryl- $\lambda^{3}$ - iodanes

\subsection{Prior art of biaryl synthesis}

A number of research groups are focused on developing new and improved conditions for aryl-aryl cross-coupling reactions with diaryliodonium salts. The earliest example of a metal-free aryl-aryl cross-coupling was demonstrated by Beringer, ${ }^{23}$ but more recent examples have come from Ackermann ${ }^{28}, \mathrm{Kita}^{29}$, Baran $^{30}$ and $\mathrm{Zhou}^{31}$. Metal free cross coupling reactions are attractive because they avoid the use of toxic catalytic transition metals. Ackermann was able to show arylation of indoles without the use of transition-metal catalysts and high temperatures were required for the reaction to occur. Zhou also used simple trivalent iodanes that are not functionalized. The phenyl waste from sodium tetraphenylborate is a major drawback. Kita and co workers were able to synthesis biaryls and demonstrate the preference for transfer of electron rich aryl group. Kita also used simple arenes and the reaction was not carried out with many functional groups (Scheme 1.3). 


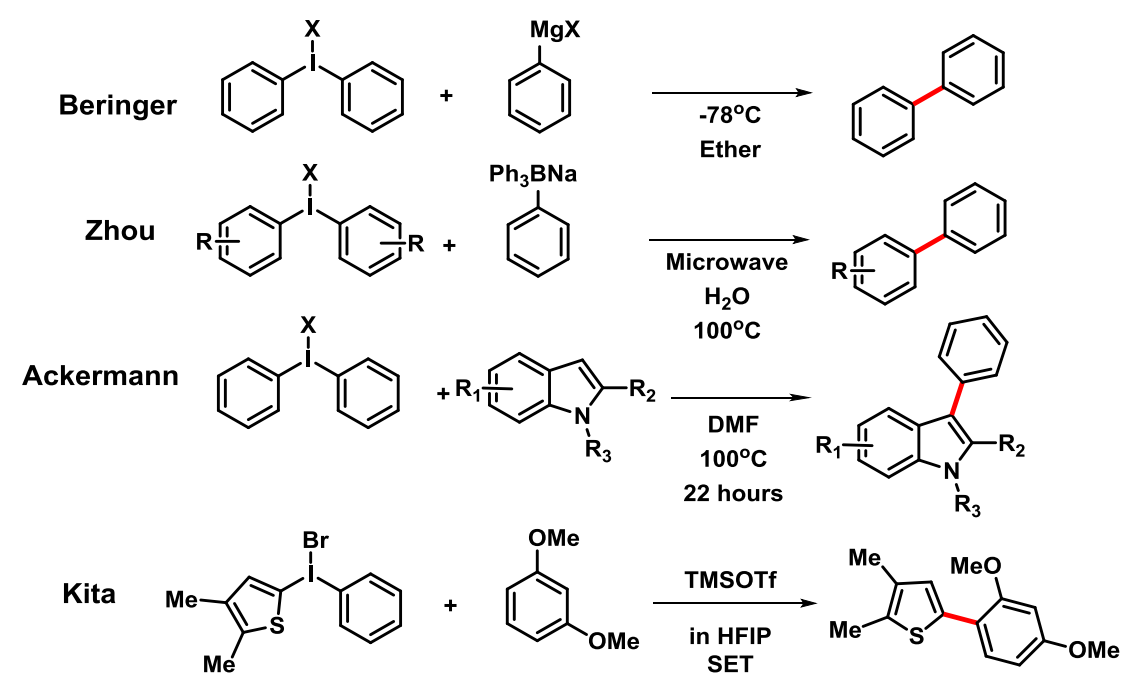

Scheme 1.3: "Transition-metal free" arylation reactions

\subsection{Triolborates- cyclic stable complexes of boronic acids}

Aryl boronic acids are trivalent organic compounds with a covalent carbon-boron bond and two hydroxyl groups bound to the boron. The central boron atom is $\mathrm{sp}^{2}$ hybridized with a vacant p-orbital orthogonal to the three substituents, therefore has a trigonal planar geometry. Changes in the valency of boron atom significantly influence the reactivity of the boron complex. ${ }^{32}$ Knochel and $\mathrm{Mayr}^{35}$ studied the relationship between the structure and nucleophilicity of aryl boron derivatives (Figure 1.6). They used furylborate derivatives as model substrates for the study. Boronic acid is not included in the study as the reactivity of its hydroxyl groups interfere with the nucleophilic reactivity study of the boron atom. The pinacolboronate has a nucleophilicity of $\mathrm{N}=2.90$ (Figure 1.6, compound 1.2. The nucleophilicity of these compounds increases immensely when boron is quaternary (Figure 1.6, compounds 1.4, 1.5, 1.6). Activation of the trivalent boron center with anionic groups such as fluoride or alkoxide results in a quaternary boron with a more nucleophilic boron-carbon bond. 
These tetracoordinated organoboron compounds are used in nucleophilic addition and coupling reaction. ${ }^{33}$ The reactivity of boronic acid compounds also depends upon the substituent/functional group attached directly to the boron atom. ${ }^{34}$ For example three electronegative fluorine atoms somewhat decrease the nucleophilicity of the borate complex relative to three oxygen atoms (Figure 1.6, compare compounds $\mathbf{1 . 4}$ and 1.6). Cyclic aryl triolborates are considered more nucleophilic compared to the other boronic acid derivatives (Figure 1.6, compound 1.6).

Different methods have been developed to prepare stable borate complexes. Trifluoroborates are typically stable compounds that are commercially available as pure crystalline material. These trifluoroborates have advantages over boronic acids in preparation and handling. ${ }^{33}$ Aryl triolborates are used in our coupling reactions. They are easily prepared from the boronic acid and the triol with good yields. ${ }^{33}$ These compounds are bench stable white powders with high nucleophilicity which can react with diaryliodonium salts to form biaryls without transition-metal catalysts.

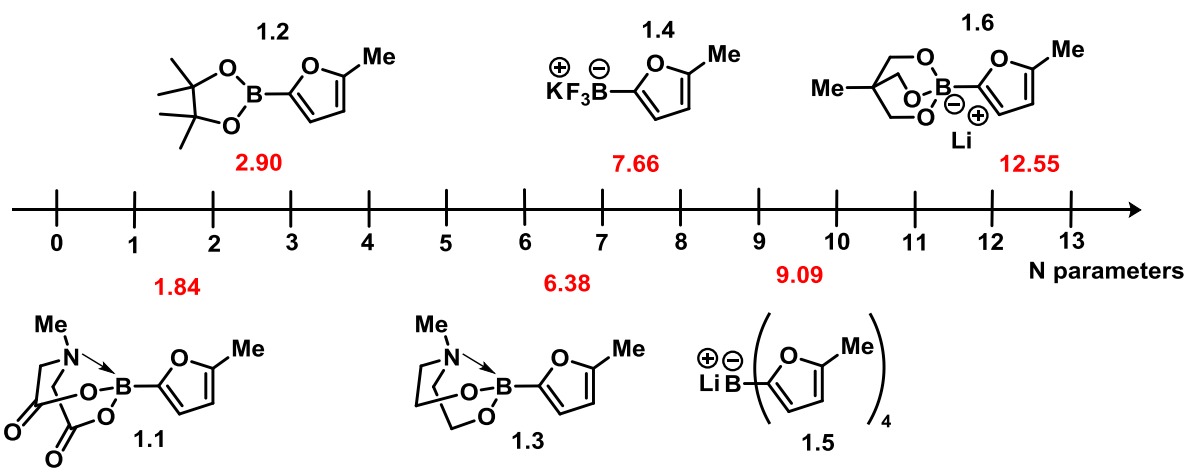

Figure 1.6: Ranking of organoboron compounds in comparison with related nucleophiles $^{35,36}$ 


\section{Chapter 2: Results and Discussion}

\subsection{Reaction discovery and development}

Aromatic and hetaroaromatic compounds are important building blocks in pharmaceuticals, agrochemicals and many other industries. ${ }^{37}$ These motifs are often part of a biaryl framework and therefore the ability to couple aromatic rings together is an important synthetic tool. This is primarily achieved via transition-metal catalysis though more environmentally and economically sustainable methods are desirable.

Diaryl- $\lambda^{3}$-iodanes were selected as a green arylation alternative based on their innate reactivity, bench stability and ease of preparation and purification. ${ }^{38,39,40}$ The primary objective of this project was to explore the reactivity of diaryl- $\lambda^{3}$-iodane electrophiles with aryl nucleophiles without a metal catalyst in a direct and metalfree synthesis of biaryl compounds. The reaction of symmetrical and unsymmetrical diaryl- $\lambda^{3}$-iodanes was explored in early reaction discovery and a model reaction was used to empirically optimize the reaction conditions.

\subsection{Reaction of diaryl- $\lambda^{3}$-iodanes with highly reactive nucleophiles}

Diaryl- $\lambda^{3}$-iodanes directly react with highly reactive aryl organometallic species such as organo lithium and Grignard reagents. ${ }^{41,42}$ These reactive species are sensitive to moisture and therefore special procedures are necessary when handling these reagents. Despite this literature precedent a general biaryl synthesis using diaryl- $\lambda^{3}$-iodanes and reactive organometallic nucleophiles has not been developed. 


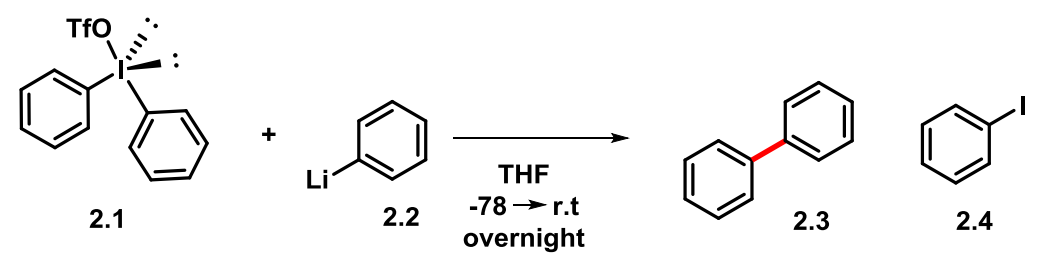

Scheme 2.1: Reaction of symmetrical diaryl- $\lambda^{3}$-iodanes with phenyl lithium reactive species

To investigate the transition-metal free synthesis of biaryls the reaction between a diaryliodonium salt (Compound 2.1) and phenyl lithium was selected with reference to Beringer's work in $1959 .^{41}$ Beringer reacted diphenyliodonium bromide with phenyl lithium compounds to give biphenyl and phenyl iodide. Here the reaction of diphenyliodonium triflate with phenyl lithium yielded products 2.3 and 2.4 in isolated yields of $21 \%$ and $17 \%$ (Scheme 2.1). These reactive species were a challenge to handle and therefore a different nucleophile was investigated for the development of transitionmetal free reactivity.

\subsection{General reaction used for proof of concept}

The previously reported highly reactive organometallic reagents were not fuctional group tolerant. A more practical and use-friendly reaction would use bench stable, functional group tolerant and mild organometallic starting materials to synthesize biaryls. A triol borate was selected as the organometallic starting material for the development of our transition-metal free cross coupling reaction with diaryliodonium salts. Both of these starting materials are bench stable and can be synthesized easily and do not require chromatographic purification. A diaryliodonium salt and aryl borate with fluorine tags were specifically selected for reaction screening (Graph 2.1). This will form 
biaryl products with fluorine tags that can be quantified by ${ }^{19} \mathrm{~F}$ NMR spectroscopy on crude reaction mixtures. The ${ }^{19} \mathrm{~F}$ nucleus has a wide chemical shift range in which signals are well resolved. Therefore the quantification of the product ratio with respect to an internal standard is readily determined. The fluorine peaks of the product were identified from a purified sample and are used as a reference peak for the biaryl product. The crude residue of the reaction mixtures were directly analyzed by ${ }^{19} \mathrm{~F}$ NMR spectra using the internal standard 1,3,5-trichloro-2,4,6-trifluorobenzene.

The counter ion and spectator ligand on the diaryliodonium salt are important parameters for reactivity and selectivity of the aryl group transfer, respectively, in this reaction. A significant change in yield was observed when these parameters were changed (Graph 2.1). The counter ions $\mathrm{Br}^{-}$and OTf gave better yields than others. When different spectator ligands were analyzed trimethoxybenzene (TMB) showed better reactivity than both 2-thiophene and mesitylene. The $\mathrm{TMB} / \mathrm{Br}^{-}$and $\mathrm{TMB} / \mathrm{OTf}$ were observed to be the best combinations giving similar maximum yields.

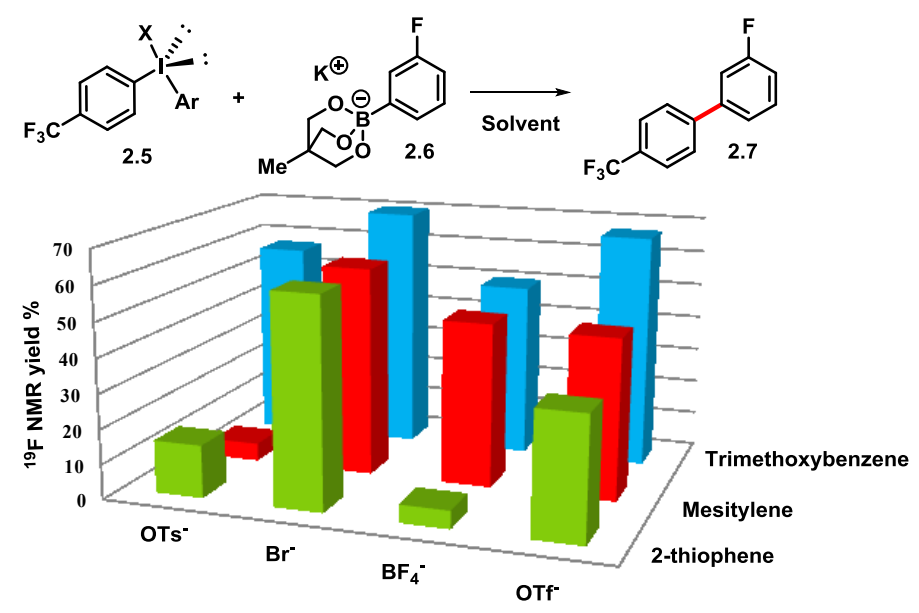

Scheme 2.1b: Comparing reaction yield with spectator ligands and counter ions 
Diaryl iodonium salts are also known to be bench stable powders. ${ }^{43}$ To confirm stability of these starting materials a few observations were made. It was observed that the stability of these compounds significantly depend on the counter ion and the spectator ligand. Some of the diaryl iodonium salts showed a change in color (Table 2.1) and texture with time. Notably, the iodanes with bromide counter ion didn't show a visible change with both mesitylene and trimethoxybenzene spectator ligands (Table 2.1, entry 1 and 5). The triflate was stable with the mesitylene (Table 2.1, entry 7). The diaryliodonium salt with the $\mathrm{TMB} / \mathrm{Br}^{-}$auxiliary and counter ion provided the highest yield and was more stable compared to TMB/OTf therefore it is used in further optimization reactions.

Table 2.1: Visible changes of diaryl- $\lambda^{3}$-iodanes

\begin{tabular}{|c|c|c|c|}
\hline Entry & $\mathrm{Ar}$ & $\mathrm{X}$ & Comment $^{a}$ \\
\hline 1 & Trimenthoxybenzene - TMB & $\mathrm{Br}^{-}$ & no change \\
\hline 2 & TMB & OTf & turned black \\
\hline 3 & TMB & $\mathrm{OTs}^{-}$ & turned black ${ }^{\mathrm{b}}$ \\
\hline 4 & TMB & $\mathrm{BF}_{4}^{-}$ & turned black \\
\hline 5 & Trimethylbenzene - MES & $\mathrm{Br}^{-}$ & no change \\
\hline 6 & MES & $\mathrm{BF}_{4}^{-}$ & turned black \\
\hline 7 & MES & OTf $^{2}$ & no change \\
\hline 8 & MES & $\mathrm{OTs}^{-}$ & turned black ${ }^{\mathrm{b}}$ \\
\hline 9 & MES & $\mathrm{TFA}^{-}$ & turned moist \\
\hline 10 & MES & $\mathrm{Cl}^{-}$ & turned moist \\
\hline
\end{tabular}

${ }^{a}$ Visible condition approximately after 3 weeks in a closed container, exposed to light at room temperature. ${ }^{\mathrm{b}}$ After 8 weeks. 


\subsection{Nucleophilicity of the triolborates}

We hypothesized that electrophile/nucleophile pairing is critical for success in the reaction and therefore it was important to select a suitable nucleophile for the synthesis of biaryls. Aryl boron nucleophiles are desirable coupling partners in transition metalcatalysed cross-coupling reactions. ${ }^{44,36}$ These reagents have significantly improved fuctional group tolerance and stability over aryl lithium and aryl magnesium reagents. Aryl boronic acids, aryl boronate esters and aryl trifluoroborates are the most common types within this class. The reactivity (nucleophilicity) is influenced by the valency of the boron center and quaternary borates are much more reactive than tertiary boronates. ${ }^{45}$

In accordance with the nucleophilicity parameter measurements shown in Figure 1.6 in Chapter 1, the phenyl pinacolborate and boronic acids have the lowest nuclephilicity and showed no detectable products in the ${ }^{19} \mathrm{~F}$ NMR spectra of the modified model reaction (Table 2.2, entry 1 and 2). The phenyl trifluoroborates and tetraphenylborate did provide products but in only trace quantities (Table 2.2, entry 4). The nucleophilicity parameters suggested that cyclic triol borates are highly nuclephilic boron reagents and these reagents provide the highest yield in the reaction with diaryliodonium salts (Table 2.2, entry 5). This is consistent with a reaction that is highly dependent on nucleophile/electrophile pairing. 
Table 2.2: Nucleophilicity of the triolborates

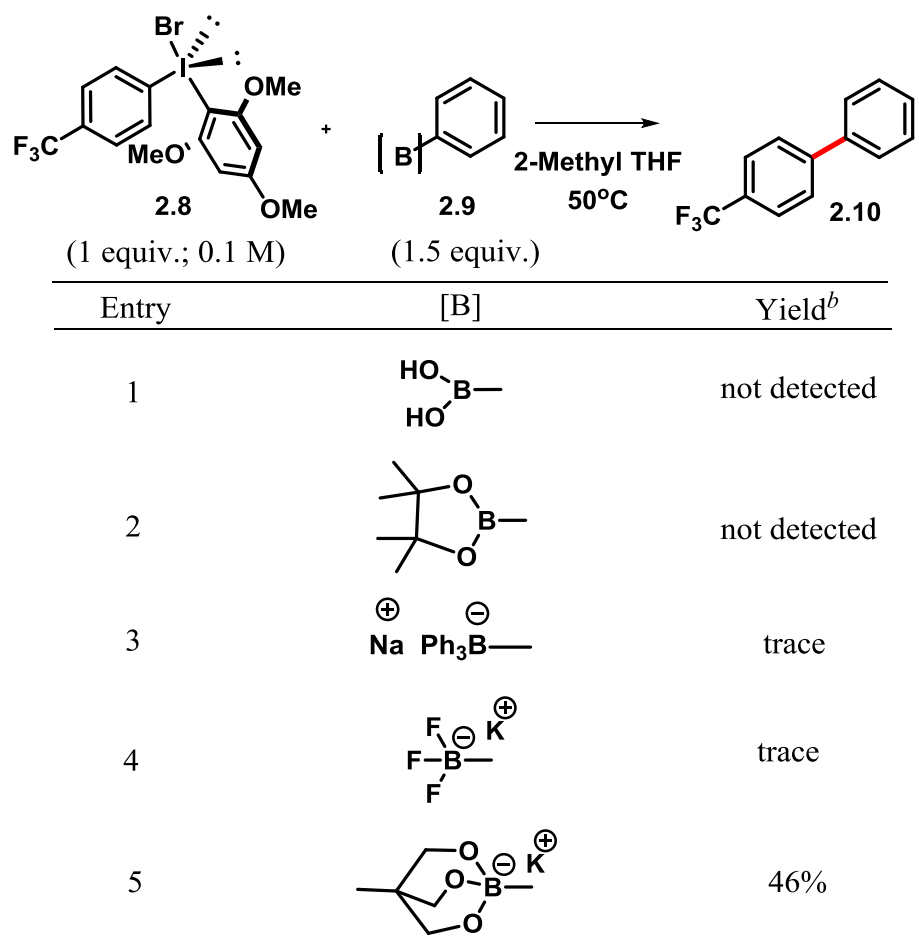

${ }^{a}$ Conditions: 2.8 (0.05 mmol, $\left.0.1 \mathrm{M}\right), \mathbf{2 . 9}$ (0.075 mmol, 1.5 equiv.), 2Methyl THF $(0.5 \mathrm{~mL}), 50{ }^{\circ} \mathrm{C}, 20 \mathrm{~h} . \quad{ }^{b}{ }^{19} \mathrm{~F}$ NMR yield with $1,3,5-$ trichloro-2,4,6-trifluorobenzene $(0.05 \mathrm{mmol})$ as internal standard.

The reactivity of different counter ions in aryl borates was an important part of our investigation (Table 2.2). The use of potassium and tetrabutyl ammonium counter ion in transition-metal catalyzed arylation reactions with aryl triolborates has been reported. ${ }^{46,47}$ Freshly prepared $\mathrm{Li}^{+}$and $\mathrm{Na}^{+}$borates gave less than $10 \%$ yield (Table 2.2 , entry 1 and 2 ), while $\mathrm{Cs}^{+}$and $\mathrm{n}-\mathrm{Bu}_{4} \mathrm{~N}^{+}$gave a moderate yield close to $50 \%$ (Table 2.2, entry 4 and 5). Potassium was still found to be the best counter ion giving $77 \%$ yield; therefore our reactions were carried out using potassium aryl borates. Notably only the n$\mathrm{Bu}_{4} \mathrm{~N}^{+}$ion completely dissolved in 2-methyl THF, while the rest of the reaction mixtures remained as a white suspension after overnight stirring. 
Table 2.3: Optimization table of triolborate counter ion

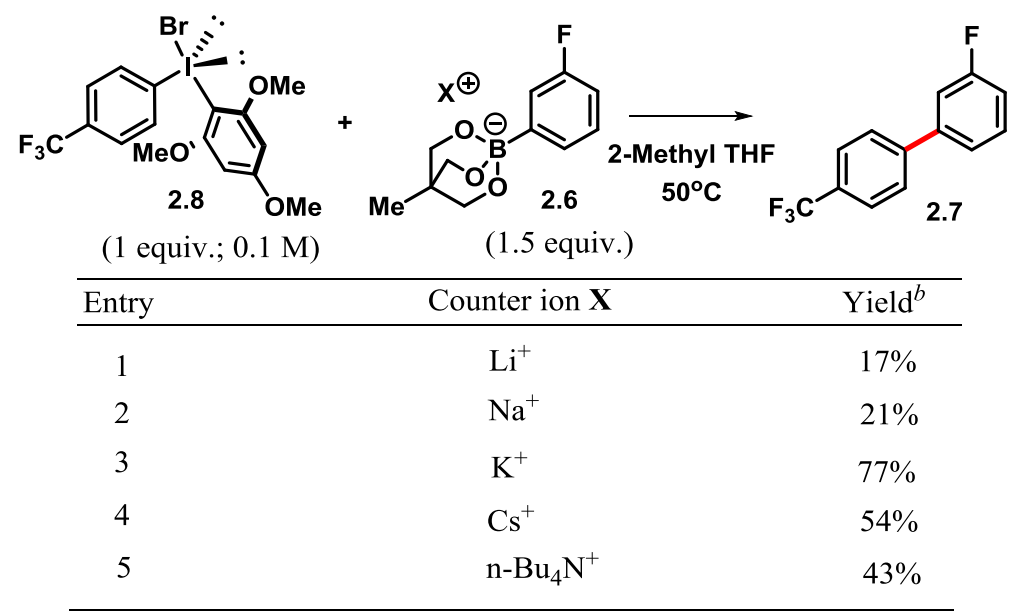

${ }^{a}$ Conditions: 2.8 (0.05 mmol, $\left.0.1 \mathrm{M}\right), 2.6(0.075 \mathrm{mmol}, 1.5$ equiv.), 2-Methyl THF (0.5 mL), $50{ }^{\circ} \mathrm{C}, 20 \mathrm{~h} .{ }^{b}{ }^{19} \mathrm{~F}$ NMR yield with 1,3,5-trichloro-2,4,6-trifluorobenzene $(0.05 \mathrm{mmol})$ as internal standard.

Cyclic triolborates are oxygen stable compounds that we found to be moderately hydroscopic. ${ }^{47}$ No change in physical appearance was observed in aryl borates upon exposure to light and air. The stability of these compounds was investigated by observing the reactivity over time. Aryl triolborates with $\mathrm{Li}^{+}$and $\mathrm{Na}^{+}$counter ions had a significant change in yield over time (Table 2.4, entries 1-4). Cesium does not show a significant change in yield compared to the other counter ions (Table 2.4, entry 7 and 8). These results show that the decrease in yield is not unique to aryl borate with potassium counter ions. 
Table 2.4: Stability of different triolborate counter ions

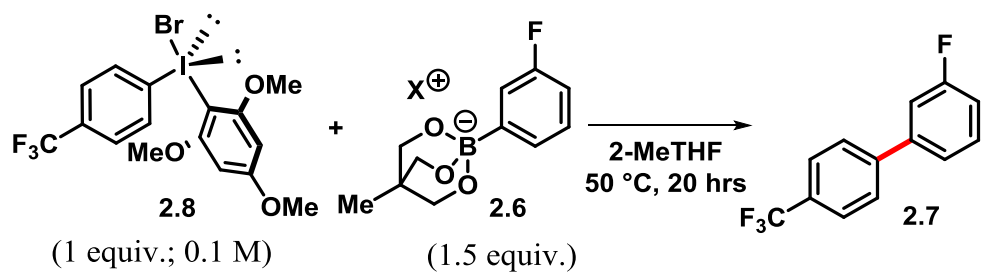

\begin{tabular}{cccc}
\hline Entry & $\mathrm{X}$ & Week & Yield $^{c}$ \\
\hline 1 & $\mathrm{Li}^{+}$ & $1^{b}$ & $17 \%$ \\
2 & $\mathrm{Li}^{+}$ & 4 & trace \\
3 & $\mathrm{Na}^{+}$ & $1^{b}$ & $21 \%$ \\
4 & $\mathrm{Na}^{+}$ & 4 & $5 \%$ \\
5 & $\mathrm{~K}^{+}$ & $1^{b}$ & $76 \%$ \\
6 & $\mathrm{~K}^{+}$ & 4 & $64 \%$ \\
7 & $\mathrm{Cs}^{+}$ & $1^{b}$ & $58 \%$ \\
8 & $\mathrm{Cs}^{+}$ & 4 & $54 \%$ \\
\hline
\end{tabular}

${ }^{a}$ Conditions: 2.8 (0.05 mmol, $\left.0.1 \mathrm{M}\right), 2.6$ (0.075 mmol, 1.5 equiv.), 2Methyl THF $(0.5 \mathrm{~mL}), 50{ }^{\circ} \mathrm{C}, 20 \mathrm{~h} .{ }^{b}$ Freshly prepared. ${ }^{c}{ }^{19} \mathrm{~F}$ NMR yield with 1,3,5-trichloro-2,4,6-trifluorobenzene $(0.05 \mathrm{mmol})$ as internal standard.

2.5. Development and optimization of the general reaction.

Extensive empirical optimization of reaction parameters lead to the "standard conditions" shown in Table 2.5 entry 1. This table outlines the pertinent reaction parameters that influence product yield. When both starting materials were freshly prepared the yield was $77 \%$ (Table 2.5 , entry 1 ). With only the aryl triolborate freshly prepared, the yield didn't have a significant deviation (Table 2.5, entry 2). This shows that older diaryl- $\lambda^{3}$-iodanes has no noteworthy effect on the reaction yield. Entry 3 shows a major change in the yield thus it indicates that older triolborates ( $\sim 12$ weeks old) lowers the yield more significantly than diaryl- $\lambda^{3}$-iodanes. 
Both the electrophilic and nucleophilic strength of the starting materials are important for the cross coupling reaction to occur. No detectable product was observed by NMR spectroscopy when the diaryl- $\lambda^{3}$-iodane was reacted with aryl boronic acid or when the aryl triolborate was reacted with aryl iodide under transition-metal free conditions (Table 2.5, entry 4 and 5). Aryl iodide and boronic acid showed no detectable products under transition-metal free reaction conditions. The eletrophilicity and redox capacity of the diaryliodonium salt and the nucleophilicity of the aryl triolborate are key parameters for reactivity. When the strength of either the electrophile or nucleophile is decreased no product is observed by ${ }^{19} \mathrm{~F}$ NMR spectroscopy.

A variety of solvents were tested and 2-Me THF was the optimal solvent for the reaction with the highest yield compared to any other solvent investigated (Table 2.5, entry 1). THF and $\mathrm{MeCN}$ afforded the desired product with a yield of $\sim 35 \%$ from the crude ${ }^{19} \mathrm{~F}$ NMR spectra (Table 2.5, entry 7 and 8 ). DMF and the chlorinated solvents, such as DCM and DCE gave lower yields of $\sim 20 \%$ (Table 2.5, entry 9). Most other solvents did not give a significant amount of the biaryl product.

When the stoichiometry of the iodane and triolborates was 1:1, the reaction gave a moderate yield of 57\%. The yield improved when 1:1.5 equivalents was used. As the equivalence was increased further the increment in yield increase was not significant (Table 2.5, compared entries 1, 10 and 11). The change in yield was less than $3 \%$ when the equivalence was increased four times. Therefore to reduce the amount of the starting materials, 1:1.5 equivalents of compounds 2.8:2.6 were used in the optimized condition. 
As illustrated in Table 2.5 at $0.05 \mathrm{M}$ concentration of the iodane the yield is $63 \%$. The ${ }^{19} \mathrm{~F}$ NMR spectra of the crude residue showed more peaks and became messy as the concentration was decreased. When the concentration is increased to $0.1 \mathrm{M}$, the yield increases more than $10 \%$. When the concentration was increased further the change in yield was not significant (Table 2.5, compare entries 1, 12 and 13). A reaction concentration of $0.1 \mathrm{M}$ was chosen as the best concentration.

At $30^{\circ} \mathrm{C}$ the yield is $57 \%$ (Table 2.5 , entry 14 ). When the temperature was increased there was a significant bump in yield at $50^{\circ} \mathrm{C}$ to $77 \%$ (Table 2.5 , entry 1 ). Increasing the temperature above $50^{\circ} \mathrm{C}$ lowered the yield significantly (Table 2.5, compare entries 1, 15 and 16). This indicates that when temperature was varied a maximum in reaction yield occurred at $50^{\circ} \mathrm{C}$. The reason for this is thought to be the degradation of starting materials at high temperatures. To confirm this result, both starting materials diaryliodonium salt and aryl triolborate were separately stirred overnight in 2-methyl THF at $55^{\circ} \mathrm{C}, 60^{\circ} \mathrm{C}$, and $70^{\circ} \mathrm{C}$. The ${ }^{1} \mathrm{H}$ NMR spectra of the crude was compared with the pure compound after 20 hours. The spectral data of the diaryliodonium salt showed a significant change when compared to the pure compound. This indicates the diaryliodonium salt starting materials are thermally unstable and degrading to form other products when exposed to high temperatures, resulting in decreased yield. 
Table 2.5: Optimization table

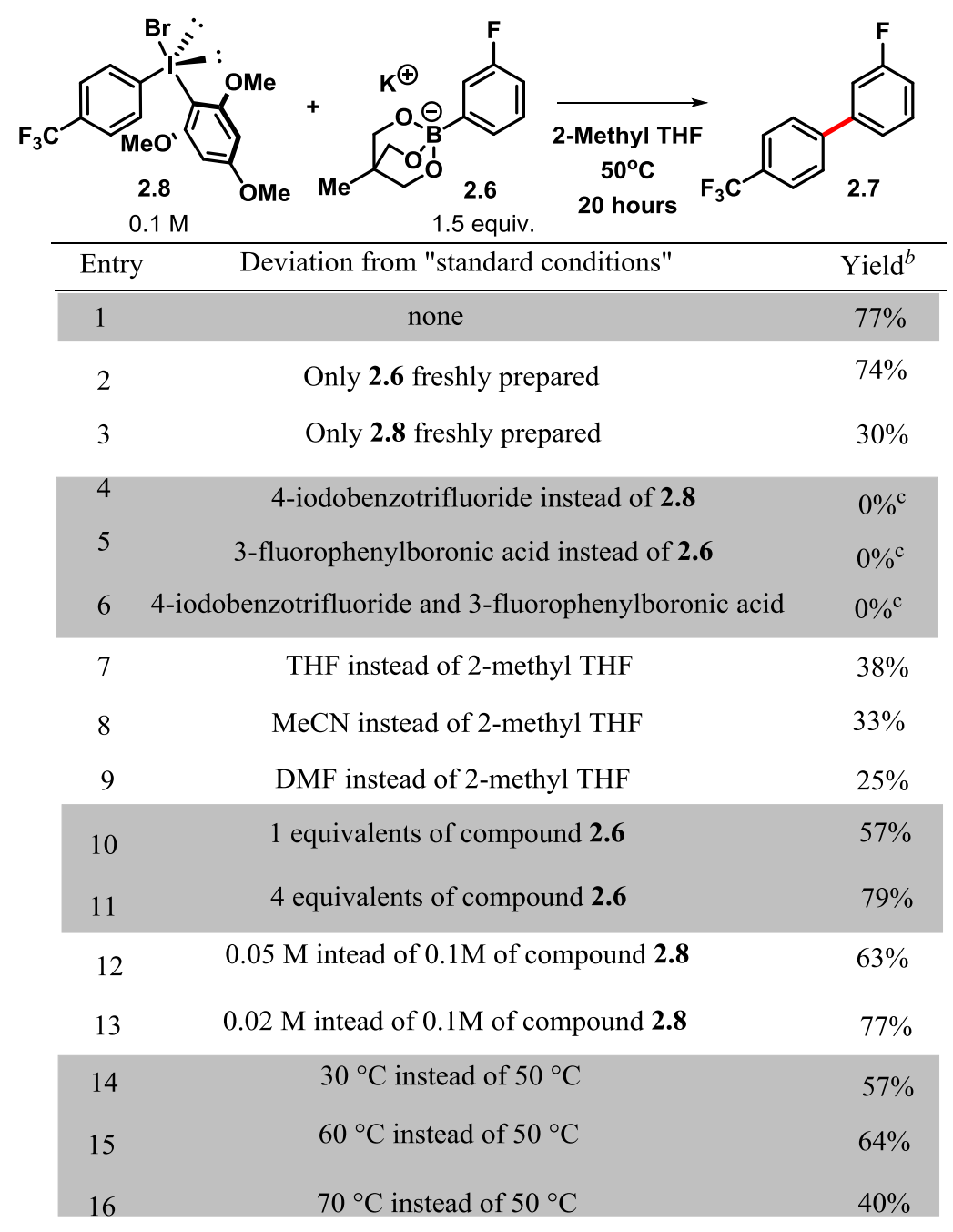

${ }^{a}$ Conditions: 2.8 (0.05 mmol, $\left.0.1 \mathrm{M}\right), 2.6$ (0.075 mmol, 1.5 equiv.), Solvent (0.5 $\mathrm{mL}), 50{ }^{\circ} \mathrm{C}, 20 \mathrm{~h} .{ }^{b}{ }^{19} \mathrm{~F}$ NMR yield with 1,3,5-trichloro-2,4,6-trifluorobenzene $(0.05 \mathrm{mmol})$ as internal standard. ${ }^{\mathrm{c}}$ No product detected in the NMR spectra.

\subsection{Scoping of the reaction with multiple substrates}

The following set of standard conditions was chosen based on the results of the optimization experiments: 1.5 equivalents of nucleophile relative to the iodane, $2-\mathrm{Me}$ THF as the solvent, $0.1 \mathrm{M}, 50^{\circ} \mathrm{C}$ and $20 \mathrm{hrs}$. These conditions were applied to a variety of diaryliodonium salts and aryl triolborate combinations. In select cases the mesitylene 
spectator ligand and triflate counter ion were used on the diaryliodonium starting materials.

This reaction was used in the formation of biaryls with different functional groups. Different combinations of iodanes and triol borates were used in scoping of the reaction. Iodanes with electron withdrawing groups attached to the para position of the aryl ring gave higher yields than others. Ester groups, nitro groups and trifluoromethyl groups were well tolerated on the aryl electrophile ring. Diaryliodonium salts with electron rich groups attached to the aryl rings were more challenging to isolate to confirm product formation. Borates tolerated a larger range of different functional groups such as, halides (Figure 2.1, compounds 2.7, 2.13, 2.17, 2.21, 2.23), heterocycles (pyridine, dibenzofuran: Figure 2.1, compounds 2.18, 2.24), basic amines (Figure 2.1, compound 2.22) and simple alkyl groups (Figure 2.1, compound 2.12). 


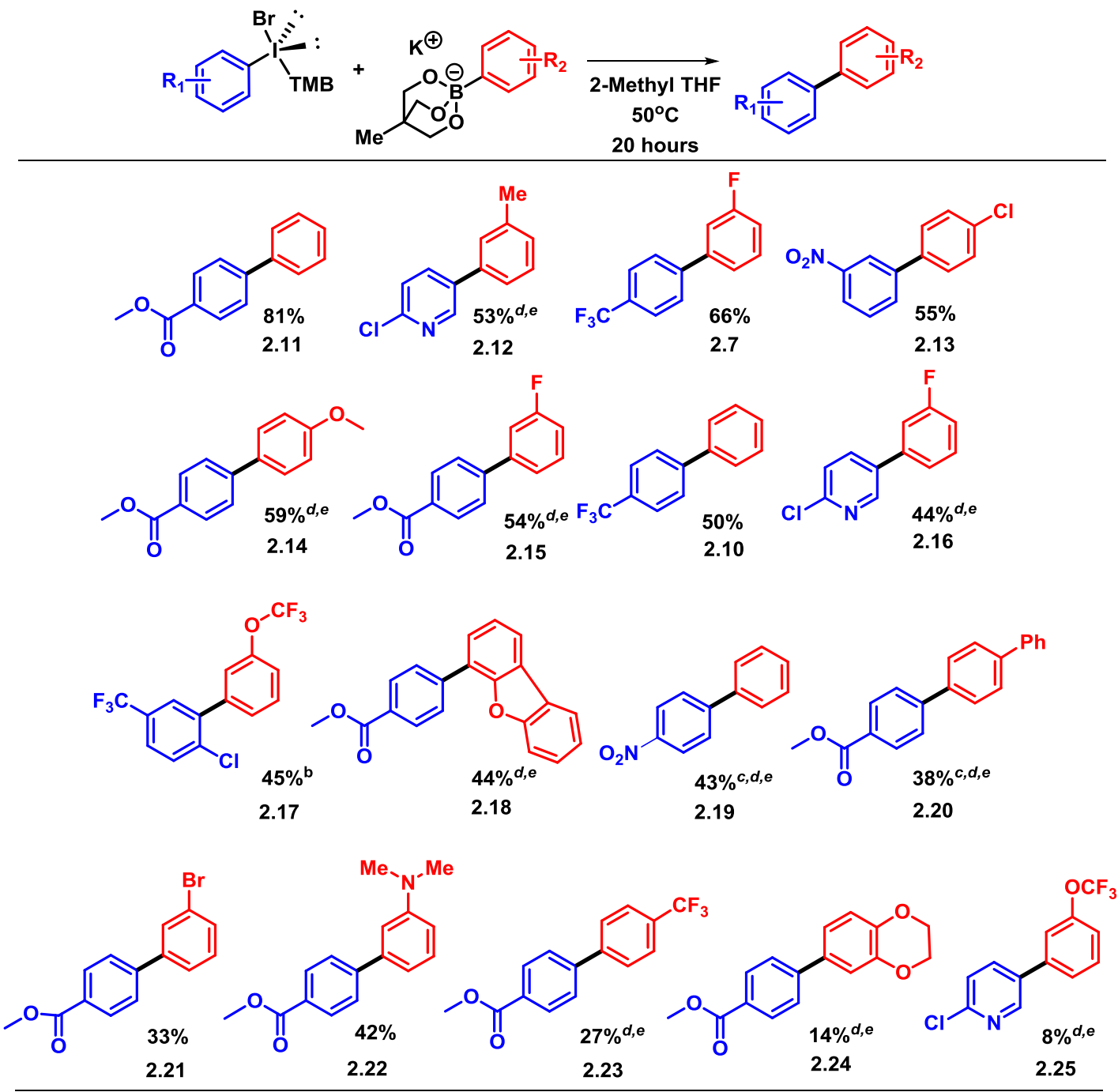

${ }^{a}$ Conditions: 1 (0.5-1.0 mmol, $\left.0.1 \mathrm{M}\right), 2$ (0.75-1.5 mmol, 1.5 equiv.), Solvent $(5-10 \mathrm{~mL}), 50{ }^{\circ} \mathrm{C}, 20 \mathrm{~h}$. Average of two experiments. ${ }^{b}$ Run one time. ${ }^{c}$ Average of 3 experiments. ${ }^{d}$ MES used as the spectator ligand. ${ }^{\mathrm{e}}$ Triflate counter ion used.

Figure 2.1: Isolated products using standard conditions

The reaction set up is more straightforward than many metal catalyzed reactions (Figure 2.2). No oxygen free conditions or special procedures in handling the chemicals were required. Diaryliodonium salts and aryl triolborates are both bench stable powders which can be weighed out in air. Technical grade solvent is then added in to the vial under atmospheric conditions and stirred for 20 hours. 


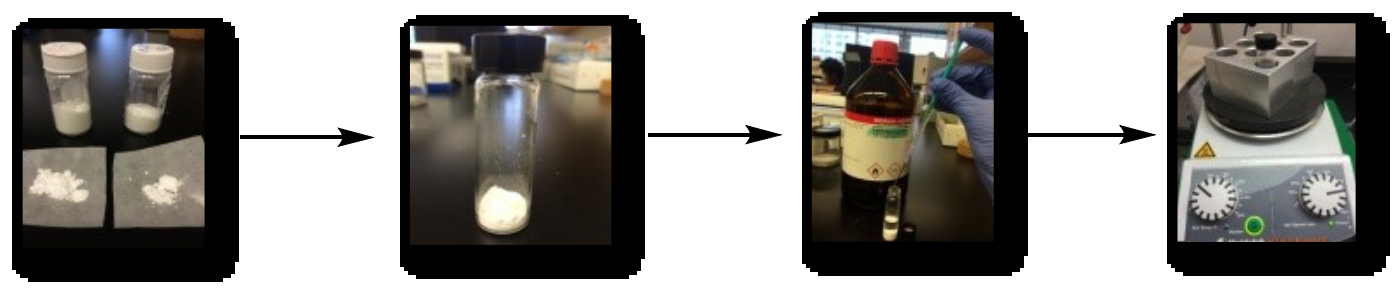

Figure 2.2: Practical simplicity of the reaction

2.7. Mechanistic hypotheses for the formation of biaryl compounds

Even though diaryl- $\lambda^{3}$-iodanes are one of the oldest, stable and highly investigated hypervalent iodine moieties, ${ }^{48}$ the mechanism of iodane reactivity in biaryl coupling isn't well understood. A common mechanism has been accepted for the reaction of diaryl- $\lambda^{3}-$ iodanes with nucleophiles under metal free reaction conditions as outlined in chapter 1.4. The diaryl- $\lambda^{3}$-iodanes forms a T-shaped intermediate with a nucleophile. Symmetric iodanes form one $\mathrm{T}$ shaped intermediate while the unsymmetrical iodanes form two intermediates that interconvert and form two arylated products. ${ }^{49}$ Thus controlling the selectivity becomes challenging with unsymmetric diaryliodonium salts and we have demonstrated success in biaryl coupling.

Several biaryl forming reactions have been developed with diaryliodonium salts. In 1960's Beringer ${ }^{41,50}$ reported aryllithium compounds reacting with aryl iodoso dichloride to give diaryliodonium salts. These iodonium salts formed a triaryliodine upon the addition of more aryllithium compounds or Grignard reagents. It was proposed that the triaryliodine compound will decompose to iodo compounds or radicals which will then react with each other or the solvent (Scheme 2.2, entry 1). Kita ${ }^{51}$ proposed that diaryliodonium salts induce single electron transfer (SET) oxidation of electron-rich 
arenes in the synthesis of biaryls. The in situ generated radical cation/radical anion pair will produce the biaryl. Transfer of the electron rich aryl or heteroaryl group from the diaryliodonium in the formation of biaryl is observed. Kita also observed the formation of the regioisomers in significant ratios (Scheme 2.2, entry 2). It is also possible for the synthesis of biaryls to be catalyzed by transition-metals. It is reported by Kang ${ }^{52,53}$ and coworkers that the electron rich group of diaryliodonium salts transfer in reaction with boronic acids in the presence of palladium or copper catalysts (Scheme 2.2, entry 3).

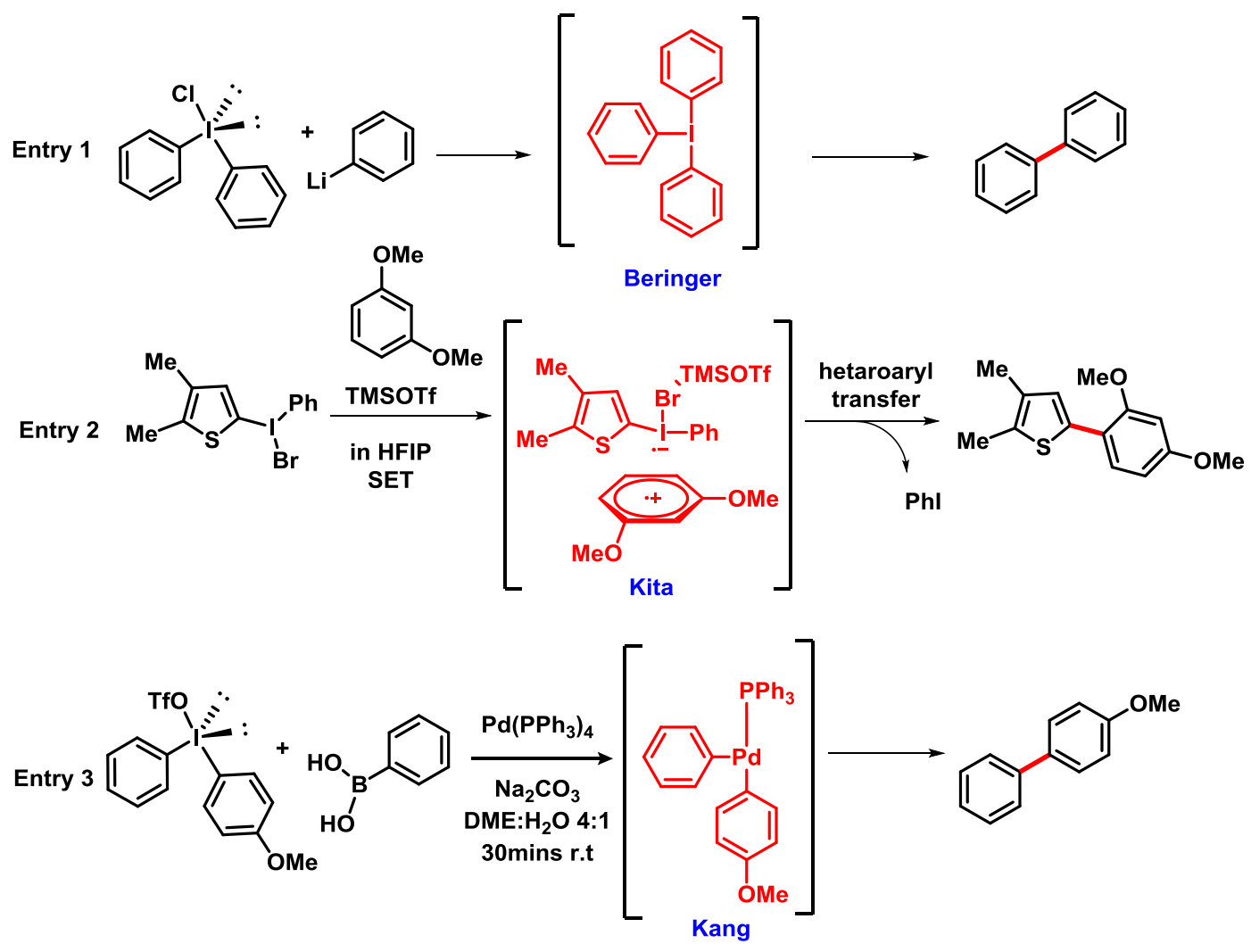

Scheme 2.2: Reported hypotheses for the formation of biaryls 
2.8. Results observed with metal catalysts

Given that monovalent idoarene compounds are good leaving groups and diaryl$\lambda^{3}$-iodanes have been used in transition metal catalyzed coupling reactions a number of experiments were performed to assess if the observed reactivity was due to the presence of trace metals. ${ }^{54,55}$ Leadbeater and Marco reported the first coupling of aryl halides with aryl boronic acids without the use of transition metal catalysts. ${ }^{56}$ This reaction was later found to be catalyzed by trace palladium present in the sodium carbonate salt used. ${ }^{57}$ Collection of ICP-MS data and addition of transition-metals to the reaction to compare yields are two steps suggested to determine whether a reaction is mediated by trace amounts of transition-metals. The ICP-MS data obtained for the starting materials used in this work, diaryliodonium salts and aryl triolborates, indicated that the total transitionmetal content was generally less than 1 ppm for individual metals (Table 2.6). The Fe content is higher than the other metals and had a concentration of $20.11 \mathrm{ppm}$ in compound 2.6. It is also known that commercially available boronic acids contain high Fe concentrations. ${ }^{58}$

Table 2.6: ICP-MS data for the starting materials

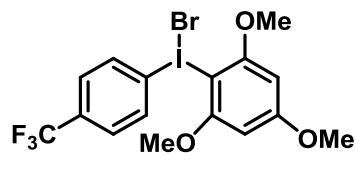

2.8

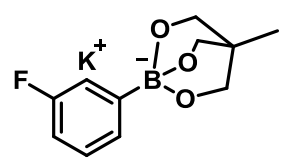

2.6

\begin{tabular}{lccccccccccc}
\hline & Fe [ppm] & Co [ppm] & Ni [ppm] & Cu [ppm] & Ru [ppm] & Rh [ppm] & Pd [ppm] & Ir [ppm] & Pt [ppm] \\
\hline Compound 2.8 & 3.25 & $<0.008$ & 0.0372 & 0.826 & 0.0260 & $<0.024$ & 1.1615 & 0.2429 & $<0.026$ \\
Compound 2.6 & 20.11 & 0.0360 & 0.6617 & 0.816 & $<0.008$ & $<0.024$ & 0.3931 & 0.1126 & $<0.026$ \\
\hline
\end{tabular}


The general reaction of the project used for the optimization was exposed to metal catalysts to probe the effect on the yield. When no catalysts were used the reaction gave a yield of $76 \%$ (Table 2.7 , entry 1 ). The reaction yield dropped significantly with the addition of transition-metals to the reaction. ${ }^{19} \mathrm{~F}$ NMR spectra showed many peaks indicating the decomposition of the starting material.

Table 2.7: Using the general reaction to explore the effect of metal catalysts

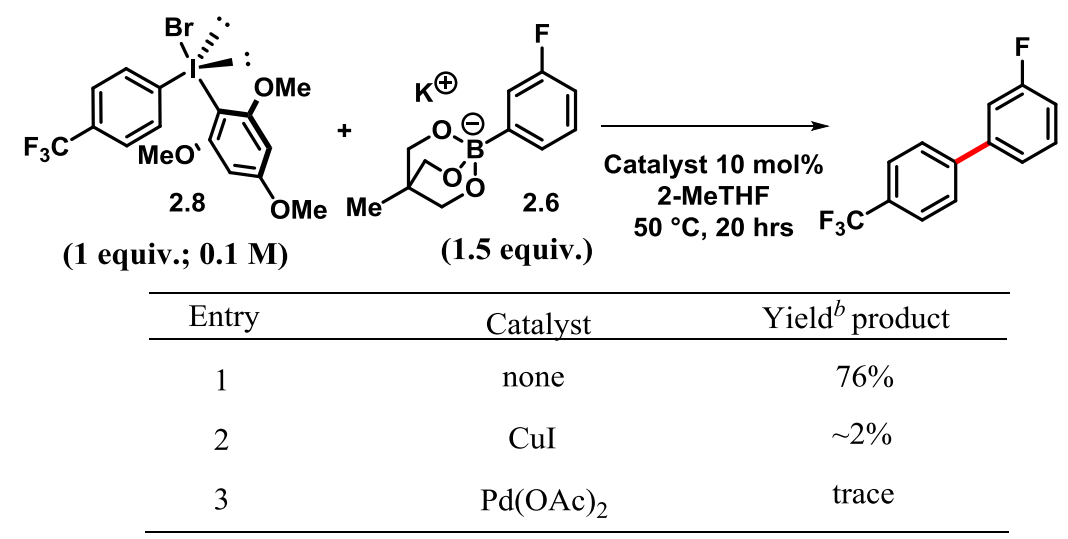

${ }^{a}$ Conditions: 2.8 (0.05 mmol, 0.1 M), 2.6 (0.075 mmol, 1.5 equiv.), 2Methyl THF $(0.5 \mathrm{~mL}), 50{ }^{\circ} \mathrm{C}, 20 \mathrm{~h} . \quad{ }^{b}{ }^{19} \mathrm{~F}$ NMR yield with 1,3,5trichloro-2,4,6-trifluorobenzene $(0.05 \mathrm{mmol})$ as internal standard.

In metal catalyzed reactions reported by Kang and co workers the electron rich aryl group transfers in the formation of the biaryl ${ }^{59,60}$ and compound $\mathbf{2 . 2 6}$ is the only observed biaryl (Table 2.8, entry 1). However, in the absence of metal catalyst the same diaryliodonium salt and boronic acid no biaryl products are detected in the crude ${ }^{19} \mathrm{~F}$ NMR spectra under the reaction conditions developed here (Table 2.8, entry 2). Significantly, under our reaction conditions reactivity is observed with the triolborates and an exclusive switch in aryl transfer selectively is observed: the electron-deficient aryl group transfers to the nucleophile. This is observed with both the triflate and bromide 
counter ions on the iodonium salt which gives moderate yields of $40 \%$ and $62 \%$ (Table 2.8, entries 3 and 4). Collectively, the low levels of trace metal $(<1 \mathrm{ppm})$ and the difference in aryl transfer selectivity are not consistent with trace metal catalysis producing the biaryl product under our reaction conditions.

Table 2.8: Reaction used to probe the effect of metal catalysts

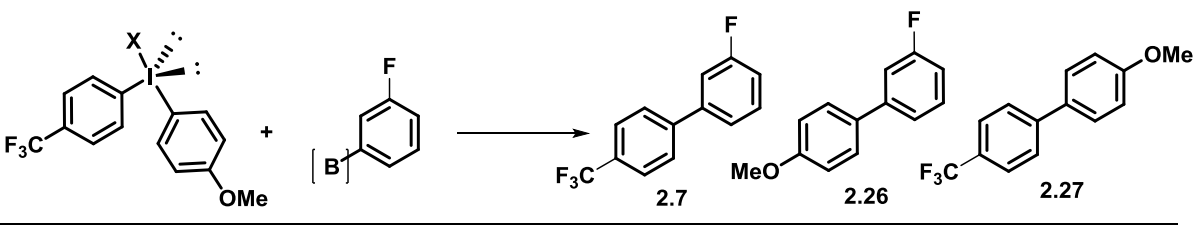

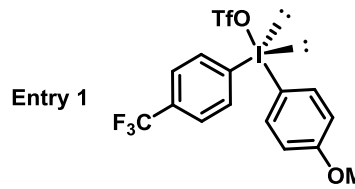<smiles>OB(O)c1cccc(F)c1</smiles>

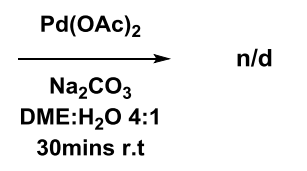
$90 \%$ $5 \%$ Entry 2<smiles>COc1ccc(C(C)(C)[Ge]([O-])(O)c2ccc(C(F)(F)F)cc2)cc1</smiles><smiles>OB(O)c1cccc(F)c1</smiles>

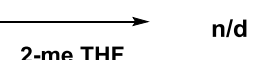

$2-\mathrm{me}$ THF
$50^{\circ} \mathrm{C}$

$17 \mathrm{~h}$

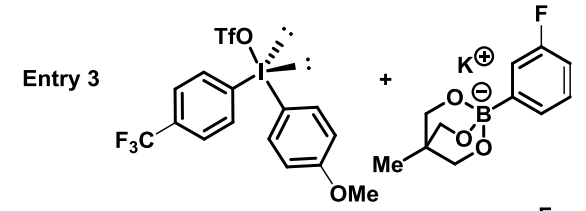

$\underset{2-\mathrm{me}}{\longrightarrow} \quad 40 \%$

2-me THF

$40 \%$

n/d

$\mathbf{n} / \mathbf{d}$

$n / d$

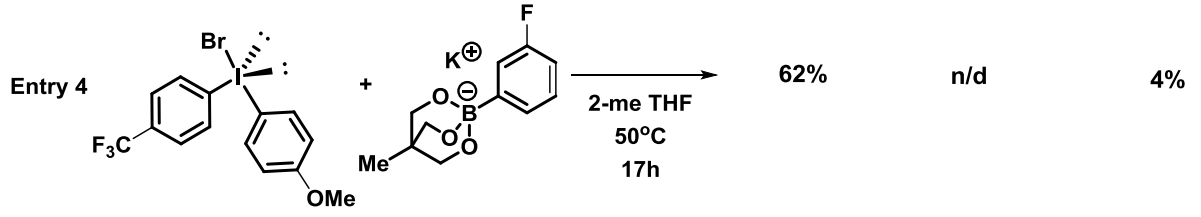

${ }^{a}$ Conditions: Iodane $(0.05 \mathrm{mmol}, 0.1 \mathrm{M}){ }^{b}{ }^{19} \mathrm{~F}$ NMR yield with 1,3,5-trichloro-2,4,6-trifluorobenzene $(0.05 \mathrm{mmol})$ as internal standard. ${ }^{\mathrm{c}}$ No product detected in the NMR spectra.

2.9. Our proposed mechanism for the metal free synthesis of biaryls

When the diaryl- $\lambda^{3}$-iodanes and cyclic triolborates react to form the T-shaped intermediate, it is considered that the counter ion of the iodane is replaced by the nucleophilic aryl group. It is also reasonable to believe that the bulkiest aryl group 
occupies the equatorial position which is less hindered compared to the axial group in the T-shaped intermediate to reduce the steric strain. ${ }^{61}$ When the proposed tri substituted intermediate is formed aryl-aryl coupling will occur through reductive elimination. In an unselective reaction six products are formed (Figure 2.3). Due to Berry-pseudo rotation the axial and equatorial groups undergo rapid isomerisation. ${ }^{62}$ Reductive ligand coupling will take place from cis oriented aryl groups and therefore three different biaryls and three aryl iodides may be formed. Selection of the appropriate spectator ligand is expected to change this scenario and limit the number of products, forming one major biaryl and one aryl iodide. We have found that trimethoxybenzene functions as a successful spectator ligand in this regard. However, conclusive evidence of the formation of the triaryliodane intermediate has not been forthcoming.

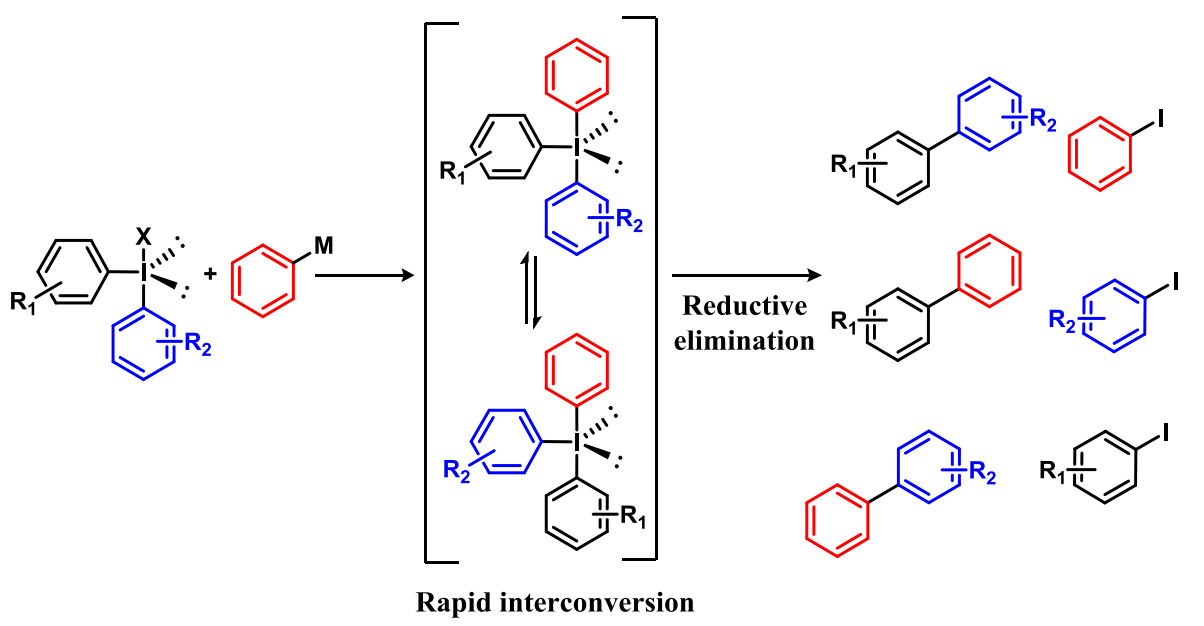

Figure 2.3: Berry-pseudo rotation of the T-shaped reaction intermediate

2.10. Isolation of the proposed salt metathesis product

In our efforts to study the hypothesized mechanism of the reaction, we have isolated a salt metathesis product from reaction of poorly reactive diaryl- $\lambda^{3}$-iodanes and 
cyclic triolborates (Scheme 2.3, entry 1). We found the salt metathesis reaction was most successful in DMF or water as the solvent, and in DMF we found that this product precipitates from the reaction mixture within 2 minutes.

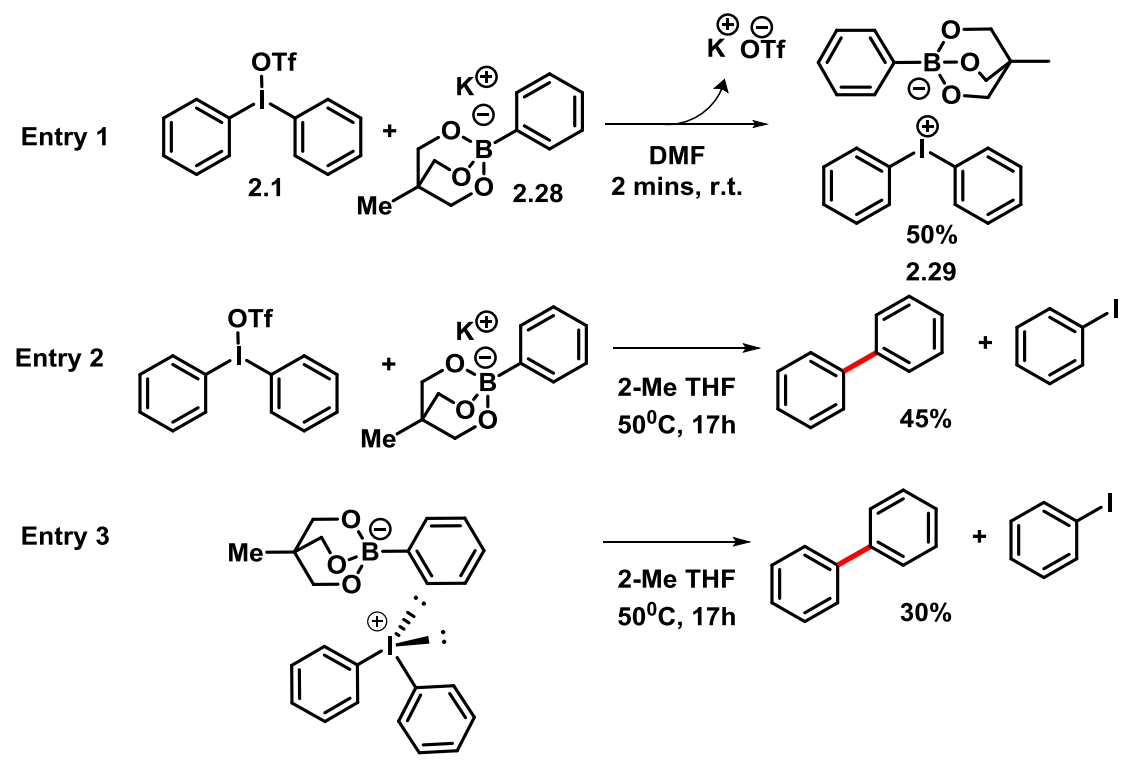

Scheme 2.3: Synthesis of the proposed T-shaped intermediate

${ }^{1} \mathrm{H}$ and ${ }^{19} \mathrm{~F}$ NMR spectra confirmed the formation of the salt metathesis intermediate (Figures 2.4 and 2.5). Disappearance of the OTf fluorine peak at $77 \mathrm{ppm}$ in ${ }^{19}$ F NMR spectra indicated that the solid formed is not the two starting materials cocrystallized (Figure 2.5). The reaction yield for the formation of the salt metathesis product was $50 \%$ (Sheme 2.4, entry 1). When the salt metathesis product was stirred in 2Methyl THF at $50^{\circ} \mathrm{C}$ for 17 hours the yield observed by the ${ }^{1} \mathrm{H}$ NMR spectra was $30 \%$ (Scheme 2.4, entry 3). This is consistant with the yield obtained from a reaction of diphenyliodonium triflate and potassium phenyl triolborates (Scheme 2.3, entry 2). A more complete mechanistic picture is presented in Figure 2.6. 


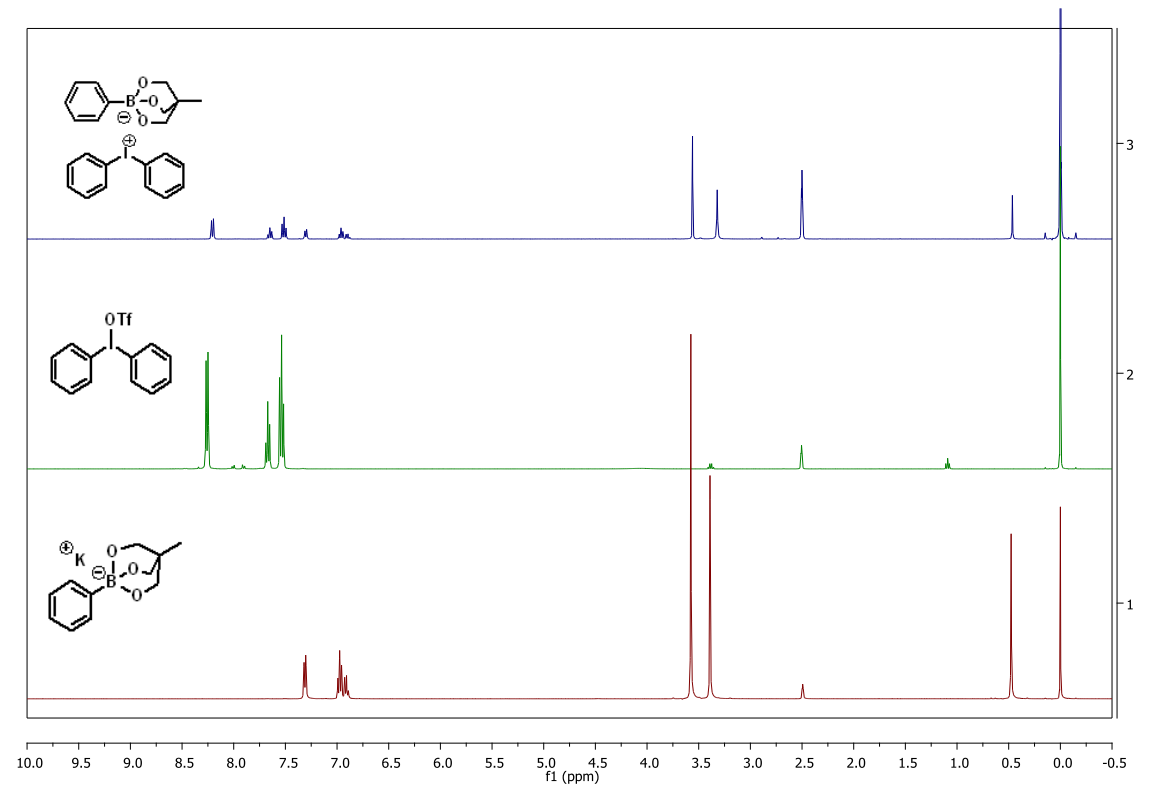

Figure 2.4: ${ }^{1} \mathrm{H}$ NMR spectra confirmed the formation of the salt metathesis product

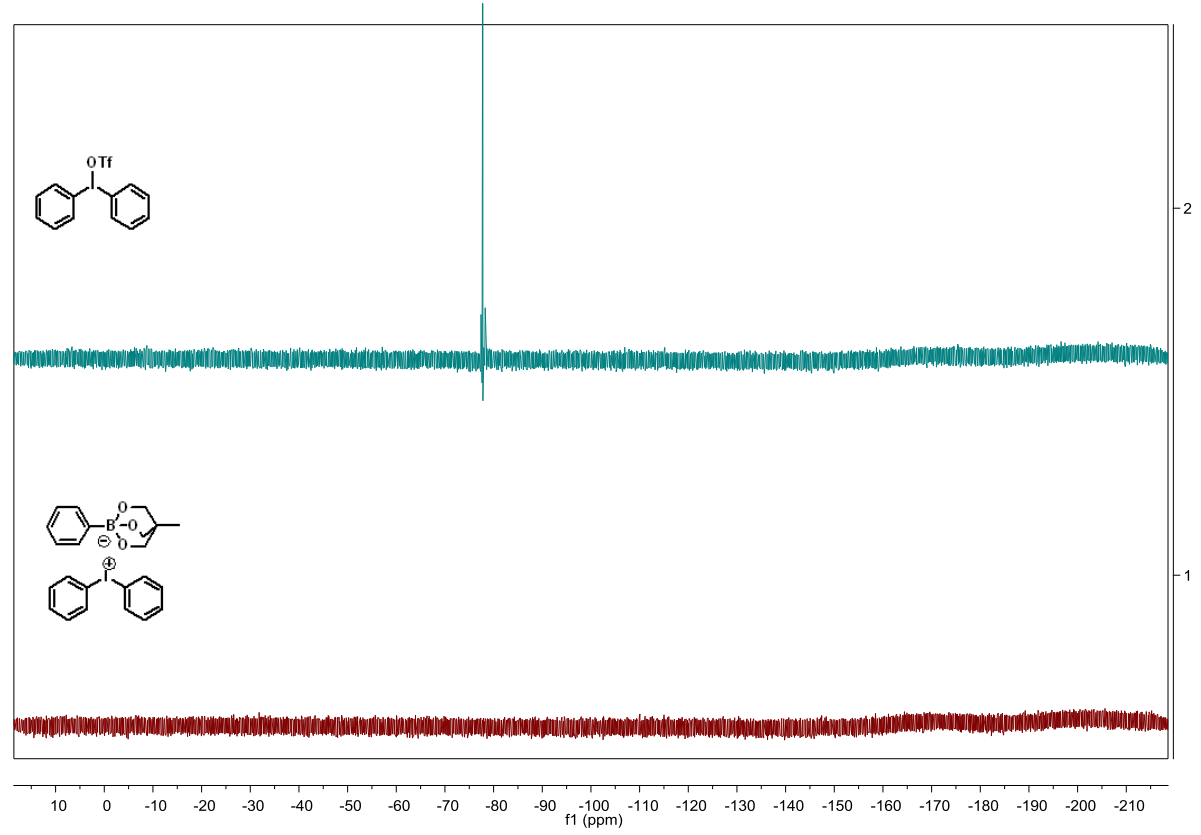

Figure 2.5: ${ }^{19} \mathrm{~F}$ NMR spectra confirmed the disappearance of the triflate peak 
The T-shaped intermediate can be formed via two pathways: an open shell pathway proposed by Kita and co-workers ${ }^{63}$ involving a single electron transfer (SET) via a charged complex or a closed shell pathway proposed by Beringer. ${ }^{64}$

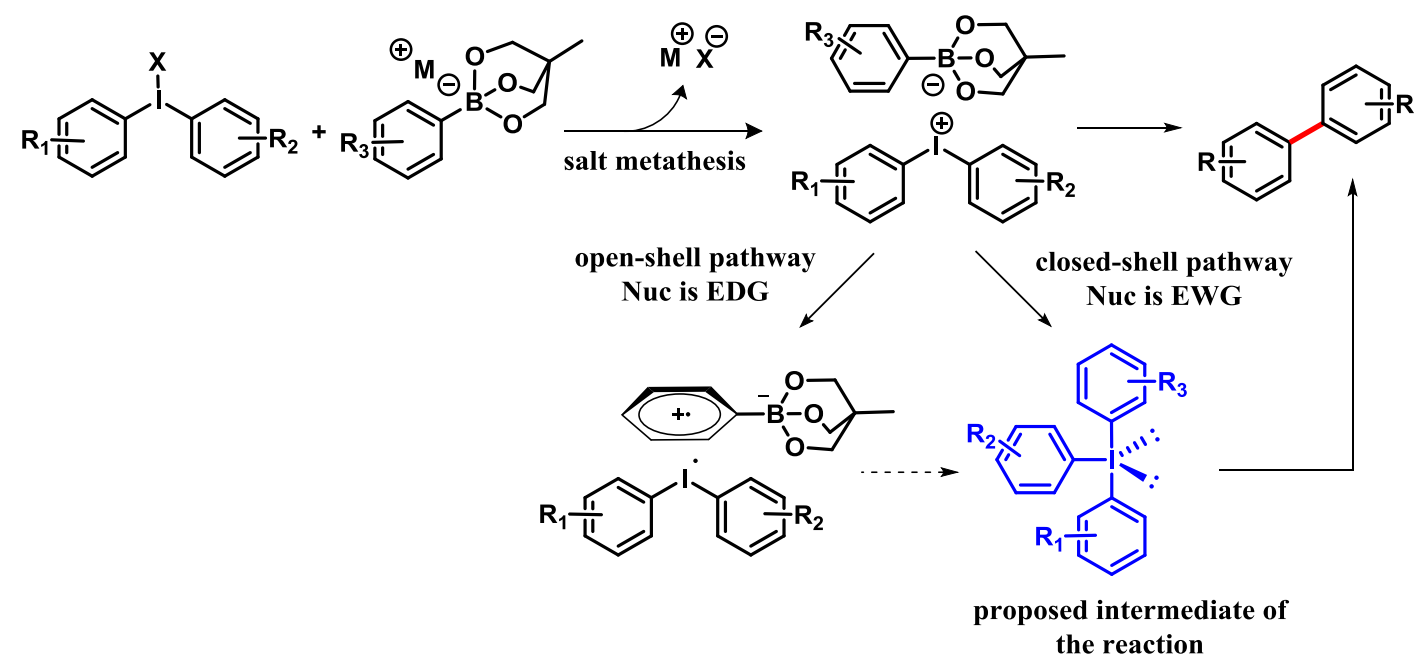

Figure 2.6: Proposed mechanism of the reaction

When diaryliodonium salts and aryl groups are reacted under conditions shown in Kita's chemistry the electron rich trimethoxybenzene group transfers (Scheme 2.4, entry 1). He proposed that this product is formed via a SET mechanism. In our chemistry the electron deficient aryl group transfers exclusively (Scheme 2.4, entry 2). This difference in selectivity also suggests a biaryl product forming-intermediate that is distinct from Kita's. Therefore we suggest the reaction to occur through a closed shell pathway, similar to the mechanism proposed by Beringer (Figure 2.6). 

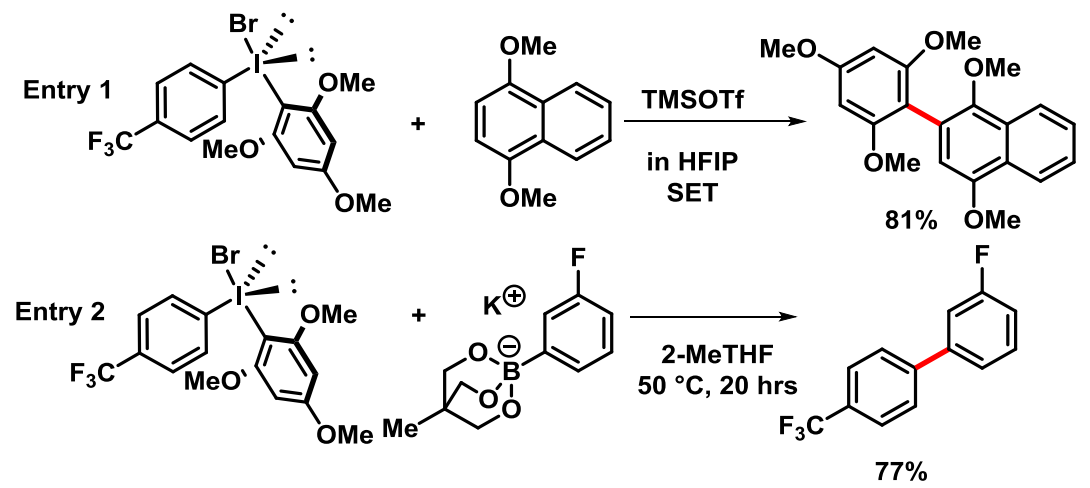

Scheme 2.4: Transfer of electron-rich and electron-deficient aryl groups

In summary we have developed a new metal-free synthesis of biaryl compounds from unsymmetrical diaryliodonium bromides and potassium aryltriolborates. The yield depends remarkably on the counter ion and the spectator ligand of the iodonium compounds. 


\section{Chapter 3: Experimental Methods}

\subsection{Materials}

Commercially available reagents and solvents were used without further purification unless otherwise stated. 2-Me THF was purchased from Sigma-Aldrich. DMF and DCM were purchased from Acros Organics. HFIP and TFE were purchased from TCI America. THF was purchased from Omnisolv. Anhydrous DCM was obtained from Sigma-Aldrich and dried through an MB SPS MBRAUN solvent system. Arylboronic acids were purchased from either Sigma-Aldrich or Frontier Scientific. Iodobenzene diacetate and iodomesitylene diacetate were purchased from TCI America and stored at $5^{\circ} \mathrm{C}$. $\mathrm{BF}_{3} \cdot \mathrm{OEt}_{2}$ was purchased from Acros Organics and stored at $5^{\circ} \mathrm{C}$ under a nitrogen atmosphere. $\mathrm{KBr}$ was purchased from Fisher Scientific, NaOTf was purchased from TCI America, $\mathrm{NaBF}_{4}$ was purchased from Sigma-Aldrich. $m$-CPBA (70\% oxidant) and magnesium sulfate were purchased from Sigma-Aldrich. All other materials were prepared by known literature procedures or are described in detail below.

\subsection{Methods and Instrumentation}

Reactions performed above ambient room temperature were done so in an oil bath or aluminum block heated externally by a Heidolph MR Hei-Standard heating/stirring mantel equipped with a Heidolph EKT HeiCON temperature control. Crude reaction mixtures were analyzed by ${ }^{1} \mathrm{H}$ NMR spectroscopy, ${ }^{19} \mathrm{~F}$ NMR spectroscopy or TLC on Selecto Scientific Flexible TLC plates (silica gel $60 \AA \AA$ F-254) and visualized by UV irradiation. Crude material was purified by flash column chromatography on Silicycle

silica gel SiliaFlash P60, unless otherwise stated. ${ }^{1} \mathrm{H},{ }^{13} \mathrm{C}$, and ${ }^{19} \mathrm{~F}$ NMR spectra were 
recorded in $\mathrm{CDCl}_{3}$ or DMSO- $d_{6}$ (with TMS as a reference) on a Bruker Avance II 400 MHz spectrometer; the following notation is used: br - broad, $\mathrm{s}-$ singlet, $\mathrm{d}-$ doublet, $\mathrm{t}-$ triplet, $\mathrm{q}-$ quartet, $\mathrm{m}-$ multiplet, $\mathrm{dd}-$ doublet of doublets. FTIR spectra were recorded on Thermo Scientific Nicolet iS5 Infra-red spectrometer. HRMS were recorded on Thermo Scientific LTQ Orbitrap Mass spectrometer. Melting points were recorded on Mel-Temp (Thermo scientific) and are reported as uncorrected.

\subsection{Reaction schemes}

3.3.1. Synthesis of diaryl- $\lambda^{3}$-iodanes- Representative procedure $A^{65}$

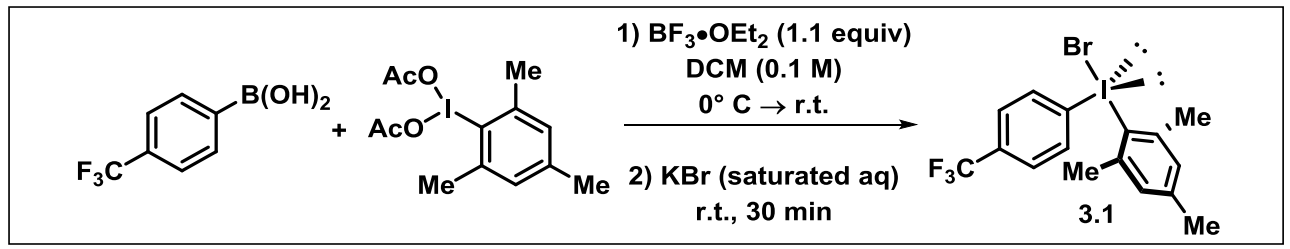

Arylboronic acid (2.0 g, $11.11 \mathrm{mmol}, 1.0$ equiv.) was weighed and transferred to a pear-shaped flask equipped with a magnetic stir bar and rubber septum. The flask was flushed with nitrogen and left under a static nitrogen atmosphere. DCM (90 mL) was added via syringe to the arylboronic acid and the solution is cooled to $\sim 0^{\circ} \mathrm{C}$ in an icewater bath with stirring. $\mathrm{BF}_{3} \cdot \mathrm{OEt}_{2}(1.57 \mathrm{~mL}, 11.11 \mathrm{mmol}, 1$ equiv. $)$ is added via syringe to the arylboronic acid solution and the reaction mixture was stirred for 10 minutes at $0^{\circ}$ C. Iodomesitylene diacetate (4.05 g, $11.11 \mathrm{mmol}, 1$ equiv.) was weighed and transferred to a separate pear-shaped flask equipped with rubber septa. The flask was flushed with nitrogen and left under a static nitrogen atmosphere. DCM $(32 \mathrm{~mL})$ was added to the iodomesitylene diacetate. The iodomesitylene diacetate solution was added to the arylboronic acid/ $\mathrm{BF}_{3} \cdot \mathrm{OEt}_{2}$ solution drop-wise via syringe at $\sim 0^{\circ} \mathrm{C}$. The reaction 
mixture was allowed to warm to ambient room temperature and stirred overnight. The septum was removed and an aqueous saturated solution of $\mathrm{KBr}(200 \mathrm{~mL})$ was added with vigorous stirring for $\sim 30$ minutes. The biphasic mixture was added to a separatory funnel and the DCM/water layers separated. The water layer was extracted with a further $3 \times 30 \mathrm{~mL}$ of DCM. The combined DCM layers were dried over $\mathrm{MgSO}_{4}$, filtered, and the DCM removed on a rotovap. The crude residue was triturated with diethyl ether to yield analytically pure diaryliodonium bromide. See below for yield and characterization data. This procedure can also be used to make the tetrafluoroborate by replacing $\mathrm{KBr}$ with $\mathrm{NaBF}_{4}$.

Representative procedure B: ${ }^{66,67}$

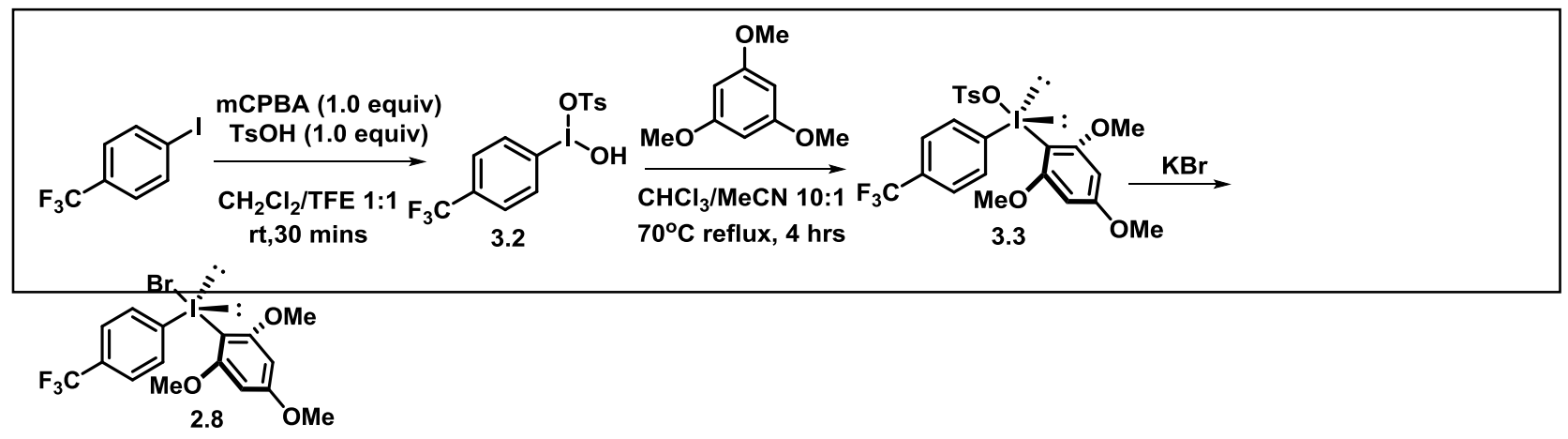

To a stirred solution of iodoarene $(0.54 \mathrm{~mL}, 3.67 \mathrm{mmol}, 1$ equiv. $)$ in dichloromethane/TFE (1:1 v/v, $36 \mathrm{~mL})$ was added $m$-CPBA ( $0.98 \mathrm{~g} 3.70 \mathrm{mmol}, 1$ equiv.), followed by $\mathrm{TsOH} \cdot 3 \mathrm{H}_{2} \mathrm{O}(0.7 \mathrm{~g}, 3.73 \mathrm{mmol}, 1.02$ equiv. $)$. The resulting solution was stirred at room temperature for $30 \mathrm{~min}$ and concentrated under a vacuum and diethyl ether $(10 \mathrm{~mL})$ was added to the remaining residue. The resulting white precipitate was filtered off and dried in vacuo to give compound 3.2 as a solid. Trimethoxybenzene (1.83 g, $10.8 \mathrm{mmol}, 2.5$ equiv. $)$ and the crude compound $3.2(2 \mathrm{~g}, 4.32 \mathrm{mmol})$ was refluxed for 
$4 \mathrm{hrs}$ at $70^{\circ} \mathrm{C}$ in choloform/acetonitrile $(10: 1 \mathrm{v} / \mathrm{v} 100: 10 \mathrm{~mL})$. Solvent was then removed under reduced pressure, and the oily residue was triturated with $\mathrm{Et}_{2} \mathrm{O}$. Precipitate was filtered off, washed with $\mathrm{Et}_{2} \mathrm{O}$ and dried under vacuum. To a stirred solution of crude 3.3 (1.2 g, $1.8 \mathrm{mmol}, 1.0$ equiv.) in DCM (18 mL, $0.1 \mathrm{M})$ a saturated solution of $\mathrm{KBr}(20$ $\mathrm{mL}$ ) was added and stirred for 30 minutes at room temperature. The organic layer is separated and the aqueous layer is extracted with DCM $(3 \times 20 \mathrm{~mL})$. The combined organic layer is dried over $\mathrm{MgSO}_{4}$ and evaporated under the rotovap. The resulting solid is washed and filtered using diethyl ether to give diaryliodonium bromide. This method was used to make diaryliodonium salts with different counter ions such as: $\mathrm{TFA}^{-}, \mathrm{Cl}^{-}$and OTf by replacing $\mathrm{KBr}$ with the corresponding saturated salt solution. See below for yield and characterization data.

Representative procedure $C:^{68}$

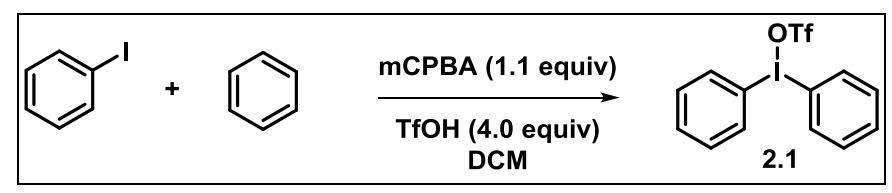

To a solution of the iodobenzene (1.12 mL, $10.0 \mathrm{mmol}, 1.0$ equiv.) in DCM (42 $\mathrm{mL}$ ) in a pear-shaped flask equipped with a magnetic stir bar, trifluoromethanesulfonic acid (3.5 mL, $40 \mathrm{mmol}, 4.0$ equiv.) was added over 2 minutes at $0{ }^{\circ} \mathrm{C}$ and stirred for 15 minutes at room temperature. Benzene $(0.98 \mathrm{~mL}, 11 \mathrm{mmol}, 1.1$ equiv. $)$ and dried $\mathrm{m}$ CPBA (2.58 g, $15.0 \mathrm{mmol}, 1.5$ equiv.) were added and the reaction was refluxed at $60^{\circ} \mathrm{C}$ for 45 minutes. The solvent was removed in vacuo and diethyl ether was added. The resulting solid was filtered and washed with diethyl ether to give the iodonium triflate as 
a solid that was dried under vacuum for 1 hour. See below for yield and characterization data.

Representative procedure D: ${ }^{69,70}$

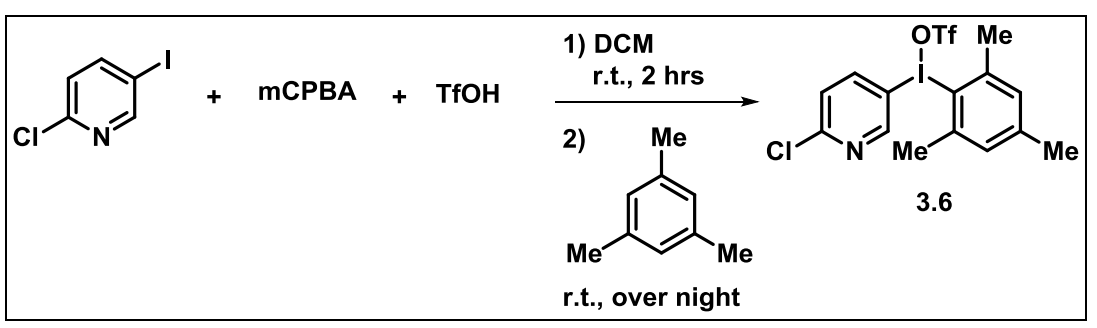

To 3-iodopyridine (0.8 g, 3.9.0 mmol, 1.0 equiv.) and dried m-CPBA (0.742 g, $4.30 \mathrm{mmol}, 1.1$ equiv. $)$ in DCM $(10 \mathrm{~mL})$ at $0{ }^{\circ} \mathrm{C}$ was added trifluoromethanesulfonic acid ( $0.55 \mathrm{~mL}, 6.24 \mathrm{mmol}, 1.6$ equiv.) dropwise over 2 minutes. The ice bath was removed and the reaction stirred for 2 hours at room temperature. It was then cooled to $0{ }^{\circ} \mathrm{C}$ and trimethylbenzene $(0.59 \mathrm{~mL}, 4.3 \mathrm{mmol}, 1.1$ equiv.) was added dropwise over 2 minutes. The reaction was allowed to warm to room temperature and stirred overnight. The solvent was removed in vacuo and diethyl ether was added. The resulting solid was filtered and washed with diethyl ether to give the iodonium triflate as a solid that was dried under vacuum for 1 hour.

3.3.2. Synthesis of cyclic triolborates- general procedure E: ${ }^{71}$

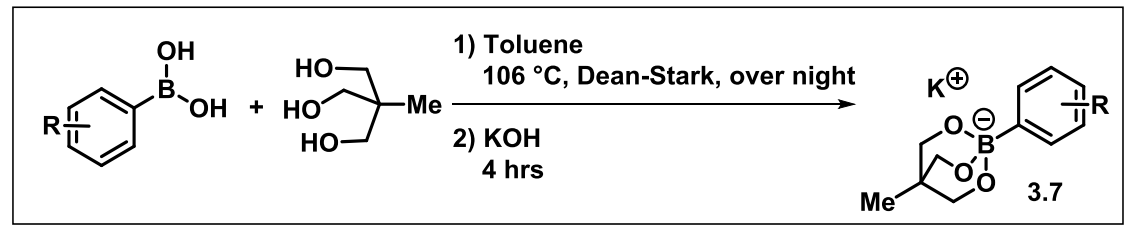


To an oven dried pear shaped flask equipped with a dry magnetic stir bar, aryl boronic acid (7.1 mmol 1 equiv. ) and 1,1,1-tris(hydroxymethyl) ethane (7.1 mmol, 1 equiv.) were weighed and was dissolved in toluene $(20 \mathrm{~mL})$. Water was removed by azeotropic distillation by the Dean-Stark method for $12 \mathrm{~h}$. To the crude reaction mixture crushed $\mathrm{KOH}$ or the corresponding metal hydroxide ( $6.4 \mathrm{mmol}, 0.9$ equiv.) were added and heated at reflux for $4 \mathrm{~h}$ by the Dean-Stark method. The white triolborate that precipitated was collected by filtration, washed with acetone, and dried under reduced pressure. See below for yield and characterization data.

\subsubsection{Synthesis of biarlys- General procedure F:}

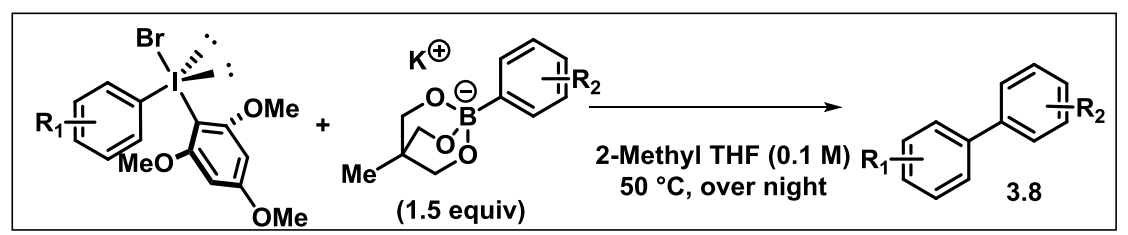

The diaryliodonium salt (0.5-1.0 mmol, 1 equiv.) and aryl borate $(0.75-1.5 \mathrm{mmol}$, 1.5 equiv.) was weighed out to air and transferred to an oven-dried vial equipped with a magnetic stir bar. 2-Me-THF $(5.0-10.0 \mathrm{~mL})$ was added and the vial was sealed with a solid cap and placed into a pre-heated $\left(50^{\circ} \mathrm{C}\right)$ aluminum block. The cloudy white mixture stirred over night. The reaction was then removed from the heat. The solvent was removed in vacuo. The crude residue was purified by flash column chromatography on silica gel. See below for specific eluent composition, yield and characterization data.

3.3.4. Synthesis of metathesis intermediate: Representative procedure G: 


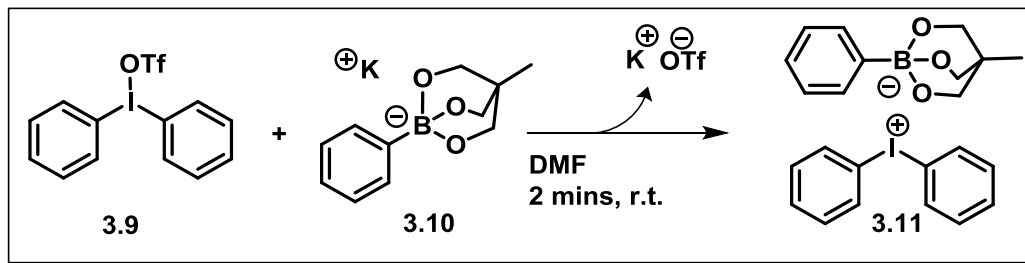

The diphenyl- $\lambda^{3}$-iodane 3.9 ( $0.108 \mathrm{~g}, 0.25 \mathrm{mmol}, 1$ equiv.) and phenyltriolborate 3.10 (0.092 g, $0.375 \mathrm{mmol}, 1.5$ equiv.) are reacted in DMF (2.50 mL) at room temperature. The mixture was sparingly soluble and within 2 minutes white precipitate $3.11(0.06 \mathrm{~g}, 0.125 \mathrm{mmol})$ was formed. The cloudy white mixture was filtered and washed with diethyl ether. ${ }^{1} \mathrm{H}$ NMR, ${ }^{19} \mathrm{~F}$ NMR spectra confirmed the formation of the salt metathesis intermediate. Water can also be used as a solvent in the above procedure. See below for yield and characterization data.

3.3.5. Synthesis of biaryls via phenyllithium $\mathrm{H}$ :

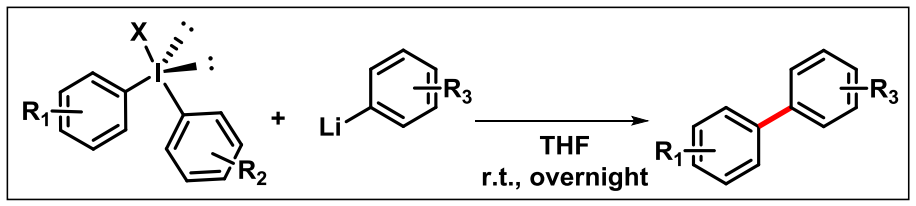

To a flame dried pear shaped flask equipped with a dry magnetic stir bar, diaryl$\lambda^{3}$-iodane (0.05 mmol 1 equiv.) was added and purged with nitrogen twice. After the flask was cooled to room temperature anhydrous THF $(0.5 \mathrm{~mL})$ was added and cooled to $-78^{\circ} \mathrm{C}$ (acetone and dry ice). Phenyllithium ( $0.75 \mathrm{mmol}, 1.5$ equiv.) was added at $-78^{\circ} \mathrm{C}$ and kept overnight after warming back to room temperature. The crude residue was purified by flash column chromatography on silica gel. 


\subsection{Characterization data}

Compound 1A

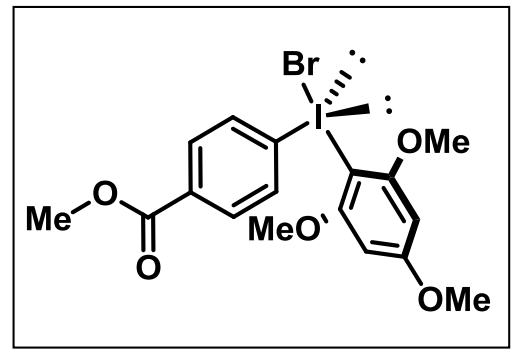

Prepared according to representative procedures B on 2.2 mmol-scale and obtained in $93 \%$ isolated yield $(1.3301 \mathrm{~g})$.

${ }^{1}$ H NMR (400 MHz, $\left.\mathbf{C D C l}_{3}\right): \delta(\mathrm{ppm}) 8.07(\mathrm{~d}, J=8.5 \mathrm{~Hz}, 2 \mathrm{H}), 7.90(\mathrm{~d}, J=9.3 \mathrm{~Hz}, 2 \mathrm{H})$, $6.15(\mathrm{~s}, 2 \mathrm{H}), 3.89(\mathrm{~s}, 3 \mathrm{H}), 3.87(\mathrm{~s}, 6 \mathrm{H}), 3.84(\mathrm{~s}, 3 \mathrm{H})$

${ }^{13}$ C NMR (100 MHz, $\left.\mathbf{C D C l}_{3}\right): \delta$ (ppm) 166.2, 165.8, 160.1, 133.6, 131.8, 131.6, 125.2, $91.8,91.6,56.9,55.8,52.5$

FTIR: 2099, 1900, 1850, 1720, 1000, $950 \mathrm{~cm}^{-1}$

HRMS: Calculated for $[\mathrm{M}-\mathrm{Br}]^{+}: 429.0193$; observed: 429.0209

MP (DCM/Et $\left.{ }_{2} \mathbf{O}\right): 170-173{ }^{\circ} \mathrm{C}$

Compound 1B

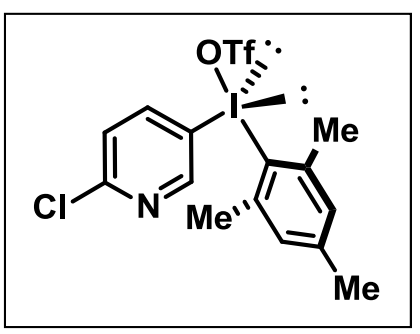

Prepared according to representative procedure D on 3.0 mmol-scale and obtained in $79 \%$ isolated yield $(1.2100 \mathrm{~g})$. Spectral data was consistent with that previously reported. ${ }^{68}$ 
${ }^{1}$ H NMR (400 MHz, CDCl$\left.)_{3}\right): \delta(\mathrm{ppm}) 8.91(\mathrm{~d}, J=2.4 \mathrm{~Hz}, 1 \mathrm{H}), 8.39-8.42(\mathrm{~m}, 1 \mathrm{H})$, $7.68(\mathrm{~d}, J=9.3 \mathrm{~Hz}, 1 \mathrm{H}), 7.23(\mathrm{~s}, 2 \mathrm{H}), 2.61(\mathrm{~s}, 6 \mathrm{H}), 2.30(\mathrm{~s}, 3 \mathrm{H})$

${ }^{13}$ C NMR (100 MHz, $\left.\mathbf{C D C l}_{3}\right): \delta(\mathrm{ppm})$ 153.6, 153.0, 145.0, 143.3, 141.6, 129.8, 129.2, 127.6, 112.4, 26.2, 20.4 (C-F not observed in our spectra)

${ }^{19}$ F NMR (377 MHz, $\left.\mathrm{CDCl}_{3}\right): \delta(\mathrm{ppm})-77.0$

Compound 1C (2.8)

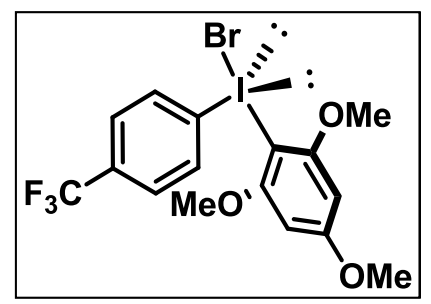

Prepared according to representative procedures B on $3.67 \mathrm{mmol}$-scale and obtained in $73 \%$ isolated yield $(1.6560 \mathrm{~g})$.

${ }^{1}$ H NMR (400 MHz, $\left.\mathbf{C D C l}_{3}\right): \delta(\mathrm{ppm}) 8.13(\mathrm{~d}, J=9.6 \mathrm{~Hz}, 2 \mathrm{H}), 7.51(\mathrm{~d}, J=7.6 \mathrm{~Hz}, 2 \mathrm{H})$, $6.15(\mathrm{~s}, 2 \mathrm{H}), 3.89(\mathrm{~s}, 6 \mathrm{H}), 3.84(\mathrm{~s}, 3 \mathrm{H})$

${ }^{13}$ C NMR (100 MHz, $\mathbf{C D C l}_{3}$ ): $\delta(\mathrm{ppm})$ 166.3, 160.1, 138.0, 134.1, 132.3 (q, $J_{\mathrm{C}-\mathrm{F}}=33.0$ $\mathrm{Hz}), 127.5\left(\mathrm{q}, J_{\mathrm{C}-\mathrm{F}}=4.0 \mathrm{~Hz}\right), 124.0,122.0,91.7,56.9,55.8$.

${ }^{19}$ F NMR (377 MHz, CDCl $\left._{3}\right): \delta(\mathrm{ppm})-63.18$

FTIR: 2000, 1950, 1800, 1700, 1000, $950 \mathrm{~cm}^{-1}$

HRMS: Calculated for $[\mathrm{M}-\mathrm{Br}]^{+}: 439.0012$; observed: 439.0018

MP (DCM/Et $\mathbf{2} \mathbf{O}): 178-179{ }^{\circ} \mathrm{C}$

Compound 1D 


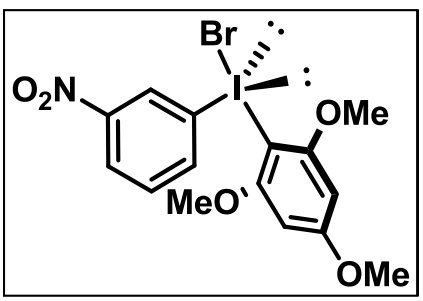

Prepared according to representative procedures B on $12 \mathrm{mmol}$-scale and obtained in $70 \%$ isolated yield $(3.8510 \mathrm{~g})$.

${ }^{1}$ H NMR (400 MHz, CDCl $)$ ): $\delta(\mathrm{ppm}) 8.67(\mathrm{t}, J=2.4 \mathrm{~Hz}, 1 \mathrm{H}), 8.51-8.54(\mathrm{~m}, 1 \mathrm{H}), 8.24$

$-8.26(\mathrm{~m}, 1 \mathrm{H}), 7.49(\mathrm{t}, J=8.2 \mathrm{~Hz}, 1 \mathrm{H}), 6.17(\mathrm{~s}, 2 \mathrm{H}), 3.93(\mathrm{~s}, 6 \mathrm{H}), 3.84(\mathrm{~s}, 3 \mathrm{H})$

${ }^{13}$ C NMR (100 MHz, $\left.\mathbf{C D C l}_{3}\right): \delta(\mathrm{ppm})$ 166.3, 160.0, 143.4, 140.0, 132.8, 131.1, 128.6, $125.1,122.9,91.7,56.9,56.3$

FTIR: $1600,1500,1339,1206 \mathrm{~cm}^{-1}$

HRMS: Calculated for $[\mathrm{M}-\mathrm{Br}]^{+}$: 415.9989; observed: 415.9992

MP (DCM/Et $\mathbf{2} \mathbf{O}): 169.4-170.1^{\circ} \mathrm{C}$

Compound 1E (3.1)

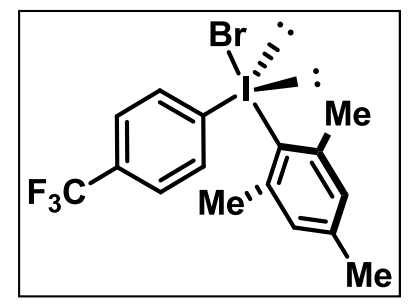

Prepared according to representative procedure A on 3.7 mmol-scale and obtained in $81 \%$ isolated yield (1.4205 g).

${ }^{1}$ H NMR (400 MHz, DMSO-d d $_{\text {): }} \delta(\mathrm{ppm}) 8.07$ (d, $\left.J=8.4 \mathrm{~Hz}, 2 \mathrm{H}\right), 7.82(\mathrm{~d}, J=8.5 \mathrm{~Hz}$, 2H), $7.20(\mathrm{~s}, 2 \mathrm{H}), 2.59$ (s, 6H), 2.29 (s, 3H)

${ }^{13}$ C NMR (100 MHz, DMSO-d $\left.\boldsymbol{d}_{6}\right): \delta(\mathrm{ppm}) 142.5,140.9,134.4,130.8\left(\mathrm{q}, J_{\mathrm{C}-\mathrm{F}}=31.7 \mathrm{~Hz}\right)$, $129.5,127.8\left(\mathrm{q}, J_{\mathrm{C}-\mathrm{F}}=3.7 \mathrm{~Hz}\right), 125.5,123.6\left(\mathrm{q}, J_{\mathrm{C}-\mathrm{F}}=270.5 \mathrm{~Hz}\right), 123.1,26.1,20.4$. 
${ }^{19}$ F NMR (377 MHz, DMSO- $\left.d_{6}\right): \delta(\mathrm{ppm})-63.0$

FTIR: $2920,1593,1329,1127,1066,1002 \mathrm{~cm}^{-1}$

HRMS: Calculated for $[\mathrm{M}-\mathrm{Br}]^{+}$391.0165; observed: 391.0182

MP (DCM/Et $\left.{ }_{2} \mathbf{O}\right): 170.4-171.3{ }^{\circ} \mathrm{C}$

Compound $1 \mathrm{~F}$

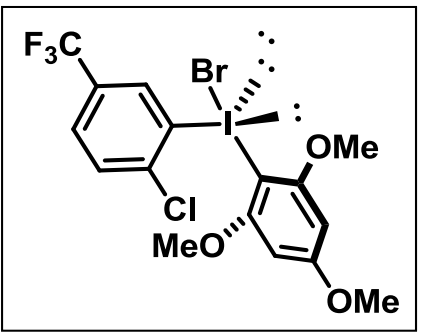

Prepared according to representative procedures B on 8 mmol-scale and obtained in $85 \%$ isolated yield $(3.62 \mathrm{~g})$.

${ }^{1}$ H NMR (400 MHz, DMSO): $\delta$ (ppm) 7.89 (s, 1H), 7.59 (m, 2H), 6.17 (s, 2H), 3.93 (s, $6 \mathrm{H}), 3.85(\mathrm{~s}, 3 \mathrm{H})$

${ }^{13}$ C NMR (100 MHz, DMSO): $\delta$ (ppm) 165.5, 159.1, 139.7, 134.92 (q, $J_{\mathrm{C}-\mathrm{F}}=3.7 \mathrm{~Hz}$ ), $130.6,129.5,128.7\left(\mathrm{q}, J_{\mathrm{C}-\mathrm{F}}=33.0 \mathrm{~Hz}\right), 124.1,122.7\left(\mathrm{q}, J_{\mathrm{C}-\mathrm{F}}=272.9 \mathrm{~Hz}\right) 91.8,91.6,56.8$, 55.9 .

${ }^{19}$ F NMR (377 MHz, DMSO): $\delta(\mathrm{ppm})-62.8$

FTIR: 2943, 1586, 1445, 1379, $1312 \mathrm{~cm}^{-1}$

HRMS: Calculated for $[\mathrm{M}-\mathrm{Br}]^{+}$476.9623; observed: 476.9623

MP (DCM/Et $\left.\mathbf{t}_{2} \mathbf{O}\right): 167-169^{\circ} \mathrm{C}$

Compound $1 \mathrm{G}$ 


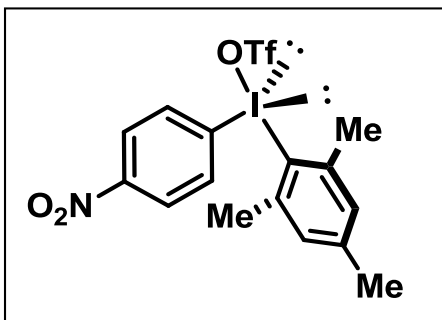

Prepared according to representative procedure D on 4.0 mmol-scale and obtained in $40 \%$ isolated yield $(0.7911 \mathrm{~g})$. Spectral data was consistent with that previously reported. 72

${ }^{1}$ H NMR (400 MHz, $\left.\mathbf{C D C l}_{3}\right): \delta(\mathrm{ppm}) 8.26(\mathrm{~d}, J=9.2 \mathrm{~Hz}, 2 \mathrm{H}), 8.17(\mathrm{~d}, J=9.2 \mathrm{~Hz}, 2 \mathrm{H})$, $7.25(\mathrm{~s}, 2 \mathrm{H}), 2.60(\mathrm{~s}, 6 \mathrm{H}), 2.31(\mathrm{~s}, 3 \mathrm{H})$

${ }^{13}$ C NMR (100 MHz, $\left.\mathbf{C D C l}_{3}\right): \delta(\mathrm{ppm})$ 148.7, 142.6, 140.9, 134.8, 129.6, 125.7, 125.4, 125.1, 26.1, 20.4. (C-F not observed)

${ }^{19}$ F NMR (377 MHz, $\left.\mathbf{C D C l}_{3}\right): \delta(\mathrm{ppm})-77.0$

Compound $1 \mathrm{H}$

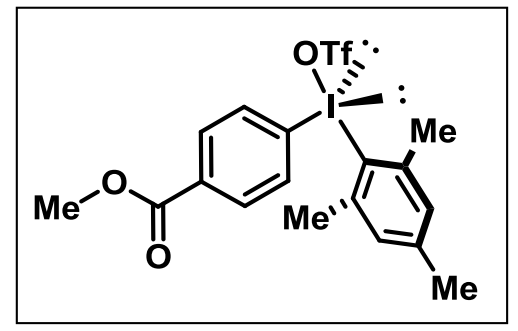

Prepared according to representative procedure D on $1.5 \mathrm{mmol}-\mathrm{scale}$ and obtained in $82 \%$ isolated yield $(0.6550 \mathrm{~g})$. Spectral data was consistent with that previously reported. 73

${ }^{1}$ H NMR (400 MHz, CDCl $)$ ): $\delta$ (ppm) $8.00(\mathrm{~d}, J=8.7 \mathrm{~Hz}, 2 \mathrm{H}), 7.99(\mathrm{~d}, J=8.7 \mathrm{~Hz}, 2 \mathrm{H})$, $7.24(\mathrm{~s}, 2 \mathrm{H}), 3.86(\mathrm{~s}, 3 \mathrm{H}), 2.59(\mathrm{~s}, 6 \mathrm{H}), 2.31(\mathrm{~s}, 3 \mathrm{H})$

${ }^{13}$ C NMR (100 MHz, $\left.\mathbf{C D C l}_{3}\right): \delta(\mathrm{ppm})$ 165.3, 144.5, 142.5, 133.1, 132.9, 139.6, 130.3, $120.7,115.4,52.7,27.0,21.1(\mathrm{C}-\mathrm{F}$ not observed) 


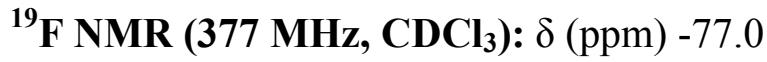

Compound 1I (2.1)

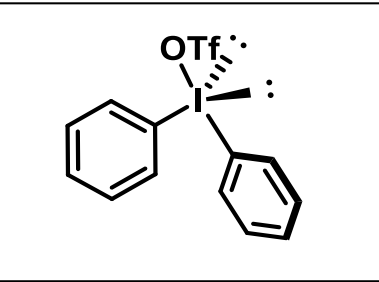

Prepared according to representative procedure $\mathrm{C}$ on $10.0 \mathrm{mmol}$-scale and obtained in 95\% isolated yield (4.1152 g). This compound is commercially available (CAS: 6600376-7)

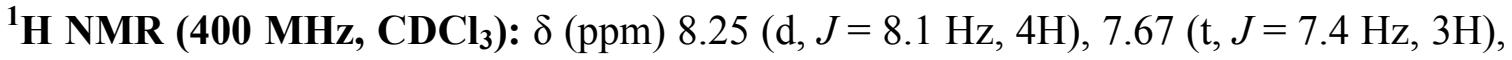
$7.54(\mathrm{t}, J=7.7 \mathrm{~Hz}, 3 \mathrm{H})$.

${ }^{13}$ C NMR (100 MHz, CDCl 3 ): $\delta$ (ppm) 135.0, 131.9, 131.6, 116.3 (C-F not observed)

${ }^{19}$ F NMR (377 MHz, $\left.\mathbf{C D C l}_{3}\right): \delta(\mathrm{ppm})-77.3$

Compound 2A (2.28)

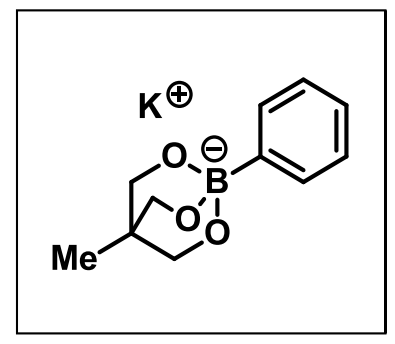

Prepared according to representative procedure E on $41.0 \mathrm{mmol}-\mathrm{scale}$ and obtained in $89 \%$ isolated yield $(8.9217 \mathrm{~g})$. Spectral data was consistent with that previously reported. $^{74}$

${ }^{1}$ H NMR (400 MHz, DMSO): $\delta$ (ppm) 7.31 (d, $J=6.9$ Hz, 2H), $6.89-6.99$ (m, 3H), $3.57(\mathrm{~s}, 6 \mathrm{H}), 0.48(\mathrm{~s}, 3 \mathrm{H})$ 
${ }^{13}$ C NMR (100 MHz, DMSO): $\delta$ (ppm) 132.0, 125.5, 124.0, 73.4, 34.3, 16.2 (C-B is not observed)

Compound 2B

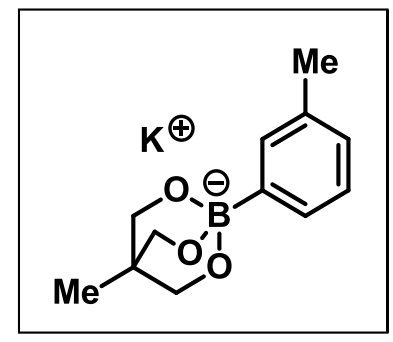

Prepared according to representative procedure E on 4.0 mmol-scale and obtained in $69 \%$ isolated yield $(0.7200 \mathrm{~g})$.

${ }^{1}$ H NMR (400 MHz, DMSO): $\delta(\mathrm{ppm}) 7.11-7.17$ (m, 2H), 6.89 (t, $\left.J=7.0 \mathrm{~Hz}, 1 \mathrm{H}\right)$, $6.77(\mathrm{~d}, J=7.41 \mathrm{~Hz}, 1 \mathrm{H}), 3.57(\mathrm{~s}, 6 \mathrm{H}), 2.18(\mathrm{~s}, 3 \mathrm{H}), 0.52(\mathrm{~s}, 3 \mathrm{H})$

${ }^{13}$ C NMR (100 MHz, DMSO): $\delta$ (ppm) 134.3, 133.5, 129.6, 126.8, 126.0, 71.0, 35.1, $21.1,16.4$ (C-B is not observed)

FTIR: $2900,1478,1317, \mathrm{~cm}^{-1}$

HRMS: Calculated for $[\mathrm{M}-\mathrm{K}]^{-}$219.1198; observed: 219.1200

MP (DCM/Et $\mathbf{2} \mathbf{O}): 289-291^{\circ} \mathrm{C}($ decomp)

Compound 2C (2.6)

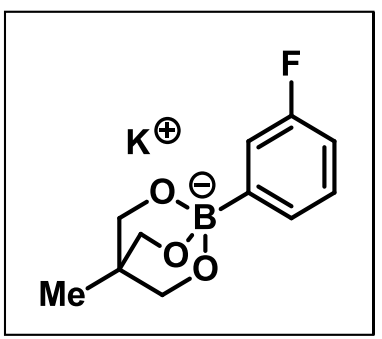

Prepared according to representative procedure E on $7.1 \mathrm{mmol}$-scale and obtained in $93 \%$ isolated yield $(1.7223 \mathrm{~g})$. 
${ }^{1}$ H NMR (400 MHz, DMSO): $\delta$ (ppm) $7.15(\mathrm{~d}, J=7.12 \mathrm{~Hz}, 1 \mathrm{H}), 6.95-7.01(\mathrm{~m}, 2 \mathrm{H})$, $6.63-6.68(\mathrm{~m}, 1 \mathrm{H}), 3.56(\mathrm{~s}, 6 \mathrm{H}), 0.48(\mathrm{~s}, 3 \mathrm{H})$

${ }^{13}$ C NMR (100 MHz, DMSO): $161.5\left(\mathrm{~d}, J_{\mathrm{C}-\mathrm{F}}=241.0 \mathrm{~Hz}\right), 127.6\left(\mathrm{~d}, J_{\mathrm{C}-\mathrm{F}}=1.8 \mathrm{~Hz}\right), 127.0$ $\left(\mathrm{d}, J_{\mathrm{C}-\mathrm{F}}=7.0 \mathrm{~Hz}\right), 117.5\left(\mathrm{~d}, J_{\mathrm{C}-\mathrm{F}}=15.8 \mathrm{~Hz}\right), 110.3\left(\mathrm{~d}, J_{\mathrm{C}-\mathrm{F}}=20.5 \mathrm{~Hz}\right), 73.5,34.3,16.0$. (C-B is not observed)

${ }^{19}$ F NMR (377 MHz, DMSO): $\delta$ (ppm) -116.87

FTIR: $3492,3090,2955,1727,1584,1443,1395 \mathrm{~cm}^{-1}$

HRMS: Calculated for $[\mathrm{M}-\mathrm{K}]^{-}$223.0947; observed: 223.0943

MP (DCM/Et $\mathbf{2} \mathbf{O}): 270-272^{\circ} \mathrm{C}($ decomp $)$

Compound 2D

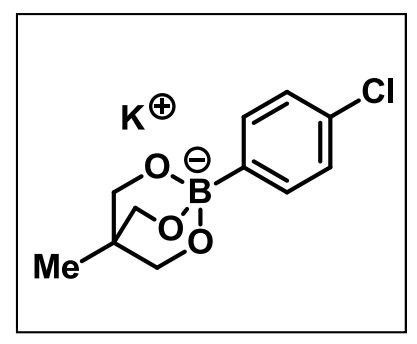

Prepared according to representative procedure E on 4.0 mmol-scale and obtained in $70 \%$ isolated yield $(0.7800 \mathrm{~g})$.

${ }^{1}$ H NMR (400 MHz, DMSO): $\delta(\mathrm{ppm}) 7.30(\mathrm{~d}, J=8.63 \mathrm{~Hz}, 2 \mathrm{H}), 6.98(\mathrm{~d}, J=6.9 \mathrm{~Hz}$, 2H), $3.56(\mathrm{~s}, 6 \mathrm{H}), 0.47(\mathrm{~s}, 3 \mathrm{H})$

${ }^{13}$ C NMR (100 MHz, DMSO): $\delta$ (ppm) 139.1, 134.0, 130.6, 78.8, 39.6, 21.3. (C-B is not observed)

FTIR : 2900, 1650, 1600, 1450,1400 $\mathrm{cm}^{-1}$

HRMS: Calculated for $[\mathrm{M}-\mathrm{K}]^{-}$239.0652; observed: 239.0653

MP (DCM/Et $\left.{ }_{2} \mathbf{O}\right): 280^{\circ} \mathrm{C}($ decomp$)$ 


\section{Compound 2E}

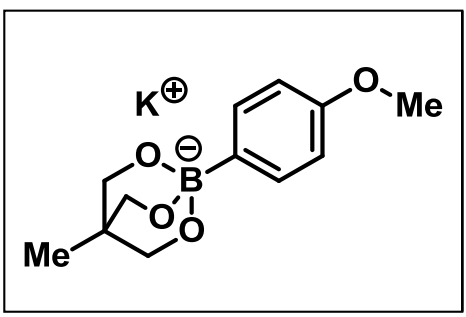

Prepared according to representative procedure E on 13.16 mmol-scale and obtained in $77 \%$ isolated yield (2.7019 g). Spectral data was consistent with that previously reported. $^{74}$

${ }^{1}$ H NMR (400 MHz, DMSO): $\delta$ (ppm) 7.20 (d, $\left.J=8.6 \mathrm{~Hz}, 2 \mathrm{H}\right), 6.55$ (d, $\left.J=8.2 \mathrm{~Hz}, 2 \mathrm{H}\right)$, $3.65(\mathrm{~s}, 3 \mathrm{H}), 3.56(\mathrm{~s}, 6 \mathrm{H}), 0.48(\mathrm{~s}, 3 \mathrm{H})$

${ }^{13}$ C NMR (100 MHz, DMSO): $\delta$ (ppm) 156.6, 132.9, 111.1, 73.4, 54.3, 34.4, 16.2. (C-B is not observed)

\section{Compound 2F}

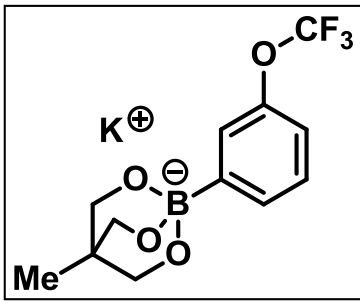

Prepared according to representative procedure E on 2.0 mmol-scale and obtained in $72 \%$ isolated yield $(0.4743 \mathrm{~g})$.

${ }^{1}$ H NMR (400 MHz, DMSO): $\delta$ (ppm) 7.29 (d, $\left.J=7.3 \mathrm{~Hz}, 1 \mathrm{H}\right), 7.18$ (s, 1H), 7.08 (t, $J$ $=8.0 \mathrm{~Hz}, 1 \mathrm{H}), 6.83(\mathrm{~d}, J=7.3 \mathrm{~Hz}, 1 \mathrm{H}), 3.56(\mathrm{~s}, 6 \mathrm{H}), 0.47(\mathrm{~s}, 3 \mathrm{H})$

${ }^{13}$ C NMR (100 MHz, DMSO): $\delta$ (ppm) $\delta$ 147.6, 130.8, 127.0, 123.4, 120.3, (q, $J_{\mathrm{C}-\mathrm{F}}=$ 254.2 Hz), 116.1, 73.7, 34.5, 16.0. (C-B is not observed)

${ }^{19}$ F NMR (377 MHz, DMSO): $\delta(\mathrm{ppm})-55.8$ 
FTIR: $2823,1592,1550,1448,1391,1322 \mathrm{~cm}^{-1}$

HRMS: Calculated for $[\mathrm{M}-\mathrm{K}]^{-}$289.0864; observed: 289.0868

MP (DCM/Et $\mathbf{2} \mathbf{O}): 292-294^{\circ} \mathrm{C}($ decomp $)$

Compound $2 \mathrm{G}$

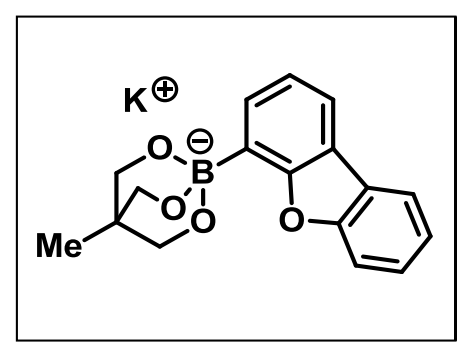

Prepared according to representative procedure E on 3.3 mmol-scale and obtained in $65 \%$ isolated yield $(0.6890 \mathrm{~g})$.

${ }^{1}$ H NMR (400 MHz, DMSO): $\delta(\mathrm{ppm}) 8.08-7.88(\mathrm{~m}, 1 \mathrm{H}), 7.71(\mathrm{~d}, J=7.5,1.5 \mathrm{~Hz}, 1 \mathrm{H})$, $7.62(\mathrm{~d}, J=8.1 \mathrm{~Hz}, 1 \mathrm{H}), 7.54(\mathrm{~d}, J=7.1,1.4 \mathrm{~Hz}, 1 \mathrm{H}), 7.47-7.34(\mathrm{~m}, 1 \mathrm{H}), 7.29-7.20$ (m, 1H), $7.06(\mathrm{t}, J=7.3 \mathrm{~Hz}, 1 \mathrm{H}), 3.66(\mathrm{~s}, 6 \mathrm{H}), 0.53(\mathrm{~s}, 3 \mathrm{H})$.

${ }^{13}$ C NMR (100 MHz, DMSO): $\delta$ (ppm) 159.5, 155.0, 133.0, 125.6, 124.7, 121.3, 121.0, $120.9,119.8,116.8,111.2,73.6,34.4,16.1$. (C-B is not observed)

FTIR: $3397,2956,2873,2359,2342,1474,1404 \mathrm{~cm}^{-1}$

HRMS: Calculated for $[\mathrm{M}-\mathrm{K}]^{-}$295.1147; observed: 295.1152

MP (DCM/Et $\left.{ }_{2} \mathbf{O}\right): 254-255^{\circ} \mathrm{C}($ decomp $)$

Compound $2 \mathrm{H}$

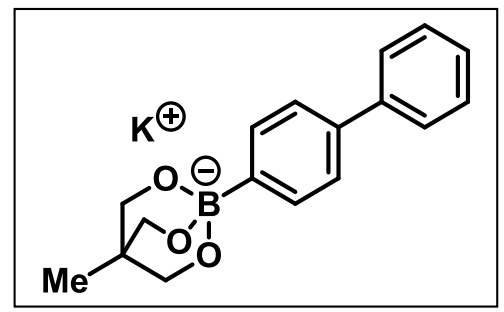


Prepared according to representative procedure E on $2.53 \mathrm{mmol}-\mathrm{scale}$ and obtained in $80 \%$ isolated yield $(0.5803 \mathrm{~g})$. Spectral data was consistent with that previously reported. 75

${ }^{1}$ H NMR (400 MHz, DMSO): $\delta$ (ppm) $7.58(\mathrm{~d}, J=7.8 \mathrm{~Hz}, 2 \mathrm{H}), 7.37-7.41$ (m, 4H), $7.23-7.30(\mathrm{~m}, 3 \mathrm{H}), 3.58(\mathrm{~s}, 6 \mathrm{H}), 0.51(\mathrm{~s}, 3 \mathrm{H})$

${ }^{13}$ C NMR (100 MHz, DMSO): $\delta$ (ppm) 141.5, 135.6, 132.6, 128.5, 126.0, 126.1, 123.8, 73.4, 34.4, 16.17 (C-B is not observed)

Compound 2I

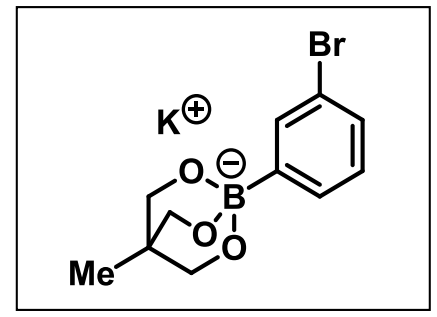

Prepared according to representative procedure E on 7.47 mmol-scale and obtained in $74 \%$ isolated yield $(1.8641 \mathrm{~g})$.

${ }^{1}$ H NMR (400 MHz, DMSO): $\delta(\mathrm{ppm}) 7.41(\mathrm{~d}, J=2.4 \mathrm{~Hz}, 1 \mathrm{H}), 7.26(\mathrm{~d}, J=7.5 \mathrm{~Hz}, 1 \mathrm{H})$, $7.06-7.08(\mathrm{~m}, 1 \mathrm{H}), 6.94(\mathrm{t}, J=8.1 \mathrm{~Hz}, 1 \mathrm{H}), 3.56(\mathrm{~s}, 6 \mathrm{H}), 0.46(\mathrm{~s}, 3 \mathrm{H})$

${ }^{13}$ C NMR (100 MHz, DMSO): $\delta$ (ppm) 134.8, 130.5, 127.9, 126.5, 120.6, 73.6, 34.4, 15.9. (C-B is not observed)

FTIR: $2955,2822,2681,1544,1468,1389,1344 \mathrm{~cm}^{-1}$

HRMS: Calculated for $[\mathrm{M}-\mathrm{K}]^{-}$283.0147; observed: 283.0148

MP (DCM/Et $\left.{ }_{2} \mathbf{O}\right): 274^{\circ} \mathrm{C}($ decomp$)$

Compound 2J 


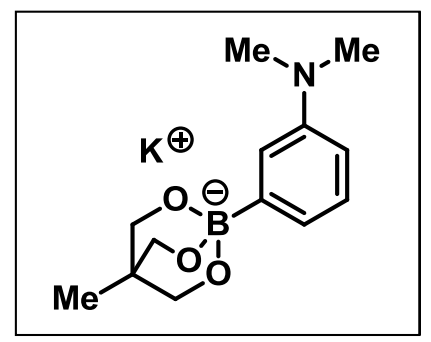

Prepared according to representative procedure E on 3.64 mmol-scale and obtained in $81 \%$ isolated yield $(0.8403 \mathrm{~g})$.

${ }^{1}$ H NMR (400 MHz, DMSO): $\delta(\mathrm{ppm}) 6.82(\mathrm{t}, J=8.9 \mathrm{~Hz}, 2 \mathrm{H}), 6.71(\mathrm{~d}, J=7.4 \mathrm{~Hz}, 1 \mathrm{H})$, $6.37(\mathrm{~d}, J=8.2 \mathrm{~Hz}, 1 \mathrm{H}), 3.56(\mathrm{~s}, 6 \mathrm{H}), 2.80(\mathrm{~s}, 6 \mathrm{H}), 0.46(\mathrm{~s}, 3 \mathrm{H})$

${ }^{13}$ C NMR (100 MHz, DMSO): $\delta$ (ppm) 149.0, 125.9, 122.0, 117.6, 109.8, 73.6, 40.9, 34.3, 16.1. (C-B is not observed)

FTIR: $3350,2952,2847,1653,0591,1568,1482,1400,1349 \mathrm{~cm}^{-1}$

HRMS: Calculated for $[\mathrm{M}-\mathrm{K}]^{-} 248.1463$; observed: 248.1461

MP (DCM/Et $\left.\mathbf{t}_{\mathbf{2}} \mathbf{O}\right): 224^{\circ} \mathrm{C}($ decomp)

\section{Compound $2 \mathrm{~K}$}

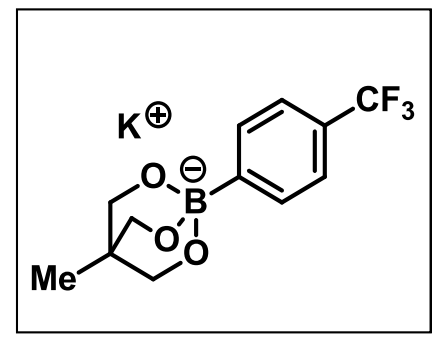

Prepared according to representative procedure E on 7.89 mmol-scale and obtained in $85 \%$ isolated yield (2.0918 g). Spectral data was consistent with that previously reported. 74

${ }^{1}$ H NMR (400 MHz, DMSO): $\delta$ (ppm) 7.50 (d, $\left.J=7.6 \mathrm{~Hz}, 2 \mathrm{H}\right), 7.28$ (d, $\left.J=8.1 \mathrm{~Hz}, 2 \mathrm{H}\right)$, $3.58(\mathrm{~s}, 6 \mathrm{H}), 0.49(\mathrm{~s}, 3 \mathrm{H})$ 
${ }^{13}$ C NMR (100 MHz, DMSO): $\delta$ (ppm) 132.4, 124.9, 123.9, 121.8 (q, $\left.J_{\mathrm{C}-\mathrm{F}}=4.2 \mathrm{~Hz}\right)$, 73.6, 34.5, 16.1. (C-B is not observed)

${ }^{19}$ F NMR (377 MHz, DMSO): $\delta$ (ppm) -60.0

Compound 2L

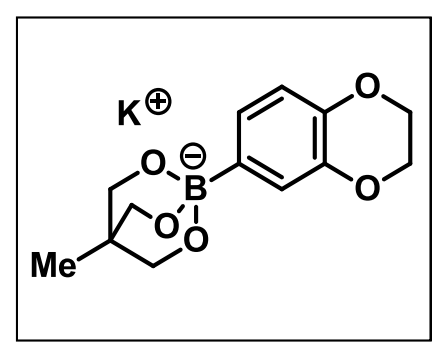

Prepared according to representative procedure E on 4.45 mmol-scale and obtained in $73 \%$ isolated yield $(0.98 \mathrm{~g})$.

${ }^{1}$ H NMR (400 MHz, DMSO): $\delta(\mathrm{ppm}) 6.73(\mathrm{~d}, J=7.8 \mathrm{~Hz}, 2 \mathrm{H}), 6.43(\mathrm{~d}, J=8.3 \mathrm{~Hz}, 1 \mathrm{H})$, $4.10(\mathrm{~s}, 4 \mathrm{H}), 3.53(\mathrm{~s}, 6 \mathrm{H}), 0.44(\mathrm{~s}, 3 \mathrm{H})$

${ }^{13}$ C NMR (100 MHz, DMSO): $\delta$ (ppm) 141.5, 140.3, 124.8, 120.3, 114.2, 73.5, 63.8, 63.8, 34.3, 16.2. (C-B is not observed)

FTIR: $2931,2875,2381,2309,1574 \mathrm{~cm}^{-1}$

HRMS: Calculated for $[\mathrm{M}-\mathrm{K}]^{-}$263.1096; observed: 263.1100

MP (DCM/Et $\left.{ }_{2} \mathbf{O}\right): 285-286{ }^{\circ} \mathrm{C}$

Compound 3A (2.11)

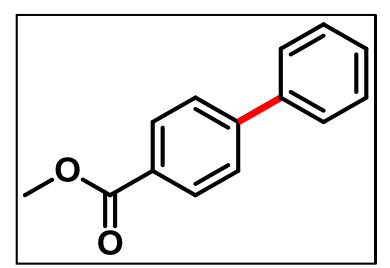


Prepared according to representative procedure F on $0.8 \mathrm{mmol}-\mathrm{scale}$ and obtained in $81 \%$ isolated yield $(0.1490 \mathrm{~g}, 0.656 \mathrm{mmol})$. Isolated by flash chromatography with 5:95 $\mathrm{Et}_{2} \mathrm{O}:$ Hexane. This compound is commercially available (CAS: 720-75-2)

${ }^{1}$ H NMR (400 MHz, $\left.\mathbf{C D C l}_{3}\right): \delta(\mathrm{ppm}) 8.09-7.92(\mathrm{~m}, 2 \mathrm{H}), 7.46-7.33(\mathrm{~m}, 2 \mathrm{H}), 7.23-$ $7.12(\mathrm{~m}, 1 \mathrm{H}), 7.06(\mathrm{~d}, J=4.6 \mathrm{~Hz}, 2 \mathrm{H}), 7.02-6.90(\mathrm{~m}, 2 \mathrm{H}), 3.90(\mathrm{~s}, 3 \mathrm{H})$.

${ }^{13}$ C NMR (100 MHz, $\left.\mathbf{C D C l}_{3}\right): \delta$ (ppm) 166.6, 161.8, 155.6, 131.6, 130.0, 124.5, 124.4, 120.1, 117.2, 52.0.

$\mathbf{R}_{\mathbf{f}}$ Value (5 :95 Et $\mathbf{2} \mathbf{O}:$ Hexane) : 0.33

Compound 3B (2.12)

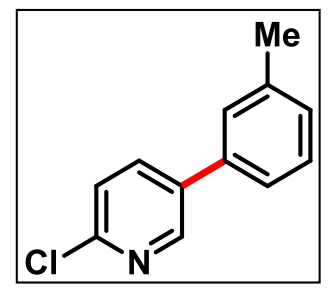

Prepared according to representative procedure F on 0.6 mmol-scale and obtained in 52\% isolated yield $(0.0635 \mathrm{~g}, 0.312 \mathrm{mmol})$. On $1.0 \mathrm{mmol}-\mathrm{scale}$ and obtained in $54 \%$ isolated yield $(0.1099 \mathrm{~g}, 0.540 \mathrm{mmol})$. Isolated by flash chromatography with 5:95 $\mathrm{Et}_{2} \mathrm{O}:$ Hexane. This compound is commercially available (CAS: 163563-07-3)

${ }^{1} \mathrm{H}$ NMR (400 MHz, $\left.\mathbf{C D C l}_{3}\right): \delta(\mathrm{ppm}) 8.59(\mathrm{~d}, J=2.5 \mathrm{~Hz}, 1 \mathrm{H}), 7.82(\mathrm{~d}, J=7.2 \mathrm{~Hz}, 1 \mathrm{H})$, 7.43-7.29 (m, 4H), $7.23(\mathrm{~d}, J=4.2,1 \mathrm{H}), 2.44(\mathrm{~s}, 3 \mathrm{H})$

${ }^{13}$ C NMR (100 MHz, $\mathbf{C D C l}_{3}$ ): $\delta$ (ppm) 150.2, 148.0, 138.9, 137.1, 136.4, 135.7, 129.2, $129.1,127.7,124.1,124.1,21.5$.

$\mathbf{R}_{\mathrm{f}}$ Value (5:95 Et $\mathrm{t}_{2} \mathrm{O}:$ Hexane) $: 0.16$

Compound 3C (2.7) 


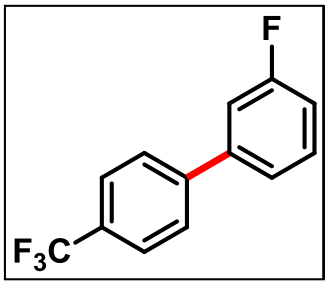

Prepared according to representative procedure $\mathrm{F}$ on 0.8 mmol-scale and obtained in $62 \%$ isolated yield (0.1190 g, $0.496 \mathrm{mmol})$. On $1.0 \mathrm{mmol}-\mathrm{scale}$ and obtained in 69\% isolated yield $(0.1656 \mathrm{~g}, 0.690 \mathrm{mmol})$. Isolated by flash chromatography with $100 \%$ Hexane. Spectral data was consistent with that previously reported. ${ }^{76}$

${ }^{1}$ H NMR (400 MHz, CDCl 3 ): $\delta(\mathrm{ppm}) 7.67$ (q, $\left.J=8.4 \mathrm{~Hz}, 4 \mathrm{H}\right), 7.47-7.38(\mathrm{~m}, 1 \mathrm{H})$, $7.36(\mathrm{t}, J=7.7 \mathrm{~Hz}, 1 \mathrm{H}), 7.31-7.25(\mathrm{~m}, 1 \mathrm{H}), 7.09(\mathrm{t}, 1 \mathrm{H})$

${ }^{13}$ C NMR (100 MHz, CDCl $)$ ): $\delta(\mathrm{ppm}) 163.2\left(\mathrm{q}, J_{\mathrm{C}-\mathrm{F}}=246.4 \mathrm{~Hz}\right), 143.4,142.0\left(\mathrm{q}, J_{\mathrm{C}-\mathrm{F}}\right.$ $=7.6 \mathrm{~Hz}), 130.5\left(\mathrm{q}, J_{\mathrm{C}-\mathrm{F}}=8.4 \mathrm{~Hz}\right), 129.9(\mathrm{q}, J=32.6 \mathrm{~Hz}), 127.9\left(\mathrm{q}, J_{\mathrm{C}-\mathrm{F}}=61.5 \mathrm{~Hz}\right)$, $125.8\left(\mathrm{q}, J_{\mathrm{C}-\mathrm{F}}=3.8 \mathrm{~Hz}\right), 124.3\left(\mathrm{q}, J_{\mathrm{C}-\mathrm{F}} 275.2 \mathrm{~Hz}\right), 122.9\left(\mathrm{q}, J_{\mathrm{C}-\mathrm{F}}=2.8 \mathrm{~Hz}\right), 115.0\left(\mathrm{q}, J_{\mathrm{C}-\mathrm{F}}=\right.$ $21.2 \mathrm{~Hz}), 114.2\left(\mathrm{q}, J_{\mathrm{C}-\mathrm{F}}=22.2 \mathrm{~Hz}\right)$.

${ }^{19}$ F NMR (377 MHz, CDCl $\left.\mathbf{3}_{3}\right): \delta(\mathrm{ppm})-61.65,-109.93$

$\mathbf{R}_{\mathbf{f}}$ Value (100\% Hexane) : 0.47

Compound 3D (2.13)

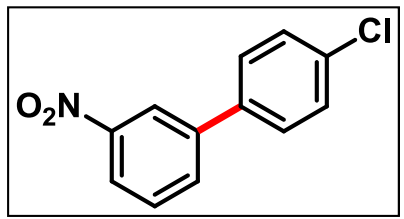

Prepared according to representative procedure $\mathrm{F}$ on 0.8 mmol-scale and obtained in $57 \%$ isolated yield $(0.1061 \mathrm{~g}, 0.456 \mathrm{mmol})$. On $1.0 \mathrm{mmol}-\mathrm{scale}$ and obtained in $52 \%$ isolated yield $(0.1290 \mathrm{~g}, 0.520 \mathrm{mmol})$. Isolated by flash chromatography with 5:95 $\mathrm{Et}_{2} \mathrm{O}: \mathrm{Hexane}$ Spectral data was consistent with that previously reported. ${ }^{77}$ 
${ }^{1}$ H NMR (400 MHz, $\left.\mathbf{C D C l}_{3}\right): \delta(\mathrm{ppm}) 8.51(\mathrm{t}, J=1.9 \mathrm{~Hz}, 2 \mathrm{H}), 8.31(\mathrm{~d}, J=8.2 \mathrm{~Hz}, 2 \mathrm{H})$, $7.98(\mathrm{~d}, J=7.8 \mathrm{~Hz}, 2 \mathrm{H}), 7.75-7.42(\mathrm{~m}, 2 \mathrm{H})$

${ }^{13}$ C NMR (100 MHz, $\left.\mathbf{C D C l}_{3}\right): \delta$ (ppm) 148.9, 147.7, 140.3, 134.7, 133.0, 130.3, 127.6, $126.6,123.3,122.1$.

$\mathbf{R}_{\mathbf{f}}$ Value (5 :95 Et $\mathbf{E}_{2} \mathbf{O}:$ Hexane) $: 0.17$

Compound 3E (2.14)

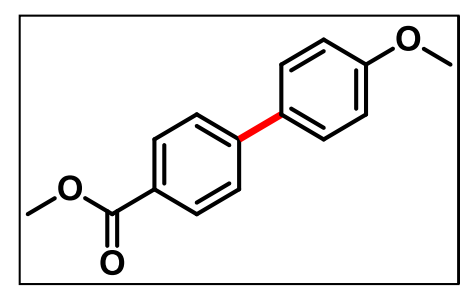

Prepared according to representative procedure F on 0.8 mmol-scale and obtained in $45 \%$ isolated yield $(0.0823 \mathrm{~g}, 0.360 \mathrm{mmol})$. On $1.0 \mathrm{mmol}-\mathrm{scale}$ and obtained in $60 \%$ isolated yield $(0.1450 \mathrm{~g}, 0.600 \mathrm{mmol})$. Isolated by flash chromatography with 5:95 $\mathrm{Et}_{2} \mathrm{O}: \mathrm{Hexane}$. This compound is commercially available (CAS: 729-17-9)

${ }^{1}$ H NMR (400 MHz, CDCl $): \delta(p p m) 7.99-7.96(\mathrm{~m}, 2 \mathrm{H}), 7.03-6.99(\mathrm{~m}, 2 \mathrm{H}), 6.95-$ $6.90(\mathrm{~m}, 4 \mathrm{H}), 3.89$ (s, 3H), $3.83(\mathrm{~s}, 3 \mathrm{H})$.

${ }^{13}$ C NMR (100 MHz, $\left.\mathbf{C D C l}_{3}\right): \delta$ (ppm) 166.6, 162.7, 156.6, 148.6, 131.6, 123.8, 121.6, $116.3,115.0,55.6,51.9$.

$\mathbf{R}_{\mathrm{f}}$ Value (5 :95 Et $\mathrm{t}_{2} \mathrm{O}:$ Hexane) $: 0.41$

Compound 3F (2.15)

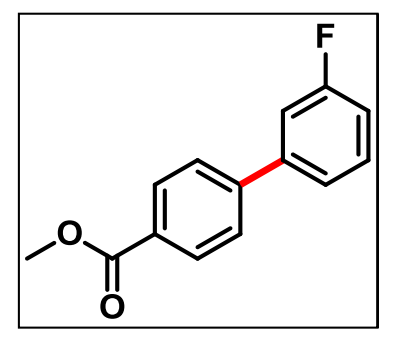


Prepared according to representative procedure F on $0.6 \mathrm{mmol}-\mathrm{scale}$ and obtained in $55 \%$ isolated yield $(0.0761 \mathrm{~g}, 0.330 \mathrm{mmol})$. On $0.6 \mathrm{mmol}-\mathrm{scale}$ and obtained in $53 \%$ isolated yield $(0.0753 \mathrm{~g}, 0.318 \mathrm{mmol})$. Isolated by flash chromatography with 5:95 $\mathrm{Et}_{2} \mathrm{O}:$ Hexane. This compound is commercially available (CAS: 80254-86-0)

${ }^{1} \mathrm{H}$ NMR (400 MHz, $\left.\mathbf{C D C l}_{3}\right): \delta(\mathrm{ppm}) 8.01(\mathrm{~d}, J=8.8 \mathrm{~Hz}, 2 \mathrm{H}), 7.29-7.36(\mathrm{~m}, 1 \mathrm{H})$, $7.02(\mathrm{~d}, J=8.2 \mathrm{~Hz}, 2 \mathrm{H}), 6.76-6.9(\mathrm{~m}, 3 \mathrm{H}), 3.92(\mathrm{~s}, 3 \mathrm{H})$

${ }^{13}$ C NMR (100 MHz, CDCl 3 ): $\delta(\mathrm{ppm})$ 166.8, $163.2\left(\mathrm{~d}, J_{\mathrm{C}-\mathrm{F}}=246.2 \mathrm{~Hz}\right), 144.2\left(\mathrm{~d}, J_{\mathrm{C}-\mathrm{F}}=\right.$ $2.2 \mathrm{~Hz}), 142.2\left(\mathrm{~d}, J_{\mathrm{C}-\mathrm{F}}=7.6 \mathrm{~Hz}\right), 130.4\left(\mathrm{~d}, J_{\mathrm{C}-\mathrm{F}}=8.4 \mathrm{~Hz}\right), 130.2,129.4,127.0,122.9(\mathrm{~d}$, $\left.J_{\mathrm{C}-\mathrm{F}}=2.8 \mathrm{~Hz}\right), 114.9\left(\mathrm{~d}, J_{\mathrm{C}-\mathrm{F}}=21.2 \mathrm{~Hz}\right), 114.2\left(\mathrm{~d}, J_{\mathrm{C}-\mathrm{F}}=22.2 \mathrm{~Hz}\right), 52.1$.

${ }^{19}$ F NMR (377 MHz, $\left.\mathbf{C D C l}_{3}\right): \delta(\mathrm{ppm})-110.3$

$\mathbf{R}_{\mathrm{f}}$ Value (5 :95 Et $\mathrm{t}_{2} \mathrm{O}:$ Hexane $): 0.15$

Compound 3G (2.10)

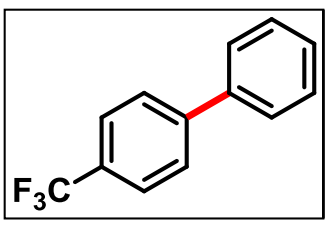

Prepared according to representative procedure F on 0.8 mmol-scale and obtained in 55\% isolated yield $(0.0867 \mathrm{~g}, 0.441 \mathrm{mmol})$. On $0.6 \mathrm{mmol}-\mathrm{scale}$ and obtained in $53 \%$ isolated yield $(0.0753 \mathrm{~g}, 0.318 \mathrm{mmol})$. Isolated by flash chromatography with $100 \%$ Hexane. This compound is commercially available (CAS: $398-36-7$ )

${ }^{1}$ H NMR (400 MHz, $\left.\mathbf{C D C l}_{3}\right): \delta(\mathrm{ppm}) 7.57(\mathrm{~d}, J=8.7 \mathrm{~Hz}, 2 \mathrm{H}), 7.37-7.41(\mathrm{~m}, 2 \mathrm{H})$, $7.17-7.20(\mathrm{~m}, 1 \mathrm{H}), 7.03-7.07(\mathrm{~m}, 4 \mathrm{H})$

${ }^{13}$ C NMR (100 MHz, $\left.\mathbf{C D C l}_{3}\right): \delta(\mathrm{ppm})$ 144.7, 139.7, $129.3\left(\mathrm{q}, J_{\mathrm{C}-\mathrm{F}}=32.5 \mathrm{~Hz}\right), 129.0$, $128.2,127.4,127.2,125.7\left(\mathrm{q}, J_{\mathrm{C}-\mathrm{F}}=3.8 \mathrm{~Hz}\right), 122.9$.

${ }^{19}$ F NMR (377 MHz, $\left.\mathbf{C D C l}_{3}\right): \delta(\mathrm{ppm})-61.42$ 
$\mathbf{R}_{\mathbf{f}}$ Value (100\% Hexane) : 0.19

Compound 3H (2.16)

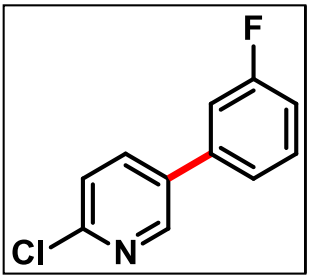

Prepared according to representative procedure $\mathrm{F}$ on $0.6 \mathrm{mmol}$-scale and obtained in $46 \%$ isolated yield $(0.0720 \mathrm{~g}, 0.276 \mathrm{mmol})$. On $1.0 \mathrm{mmol}-\mathrm{scale}$ and obtained in $42 \%$ isolated yield $(0.0872 \mathrm{~g}, 0.420 \mathrm{mmol})$. Isolated by flash chromatography with 5:95 $\mathrm{Et}_{2} \mathrm{O}: \mathrm{Hexane}$ This compound is commercially available (CAS: 76053-49-1)

${ }^{1}$ H NMR (400 MHz, CDCl $)$ ): $\delta(\mathrm{ppm}) 8.18(\mathrm{t}, J=2.2 \mathrm{~Hz}, 1 \mathrm{H}), 7.30-7.35(\mathrm{~m}, 3 \mathrm{H}), 6.86$ $-6.90(\mathrm{~m}, 1 \mathrm{H}), 6.71-6.80(\mathrm{~m}, 2 \mathrm{H})$

${ }^{13}$ C NMR (100 MHz, CDCl 3 ): $\delta(p p m) 163.26\left(\mathrm{q}, J_{\mathrm{C}-\mathrm{F}}=247.2 \mathrm{~Hz}\right), 150.96(\mathrm{~s}), 147.95$ $(\mathrm{s}), 138.69\left(\mathrm{q}, J_{\mathrm{C}-\mathrm{F}}=7.8 \mathrm{~Hz}\right), 137.1,134.4\left(\mathrm{~d}, J_{\mathrm{C}-\mathrm{F}}=2.2 \mathrm{~Hz}\right), 130.8\left(\mathrm{q}, J_{\mathrm{C}-\mathrm{F}}=8.4 \mathrm{~Hz}\right)$, $124.3,122.7\left(\mathrm{q}, J_{\mathrm{C}-\mathrm{F}}=2.9 \mathrm{~Hz}\right), 115.3\left(\mathrm{~d}, J_{\mathrm{C}-\mathrm{F}}=21.1 \mathrm{~Hz}\right), 114.0\left(\mathrm{~d}, J_{\mathrm{C}-\mathrm{F}}=22.4 \mathrm{~Hz}\right)$.

${ }^{19}$ F NMR (377 MHz, $\left.\mathbf{C D C l}_{3}\right): \delta(\mathrm{ppm})-109.7$

$\mathbf{R}_{\mathrm{f}}$ Value (5 :95 Et E $_{2} \mathbf{O}:$ Hexane) : 0.19

Compound 3I (2.17)<smiles>COc1cccc(-c2cc(C(F)(F)F)ccc2Cl)c1</smiles> 
Prepared according to representative procedure F on 0.8 mmol-scale and obtained in $45 \%$ isolated yield $(0.0823 \mathrm{~g}, 0.360 \mathrm{mmol})$. Isolated by flash chromatography with 5:95 $\mathrm{Et}_{2} \mathrm{O}$ :Hexane. This compound is commercially available (CAS: $\left.1261795-48-5\right)$

${ }^{1} \mathrm{H}$ NMR (400 MHz, $\left.\mathbf{C D C l}_{3}\right): \delta(\mathrm{ppm}) 7.61(\mathrm{~d}, J=8.6 \mathrm{~Hz}, 1 \mathrm{H}), 7.36-7.42(\mathrm{~m}, 2 \mathrm{H})$, $7.28(\mathrm{~s}, 1 \mathrm{H}), 7.02(\mathrm{~d}, J=8.5 \mathrm{~Hz}, 1 \mathrm{H}), 6.86-6.88(\mathrm{~m}, 2 \mathrm{H})$

${ }^{13}$ C NMR (100 MHz, CDCl $): \delta(p p m)$ 149.13, 139.8, 137.2 (q, $\left.J=3.8 \mathrm{~Hz}\right), 136.4$ (d, $J$ $=1.3 \mathrm{~Hz}), 130.7,130.4,129.8,129.5,128.1(\mathrm{q}, J=3.7 \mathrm{~Hz}), 127.8,126.3(\mathrm{q}, J=3.6 \mathrm{~Hz})$, $125.9(\mathrm{q}, J=3.6 \mathrm{~Hz}), 122.2,120.80$

${ }^{19}$ F NMR (377 MHz, $\left.\mathbf{C D C l}_{3}\right): \delta(\mathrm{ppm})-57.59,-62.50$

$\mathbf{R}_{\mathrm{f}}$ Value (5:95 Et $\mathrm{t}_{2} \mathrm{O}:$ Hexane) $: 0.27$

Compound 3J (2.18)

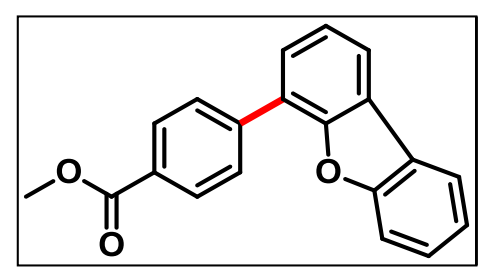

Prepared according to representative procedure F on 0.6 mmol-scale and obtained in $44 \%$ isolated yield $(0.0786 \mathrm{~g}, 0.258 \mathrm{mmol})$. Isolated by flash chromatography with $5: 95$ $\mathrm{Et}_{2} \mathrm{O}:$ Hexane.

${ }^{1}$ H NMR (400 MHz, CDCl $)$ ): $\delta(\mathrm{ppm}) 8.02(\mathrm{~d}, J=9.2 \mathrm{~Hz}, 2 \mathrm{H}), 7.98(\mathrm{~d}, J=7.7 \mathrm{~Hz}, 1 \mathrm{H})$, 7.81- $7.82(\mathrm{dd}, J=8.1 \mathrm{~Hz}, 1.9 \mathrm{~Hz}, 1 \mathrm{H}), 7.54(\mathrm{~d}, J=8.1 \mathrm{~Hz}, 1 \mathrm{H}), 7.45-7.48(\mathrm{~m}, 1 \mathrm{H})$, $7.32-7.39(\mathrm{~m}, 2 \mathrm{H}), 7.18-7.19(\mathrm{dd}, \mathrm{J}=7.1 \mathrm{~Hz}, 1.5 \mathrm{~Hz}, 1 \mathrm{H}), 7.06(\mathrm{~d}, J=8.5 \mathrm{~Hz}, 2 \mathrm{H})$, $3.9(\mathrm{~s}, 3 \mathrm{H})$

${ }^{13}$ C NMR (100 MHz, $\mathbf{C D C l}_{3}$ ): $\delta$ (ppm) 166.9, 156.1, 153.3, 141.0, 129.9, 129.2, 128.7, $127.4,126.8,125.1,124.6,124.0,123.3,122.9,120.7,120.5,111.8,52.1$. 
FTIR: $3310,2900,2820,2312,2315,1474 \mathrm{~cm}^{-1}$

HRMS: Calculated for $[\mathrm{M}+\mathrm{H}]^{+}$302.0943; observed: 302.0988

$\mathbf{R}_{\mathrm{f}}$ Value (5 :95 Et $\mathrm{t}_{2} \mathrm{O}:$ Hexane) $: 0.14$

Compound 3K (2.19)

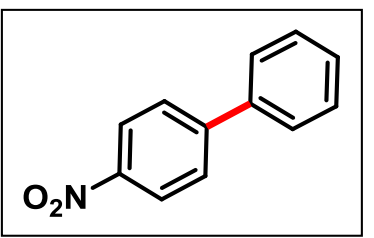

Prepared according to representative procedure F on 0.5 mmol-scale and obtained in $43 \%$ isolated yield $(0.4503 \mathrm{~g}, 0.225 \mathrm{mmol})$. Isolated by flash chromatography with 5:95 $\mathrm{Et}_{2} \mathrm{O}$ :Hexane. This compound is commercially available (CAS: 92-93-3)

${ }^{1}$ H NMR (400 MHz, CDCl $): \delta(\mathrm{ppm}) 8.30(\mathrm{~d}, J=8.1 \mathrm{~Hz}, 2 \mathrm{H}), 7.74(\mathrm{~d}, J=8.1 \mathrm{~Hz}, 2 \mathrm{H})$, $7.63(\mathrm{~d}, J=6.9 \mathrm{~Hz}, 2 \mathrm{H}), 7.43-7.52(\mathrm{~m}, 3 \mathrm{H})$

${ }^{13}$ C NMR (100 MHz, $\mathbf{C D C l}_{3}$ ): $\delta$ (ppm) 147.6, 147.1, 138.7, 129.1, 128.9, 127.8, 127.4, 124.1.

$\mathbf{R}_{\mathrm{f}}$ Value (5:95 Et $\mathbf{t}_{2} \mathrm{O}:$ Hexane) : 0.29

Compound 3L (2.20)

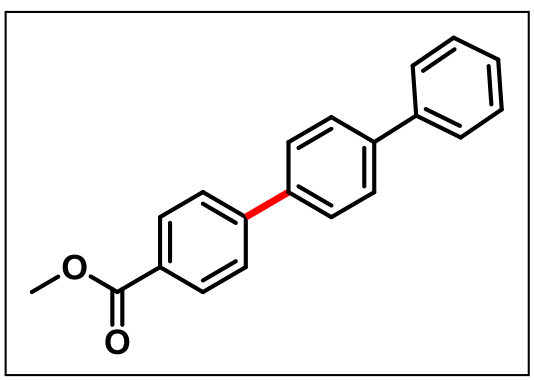

Prepared according to representative procedure F on 0.6 mmol-scale and obtained in $34 \%$ isolated yield $(0.0622 \mathrm{~g}, 0.204 \mathrm{mmol})$. On $1.0 \mathrm{mmol}-\mathrm{scale}$ and obtained in $40 \%$ isolated 
yield $(0.1152 \mathrm{~g}, 0.400 \mathrm{mmol})$. Isolated by flash chromatography with 5:95 $\mathrm{Et}_{2} \mathrm{O}: \mathrm{Hexane}$. Spectral data was consistent with that previously reported. ${ }^{78}$

${ }^{1}$ H NMR (400 MHz, $\left.\mathbf{C D C l}_{3}\right): \delta(\mathrm{ppm}) 8.03(\mathrm{~d}, J=9.0 \mathrm{~Hz}, 2 \mathrm{H}), 7.59$ (t, $\left.J=8.59 \mathrm{~Hz}, 4 \mathrm{H}\right)$, $7.44(\mathrm{t}, J=7.2 \mathrm{~Hz}, 2 \mathrm{H}), 7.35(\mathrm{t}, J=7.2 \mathrm{~Hz}, 1 \mathrm{H}), 7.13(\mathrm{~d}, J=8.5 \mathrm{~Hz}, 2 \mathrm{H}), 7.04(\mathrm{~d}, J=9.0$ $\mathrm{Hz}, 2 \mathrm{H}), 3.92(\mathrm{~s}, 3 \mathrm{H})$

${ }^{13}$ C NMR (100 MHz, $\mathbf{C D C l}$ ): $\delta$ (ppm) 166.9, 145.1, 141.0, 140.4, 138.8, 130.1, 128.9, $128.8,127.6,127.5,127.3,127.0,126.9,52.1$.

$\mathbf{R}_{\mathbf{f}}$ Value (5 :95 Et $\mathbf{~}_{2} \mathrm{O}:$ Hexane) $: 0.17$

Compound 3M (2.21)

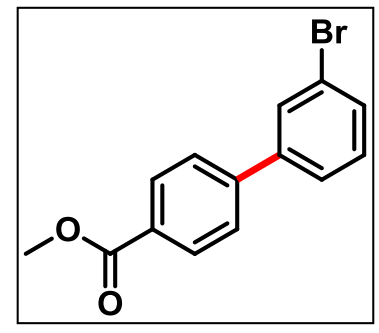

Prepared according to representative procedure F on 0.6 mmol-scale and obtained in $32 \%$ isolated yield $(0.0594 \mathrm{~g}, 0.192 \mathrm{mmol})$. On $1.0 \mathrm{mmol}-\mathrm{scale}$ and obtained in $34 \%$ isolated yield $(0.0989 \mathrm{~g}, 0.340 \mathrm{mmol})$. Isolated by flash chromatography with 5:95 $\mathrm{Et}_{2} \mathrm{O}: \mathrm{Hexane}$. This compound is commercially available (CAS: 89900-91-4)

${ }^{1}$ H NMR (400 MHz, $\left.\mathbf{C D C l}_{3}\right): \delta(\mathrm{ppm}) 8.03(\mathrm{~d}, J=8.7 \mathrm{~Hz}, 2 \mathrm{H}), 7.31(\mathrm{~d}, J=8.3 \mathrm{~Hz}, 1 \mathrm{H})$, $7.20-7.26(\mathrm{~m}, 2 \mathrm{H}), 6.98-7.02(\mathrm{~m}, 3 \mathrm{H}), 3.90(\mathrm{~s}, 3 \mathrm{H})$

${ }^{13} \mathbf{C}$ NMR (100 MHz, $\left.\mathbf{C D C l}_{3}\right): \delta$ (ppm) 166.4, 160.8, 156.6, 147.0, 131.8, 131.0, 127.4, $125.2,123.0,118.4,117.8,52.1$

$R_{f}$ Value (5 :95 Et $_{2} \mathrm{O}:$ Hexane) $: 0.33$

Compound 3N (2.22) 


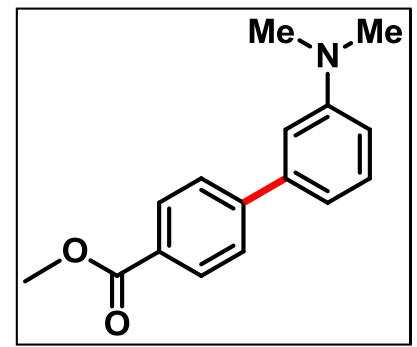

Prepared according to representative procedure F on 0.6 mmol-scale and obtained in $42 \%$ isolated yield $(0.0625 \mathrm{~g}, 0.252 \mathrm{mmol})$. Isolated by flash chromatography with 5:95 $\mathrm{Et}_{2} \mathrm{O}:$ Hexane.

${ }^{1}$ H NMR (400 MHz, CDCl $)$ : $\delta(\mathrm{ppm}) 7.98(\mathrm{~d}, J=9.3 \mathrm{~Hz}, 2 \mathrm{H}), 7.22(\mathrm{t}, J=8.6 \mathrm{~Hz}, 1 \mathrm{H})$, $6.99(\mathrm{~d}, J=8.6 \mathrm{~Hz}, 2 \mathrm{H}), 6.37-6.56(\mathrm{~m}, 3 \mathrm{H}), 3.90(\mathrm{~s}, 3 \mathrm{H}), 2.94(\mathrm{~s}, 6 \mathrm{H})$

${ }^{13}$ C NMR (100 MHz, $\left.\mathbf{C D C l}_{3}\right): \delta$ (ppm) 167.1, 150.9, 146.7, 141.0, 129.9, 129.5, 128.7, $127.2,115.7,112.3,111.3,52.0,40.6$.

FTIR: $3351,2956,2840,1600,1570,1480,1390,1340 \mathrm{~cm}^{-1}$

HRMS: Calculated for $[\mathrm{M}+\mathrm{H}]^{+}$256.1259; observed: 256.1341

$\mathbf{R}_{\mathbf{f}}$ Value (5 :95 Et E $_{2} \mathrm{O}$ Hexane) : 0.15

Compound $3 \mathrm{O}(\mathbf{2 . 2 3})$

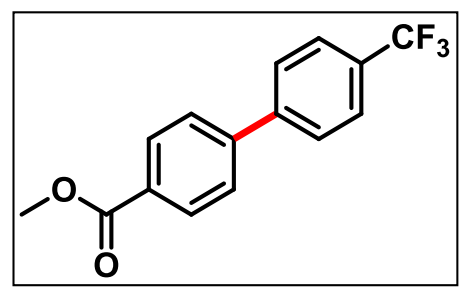

Prepared according to representative procedure F on 0.6 mmol-scale and obtained in $25 \%$ isolated yield $(0.0435 \mathrm{~g}, 0.15 \mathrm{mmol})$. On $1.0 \mathrm{mmol}-\mathrm{scale}$ and obtained in $28 \%$ isolated yield (0.0784 g, $0.280 \mathrm{mmol})$. Isolated by flash chromatography with 10:90 $\mathrm{Et}_{2} \mathrm{O}: \mathrm{Hexane}$. This compound is commercially available (CAS: 127783-73-7) 
${ }^{1}$ H NMR (400 MHz, $\left.\mathbf{C D C l}_{3}\right): \delta(\mathrm{ppm}) 8.06(\mathrm{~d}, J=8.5 \mathrm{~Hz}, 2 \mathrm{H}), 7.63(\mathrm{~d}, J=8.9 \mathrm{~Hz}, 2 \mathrm{H})$, $7.12(\mathrm{~d}, J=8.1 \mathrm{~Hz}, 2 \mathrm{H}), 7.05(\mathrm{~d}, J=9.1 \mathrm{~Hz}, 2 \mathrm{H}), 3.91(\mathrm{~s}, 3 \mathrm{H})$

${ }^{13}$ C NMR (100 MHz, $\left.\mathbf{C D C l}_{3}\right): \delta\left(\mathrm{ppm} \delta 166.7,144.0,143.5,130.2130 .1\right.$ (q, $J_{\mathrm{C}-\mathrm{F}}=34.5$

Hz) 129.8, 127.6, 127.2, $125.8\left(\mathrm{q}, J_{\mathrm{C}-\mathrm{F}}=3.7 \mathrm{~Hz}\right), 124.1\left(\mathrm{q}, J_{\mathrm{C}-\mathrm{F}}=272.1 \mathrm{~Hz}\right), 52.2$.

${ }^{19}$ F NMR (377 MHz, $\left.\mathbf{C D C l}_{3}\right): \delta(\mathrm{ppm})-61.9$

$R_{f}$ Value (10 :90 Et $\mathbf{t}_{2} \mathrm{O}:$ Hexane) $: 0.20$

Compound 3P (2.24)

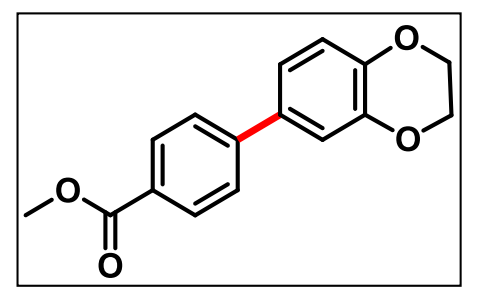

Prepared according to representative procedure F on 0.6 mmol-scale and obtained in $14 \%$ isolated yield $(0.0227 \mathrm{~g}, 0.084 \mathrm{mmol})$. Isolated by flash chromatography with 5:95 $\mathrm{Et}_{2} \mathrm{O}:$ Hexane. Spectral data was consistent with that previously reported. ${ }^{79}$

${ }^{1}$ H NMR (400 MHz, $\left.\mathbf{C D C l}_{3}\right): \delta(\mathrm{ppm}) 7.98(\mathrm{~d}, J=8.6 \mathrm{~Hz}, 2 \mathrm{H}), 6.94(\mathrm{~d}, J=8.2 \mathrm{~Hz}, 2 \mathrm{H})$, $6.60(\mathrm{~d}, J=8.6 \mathrm{~Hz}, 1 \mathrm{H}), 6.62(\mathrm{~d}, J=2.8 \mathrm{~Hz}, 1 \mathrm{H}), 6.55-6.57(\mathrm{dd}, J=8.0 \mathrm{~Hz}, 3.4 \mathrm{~Hz}, 1 \mathrm{H})$, $4.28(\mathrm{~s}, 4 \mathrm{H}), 3.90(\mathrm{~s}, 3 \mathrm{H})$

${ }^{13}$ C NMR (100 MHz, $\left.\mathbf{C D C l}_{3}\right): \delta$ (ppm) 167.0, 144.9, 143.9, 143.8, 133.4, 130.0, 128.4, $126.5,120.3,117.7,116.0,64.5,64.4,52.0$.

$\mathbf{R}_{\mathrm{f}}$ Value (5 :95 Et $\mathbf{2} \mathbf{O}:$ Hexane) $: 0.17$

Compound 3Q (2.25) 


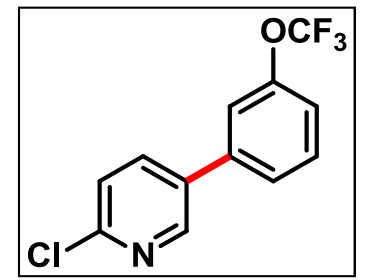

Prepared according to representative procedure $\mathrm{F}$ on $0.5 \mathrm{mmol}-\mathrm{scale}$ and obtained in $7 \%$ isolated yield $(0.0105 \mathrm{~g}, 0.035 \mathrm{mmol})$. On $1.0 \mathrm{mmol}-\mathrm{scale}$ and obtained in $9 \%$ isolated yield $(0.0245 \mathrm{~g}, 0.09 \mathrm{mmol})$. Isolated by flash chromatography with 5:95 $\mathrm{Et}_{2} \mathrm{O}:$ Hexane. Spectral data was consistent with that previously reported. ${ }^{80}$

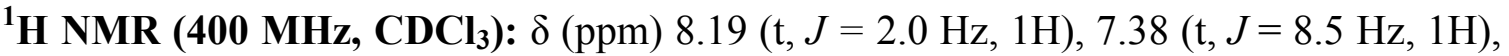
$7.32(\mathrm{~d}, J=1.6 \mathrm{~Hz}, 2 \mathrm{H}), 7.02-7.04(\mathrm{~m}, 1 \mathrm{H}), 6.89-6.94(\mathrm{~m}, 2 \mathrm{H})$

${ }^{13}$ C NMR (100 MHz, $\left.\mathbf{C D C l}_{3}\right): \delta 151.1,149.9\left(\mathrm{q}, J_{\mathrm{C}-\mathrm{F}}=1.8 \mathrm{~Hz}\right), 147.9,138.6,137.2$ $134.2,130.7,125.4,124.4,120.3\left(\mathrm{q}, J_{\mathrm{C}-\mathrm{F}}=250.2 \mathrm{~Hz}\right) 120.7,119.6$.

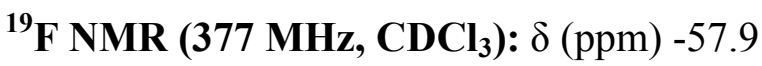

$\mathbf{R}_{\mathrm{f}}$ Value (5 :95 Et $\mathrm{E}_{2} \mathrm{O}:$ Hexane) $: 0.16$

Compound 4 A (2.29)

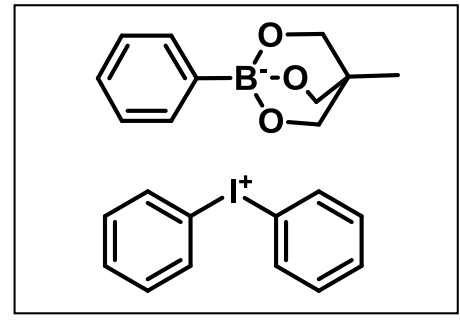

Prepared according to representative procedure $\mathrm{G}$ on $0.25 \mathrm{mmol}-\mathrm{scale}$ and obtained in $50 \%$ isolated yield $(0.0606 \mathrm{~g}, 0.125 \mathrm{mmol})$.

${ }^{1}$ H NMR (400 MHz, CDCl $): \delta(p p m) ~ 8.29-8.09$ (m, 4H), 7.65 (t, $\left.J=7.4 \mathrm{~Hz}, 2 \mathrm{H}\right), 7.51$ $(\mathrm{d}, J=10.7,4.7 \mathrm{~Hz}, 4 \mathrm{H}), 7.37-7.20(\mathrm{~m}, 2 \mathrm{H}), 6.97(\mathrm{~d}, J=11.1,4.3 \mathrm{~Hz}, 2 \mathrm{H}), 6.93-6.87$ $(\mathrm{m}, 1 \mathrm{H}), 3.56(\mathrm{~s}, 6 \mathrm{H}), 0.46(\mathrm{~s}, 3 \mathrm{H})$. 
${ }^{13}$ C NMR (100 MHz, $\left.\mathbf{C D C l}_{3}\right): \delta$ (ppm) 134.4, 132.1, 131.5, 131.4, 125.5, 124.2, 116.9, $73.2,34.4,16.1$

FTIR: $3311,2800,1650,1500,1452,1345,1300 \mathrm{~cm}^{-1}$

HRMS: $\quad\left[\mathbf{M}-\mathbf{I}(\mathbf{P h})_{2}\right]^{-} \quad$ Calculated $280.9821 \quad ; \quad$ observed: $280.9817, \quad$ [M$\left.\left.\mathbf{B}(\mathbf{P h})\left(\mathbf{O C H}_{2}\right)_{\mathbf{3}} \mathbf{C C H}_{3}\right)\right]^{+}$Calculated ; 205.1030 observed: 205.10348

MP (DCM/Et $\left.\mathbf{2}_{\mathbf{2}} \mathbf{O}\right): 299{ }^{\circ} \mathrm{C}(\operatorname{decomp})$ 


\section{Chapter 4: Conclusion}

Aromatic and heteroaromatic compounds are important moieties in many industries. Carbon-carbon and carbon-hetero atom bond forming reactions are mainly carried out via transition-metal catalyzed reactions. In our chemistry we were able to discover and develop a biaryl forming reaction without the use of transition-metals. Reaction of reactive organolithium and Grignard reagents to give biaryl products with diaryliodonium salts at low temperatures was reported by Beringer and co-workers. Since handling reactive species were challenging we investigated a different nucleophile to react with diaryliodonium salts. Aryl triolborates were found to be nucleophilic enough to react with iodanes to form biaryls under metal free conditions. The counter ion and spectator ligand of the diaryliodonium salt are important parameters for reactivity of this reaction. The $\mathrm{TMB} / \mathrm{Br}$ spectator ligand/counter on combination was found to be the best giving maximum yields. After optimization of the reaction conditions we found the standard reaction conditions to be: 1 equivalent of diaryliodonium salt, 1.5 equivalents of arylborate, 2-methyl $\mathrm{THF}, 50^{\circ} \mathrm{C}, 17$ hours. The isolated yields of $45-82 \%$ for a range of biaryl products were obtained.

The mechanism for this reaction is yet unknown. Collection of ICP-MS data, addition of transition-metals to the reaction to compare yields and study of selectivity are directing this novel reaction to be transition metal-free. In summary we have developed a new metal-free synthetic method for biaryl formation reacting diaryliodonium salts and aryl triolborates. 


\section{References}

${ }^{1}$ Hong, Y. P.; Senanayake, C. H.; Xiang, T. J.; Vandenbossche, C. P.; Tanoury, G. J.; Bakale, R. P.; Wald, S. A. Tetrahedron Lett. 1998, 39, 3121-3124.

2 Otto, N.; Opatz, T. Beilstein J. Org. Chem. 2012, 8, 1105-1111

${ }^{3}$ Belfield, A. J.; Foubister, A. J.; Park, A.; Metal, T.; Methods, C.; Methods, T. M.; Options, S. 1999, 55, 11399-11428

${ }^{4}$ Ullmann, F.; Bielecki, J. Ber. Dtsch. Chem. Ges. 1901, 34, 2174-2185

${ }^{5}$ Lewin, A. H.; Cohen, T. Tetrahedron Lett. 1965, 4531-4536.

${ }^{6}$ Miyaura, N.; Suzuki, A. Chemical Reviews, 1995, 95 (7): 2457-2483

${ }^{7}$ Tamao, K.; Sumitani, K.; Kumada, M. J. Am. Chem. Soc. 1972, 94, 4374-4376

${ }^{8}$ O. King, A.; Okukado, N.; Negishi, E. J. Chem. Soc., Chem. Commun., 1977, 683684

${ }^{9}$ Milstein, D.; Stille, J.K., J. Am. Chem. Soc. 1978, 100, 3636-3638.

${ }^{10}$ Hatanaka, Y.; Hiyama, T. J. Org. Chem, 1988, 53, 918-920

${ }^{11}$ Miyaura, N.; Yamada.N.; Suzuki, A. Tetrahedron Letters, 1979, 20 (36), 3437-3440

12 Yan, J.; Zhou, Z.; Zhu, M. Eur. J. Org. Chem. 2006, 2060 - 2062.

${ }^{13}$ Miyaura, N.; Yamada.N.; Suzuki, A. Tetrahedron Letters, 1979, 20 (36), 3437-3440

${ }^{14}$ Yan, J.; Zhou, Z.; Zhu, M. Eur. J. Org. Chem. 2006, 2060 - 2062.

${ }^{15}$ Wirth, T., Angew. Chem., Int. Ed., 2005, 44, 3656-3665.

${ }^{16}$ Stang, P. J. J. Org. Chem., 2003, 68, 2997-3008

${ }^{17}$ Aggarwal, V. K.; Olofsson, B. Angew. Chem., Int. Ed., 2005, 44, 5516-5519

${ }^{18}$ Ryan, J. H.; Stang, P. J. Tetrahedron Lett., 1997, 38, 5061-5064

${ }^{19}$ Kalyani, D.; Deprez, N. R.; Desai, L. V.; Sanford, M. S. J. Am.Chem. Soc., 2005, 127, $7330-7331$

${ }^{20}$ Deprez, N. R.; Kalyani, D.; Krause, A.; Sanford, M.S. J. Am. Chem. Soc., 2006, 128, 4972-4973

${ }^{21}$ Bielawski, M.; Olofsson, B. Chem. Commun. (Camb). 2007, 2, 2521-2523

${ }^{22}$ Yusubov, M. S.; Maskaev, A. V.; Zhdankin, V. V. ARKIVOC 2011, 1, 370-409

${ }^{23}$ Beringer, F. M.; Forgione, P. S.; Yudis, M. D. Tetrahedron, 1960, 8, 49-63

${ }^{24}$ Merritt, E. A.; Olofsson, B. Angew. Chem. Int. Ed. 2009, 48, 9052 - 9070 
${ }^{25}$ Bielawski, M.; Zhu, M.; Olofsson, B. Adv. Synth. Catal. 2007, 349, 2610

${ }^{26}$ Ochiai, M.; Toyonari, M.; Nagaoka, T.; Chen, D.-W.; Kida, M. Tetrahedron Letters $1997,38,6709-6712$

${ }^{27}$ Merritt, E. A; Carneiro, V. M. T.; Silva, L. F.; Olofsson, B. J. Org. Chem. 2010, 75, 7416-7419

28 Ackermann.L.; Dell'Aqua.M.; Fenner.S.; Vicente.R.; Sandmann.R.;

Org.Lett., 2011, 13 (9), 2358-2360

29 Kita.Y.; Morimto. K.; Ito.M.; Ogawa.C.; Goto.A.; Dohi.T. J. Am. Chem., 2009, 131 (5), 1668-1669

${ }^{30}$ Eastman. K.; Baran. P. Tetrahedron, 2009, 65, 3149-3154

${ }^{31}$ Yan.J.; Zhu.M.; Zhou.Z. Eur.J.Org.Chem. 2006, 2060-2062

${ }^{32}$ Miyaura, N.; Suzuki, A. Chemical Reviews, 1995, 95 (7), 2457-2483

${ }^{33}$ Yamamoto, Y.; Takizawa, M.; Yu, X. Q.; Miyaura, N. Angew. Chem. Int. Ed. 2008, 47, 928-931

${ }^{34}$ Boronic Acids, ed. D. G. Hall, Wiley-VCH, Weinheim, 2005

${ }^{35}$ Berionni, G.; Maji, B.; Knochel, P.; Mayr, H. Chem. Sci. 2012, 3, 878.

36 Database for $\mathrm{N}, \mathrm{sN}$ and E-parameters and references to original literature: www.cup.uni-muenchen.de/oc/mayr/DBintro.html

${ }^{37}$ Bielawski, M.; Aili, D.; Olofsson, B. J. Org. Chem. 2008, 73, 4602-4607.

${ }^{38}$ Stang, P. J. J. Org. Chem. 2003, 68, 2997-3008

${ }^{39}$ Miyaura, N.; Suzuki, A. Am. Chem. Soc. 1995, 2457-2483

${ }^{40}$ Suzuki, A. Angew. Chem. Int. Ed. Engl. 2011, 50, 6722-6737

${ }^{41}$ Dehn, J.; Winicov, M.; Beringer, M. J. Org. Chem. 1959, 82, 2948.

${ }^{42}$ Beringer, M. J. Am. Chem. Soc., 1960, 82 (11), 2948-2952

${ }^{43}$ Merritt, E. A.; Olofsson, B. Angew. Chem. 2009, 121, 9214 -9234

${ }^{44}$ Molander, G. A.; Cavalcanti, L. N. J. Org.Chem., 2011, 76, 7195

${ }^{45}$ Berionni, G.; Maji, B.; Knochel, P.; Mayr, H. Chem. Sci. 2012, 3, 878

${ }^{46}$ Yu, X.-Q.; Yamamoto, Y.; Miyaura, N. Chem. Asian J. 2008, 3, 1517-1522.

${ }^{47}$ Yamamoto, Y.; Takizawa, M.; Yu, X.-Q.; Miyaura, N. Angew. Chem. Int. Ed. Engl. 2008, 47, 928-931

${ }^{48}$ Stang, P. J. J. Org. Chem. 2003, 68, 2997-3008 
${ }^{49}$ Malmgren, J.; Santoro, S.; Jalalian, N.; Himo, F.; Olofsson, B. Chemistry 2013, 19, 10334-10342

${ }^{50}$ Beringer, M. J. Org. Chem, 1969, 34, 1981

${ }^{51}$ Yamaoka, N.; Sumida, K.; Itani, I.; Kubo, H.; Ohnishi, Y.; Sekiguchi, S.; Dohi, T.; Kita, Y. Chemistry 2013, 19, 15004-15011.

${ }^{52}$ Kang, S.; Hong-Woo, L.; Jang.S.; Ho, P. J. Org. Chem. 1996, 61,4720-4724

${ }^{53}$ Kang.S.; Yamaguchi.T,; Kim.T.; Ho.P. . J. Org. Chem. 1996, 61, 9082-9083

${ }^{54}$ Lancer, K. M.; Wiegand, G. H. J. Org. Chem. 1976, 41, 3360-3364

${ }^{55}$ Bellina, F.; Rossi, R. Tetrahedron, 2009, 65, 10269-10310

${ }^{56}$ Leadbeater. N. E.; Marco. M. J. Org. Chem. 2003, 68, 5660-5667

${ }^{57}$ Leadbeater. N. Nature Chemistry. 2010, 2, 1007-1009

${ }^{58}$ Xiao, Q.; Tian, L.; Tan, R.; Xia, Y.; Qiu, D.; Zhang, Y.; Wang. J. Org. Lett. 2012, 14, $4230-4233$.

${ }^{59}$ Kang, S.; Lee, H.; Jang, S.; Ho, P. J. Org. Chem. 1996, 3263, 4720-4724.

${ }^{60}$ Kang, S.; Yamaguchi, T. 1996, 3263, 9082-9083.

${ }^{61}$ Lancer, K. M.; Wiegand, J. Org. Chem. 1976, 41, 3360

${ }^{62}$ Berry, R. S. J. Chem. Phys. 1960, 32, 933-938

${ }^{63}$ Dohi, T.; Kita, Y. Chem. Commun. (Camb). 2009, 2073-2085

${ }^{64}$ Beringer, M. J. Org. Chem, 1969, 34, 1981

${ }^{65}$ Ochiai, M.; Toyonari, M.; Nagaoka, T.; Chen, D.-W.; Kida, M. Tetrahedron Letters. $1997,38,6709-6712$

${ }^{66}$ Merritt, E.; Carneiro, V. M. T.; Silva, L. F.; Olofsson, B. J. Org. Chem. 2010, 75, 7416-7419

${ }^{67}$ Jalalian, N.; Olofsson, B. Org. Synth. 2013, 90, 1.

68 Bielawski, M.; Malmgren, J.; Pardo, L. M.; Wikmark, Y.; Olofsson, B. ChemistryOpen. 2014, 3, 19-22

${ }^{69}$ Bielawski, M.; Olofsson, B. Chem. Commun. 2007, 252-2523

${ }^{70}$ Jalalian, N.; Ishikawa, E. E.; Silva, L. F. Olofsson, B. Org. Lett. 2011, 13, 1552-1555

${ }^{71}$ Yamamoto, Y.; Takizawa, M.; Yu, X.-Q.; Miyaura, N. Angew. Chem. Int. Ed. Engl. 2008, 47, 928-931

72 Jalalian, N.; Ishikawa, E. E.; Silva, L. F.; Olofsson, B. Org. Lett. 2011, 13, 1552-1555. 
${ }^{73}$ Bedford, R. B.; Webster, R. L.; Mitchell, C. J. Org. Biomol. Chem. 2009, 7, 48534857.

${ }^{74}$ Pascanu, V.; Yao, Q.; Bermejo Gómez, A.; Gustafsson, M.; Yun, Y.; Wan, W.; Samain, L.; Zou, X.; Martín-Matute, B. Chemistry. 2013, 19, 17483-17493

${ }^{75}$ Church, R.; Trust, R.; Albright, J. D.; Powell, D. W. 1995, 3750-3758.

${ }^{76}$ Wang, Z.-Y.; Ma, Q.-N.; Li, R.-H.; Shao, L.-X. Org. Biomol. Chem. 2013, 11, 78997906

${ }^{77}$ Santra, S.; Hota, P. K.; Bhattacharyya, R.; Bera, P.; Ghosh, P.; Mandal, S. K. ACS Catal. 2013, 3, 2776-2789.

${ }^{78}$ Qiu, D.; Wang, S.; Tang, S.; Meng, H.; Jin, L.; Mo, F.; Zhang, Y.; Wang, J. J. Org. Chem. 2014, 79, 1979-1988.

${ }^{79}$ Cited, R.; Documents, U. S. A.; Jay, D.; Company, A. C. United States Patent [19], 1981

${ }^{80}$ Okuno, T.; Sakagami, M. Jpn. Kokai Tokkyo Koho. 2010, 167 
Appendix ${ }^{1} \mathrm{H},{ }^{13} \mathrm{C}$, and ${ }^{19} \mathrm{~F}$ NMR spectra of new compounds 


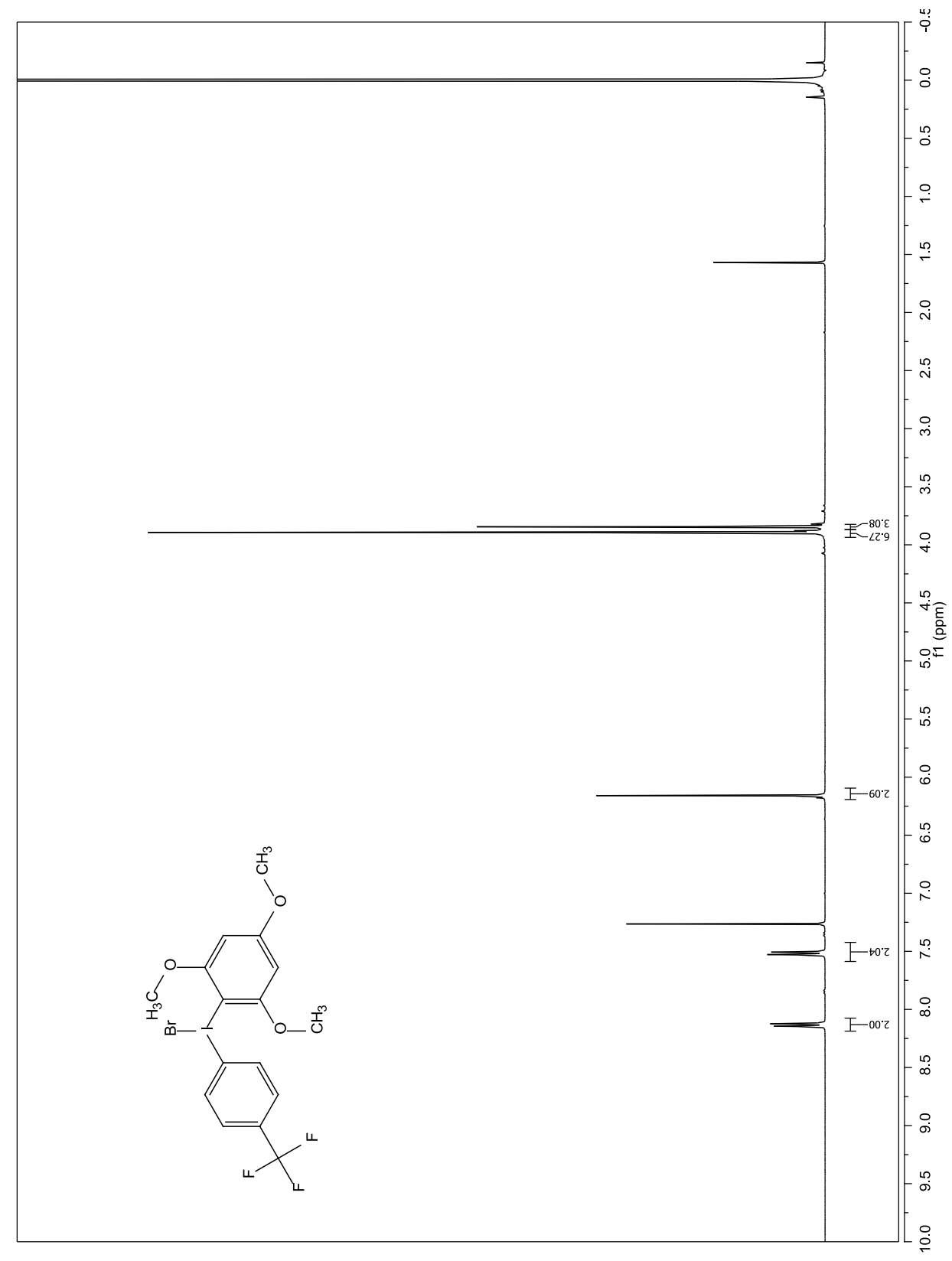




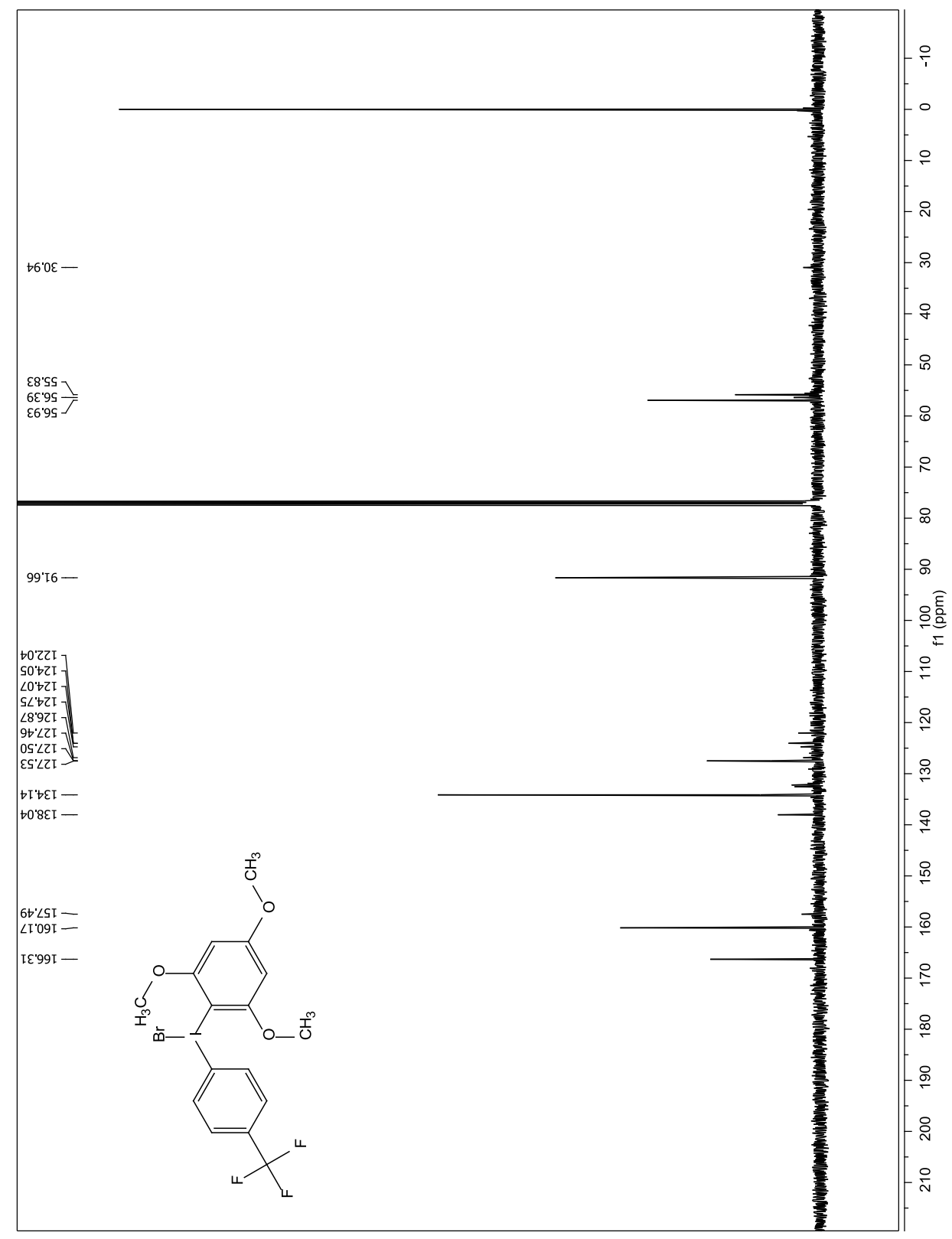




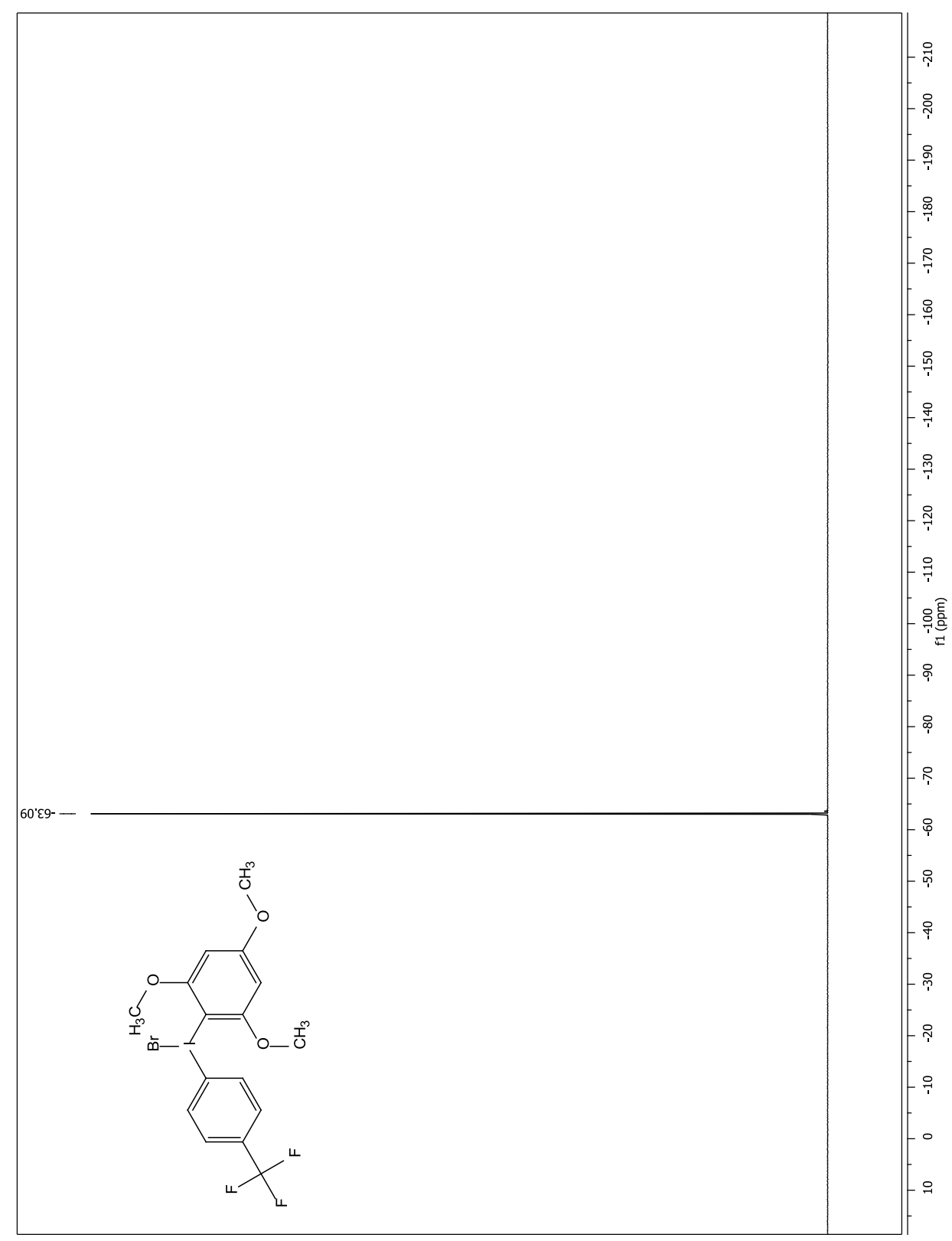




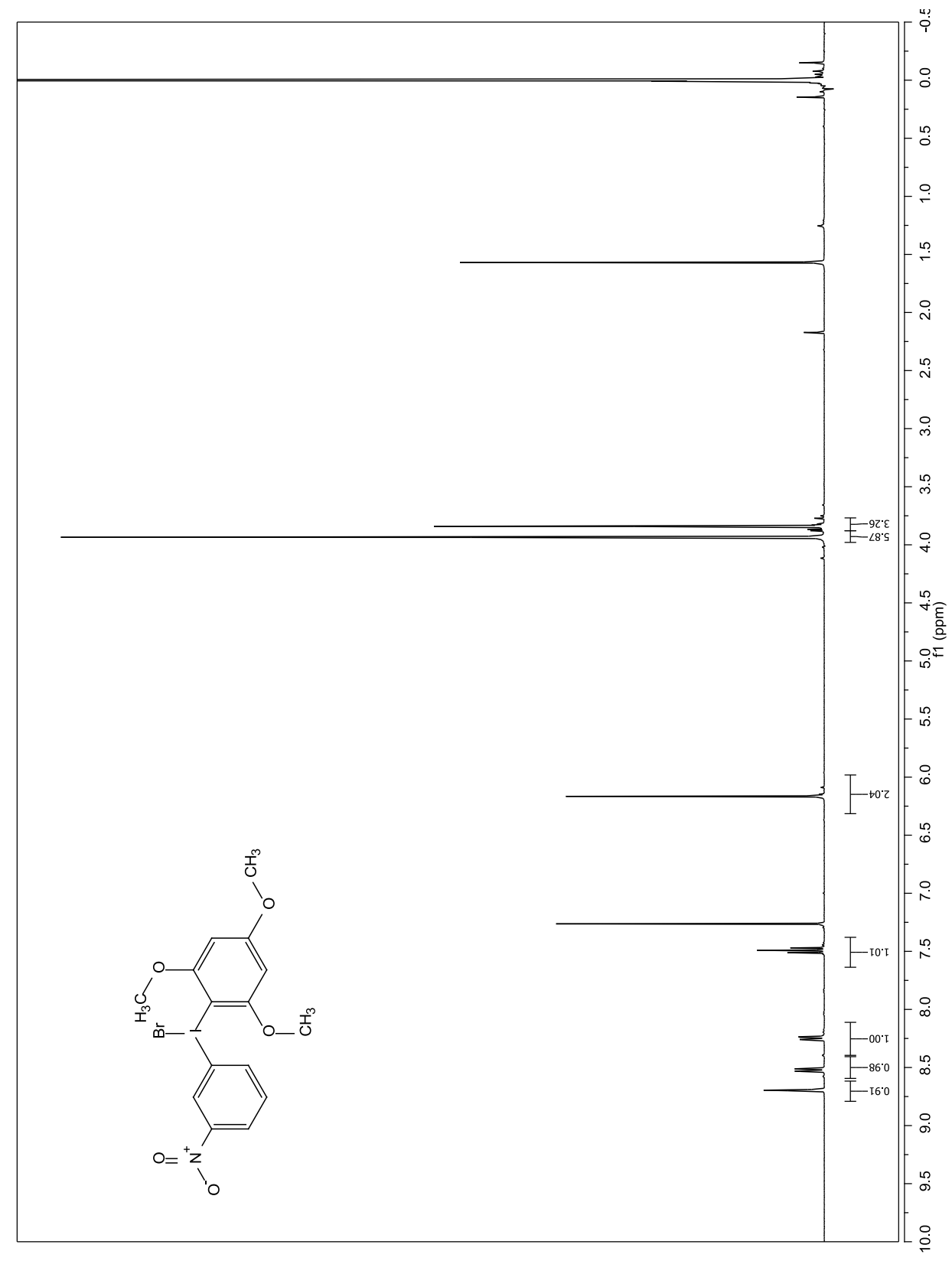




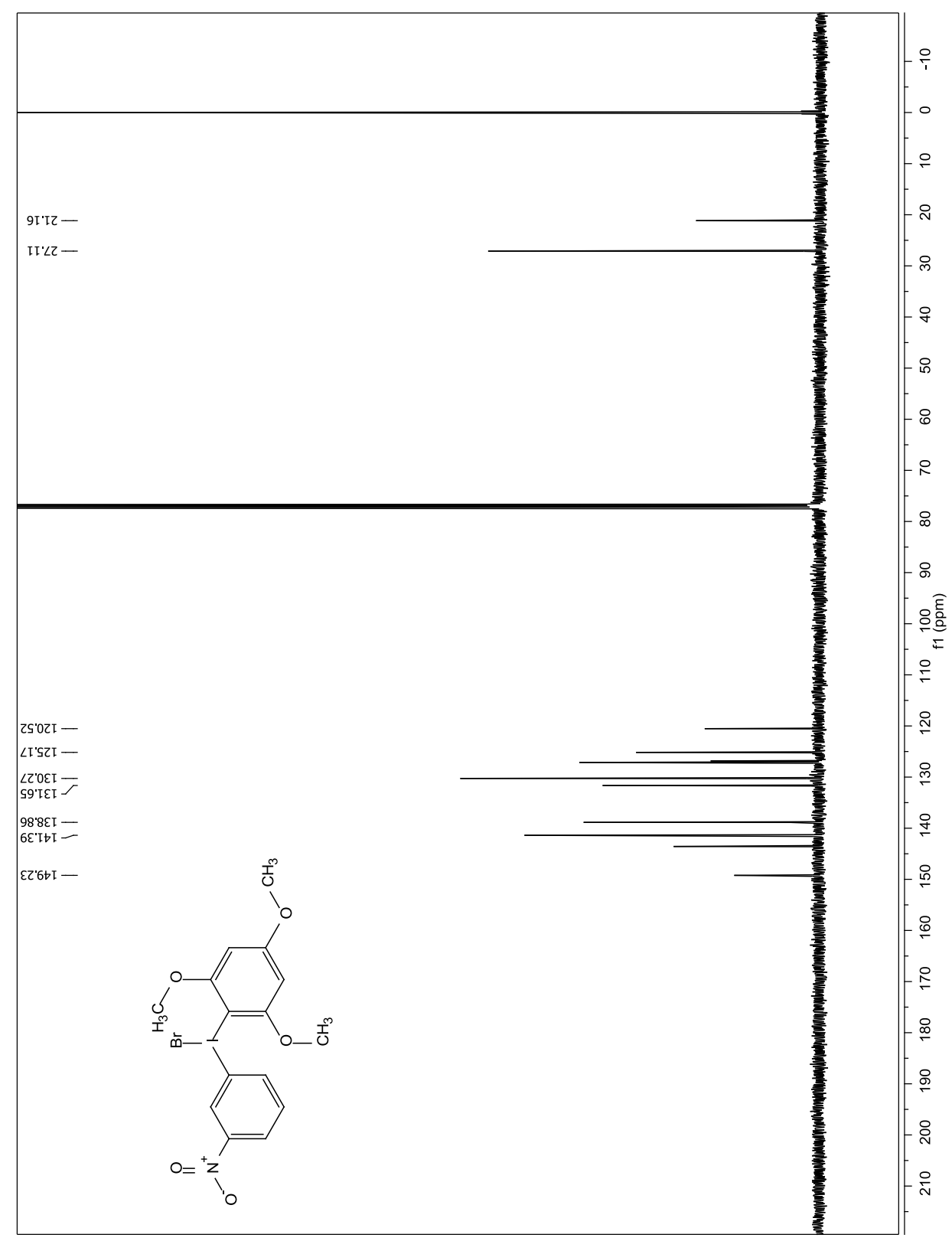




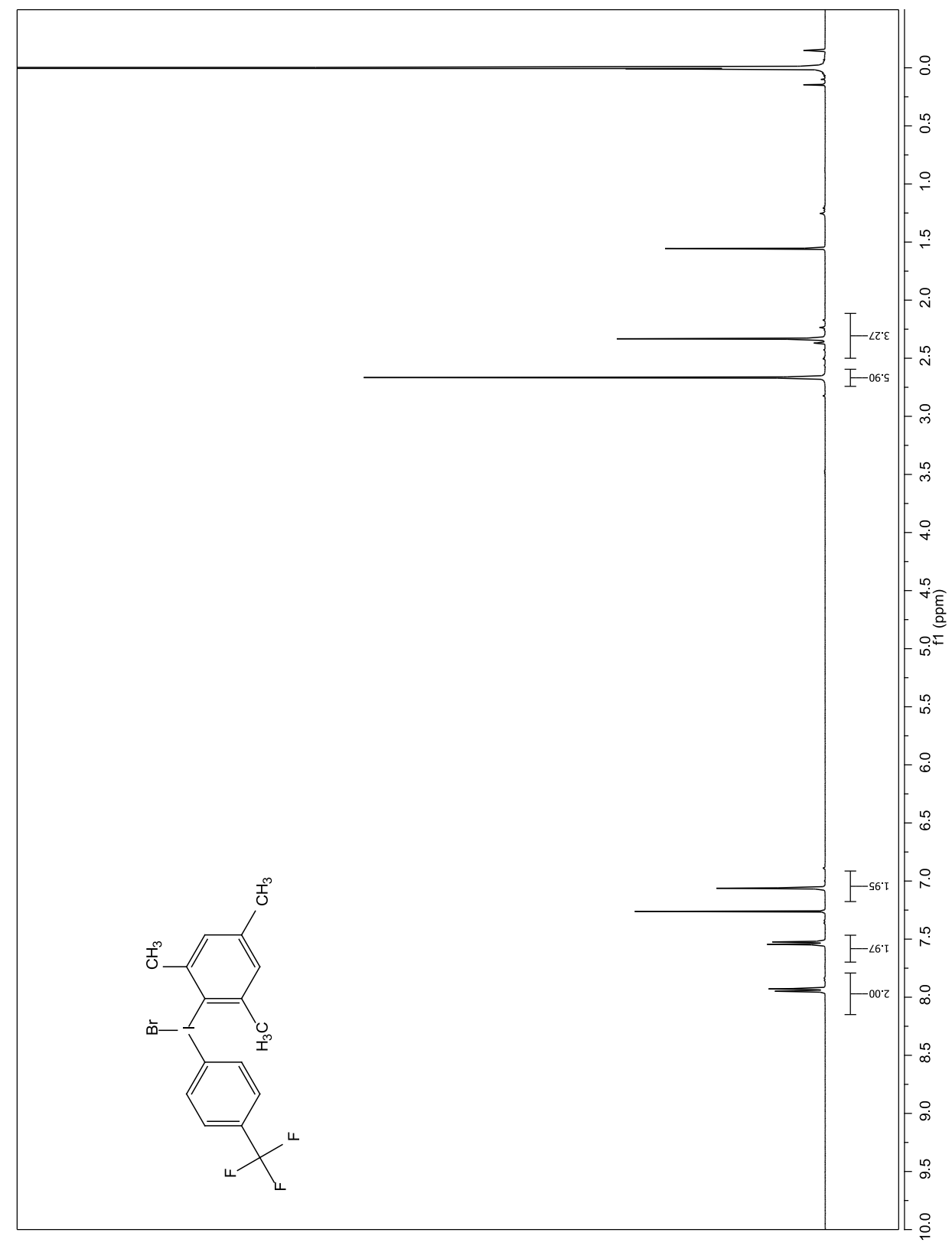




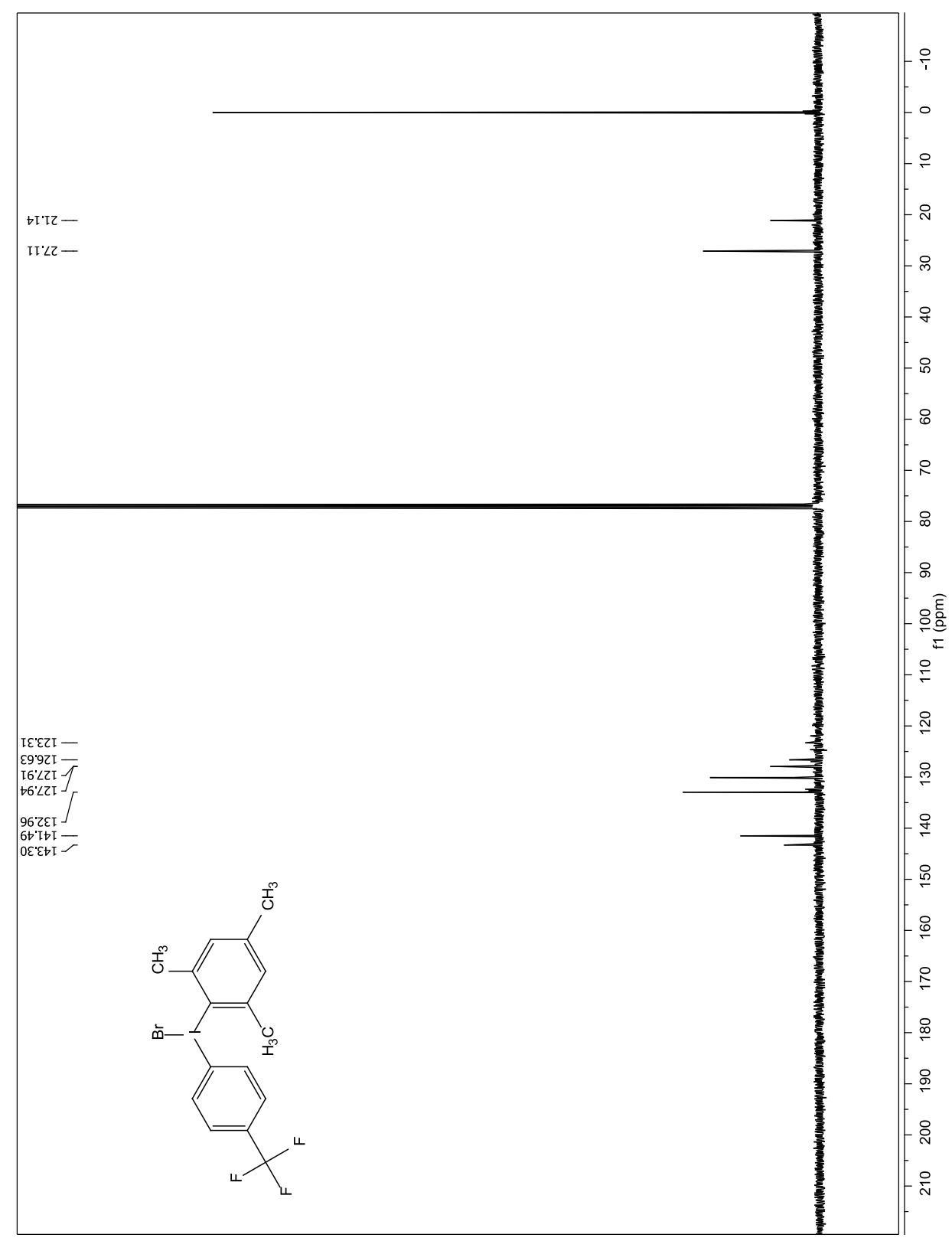




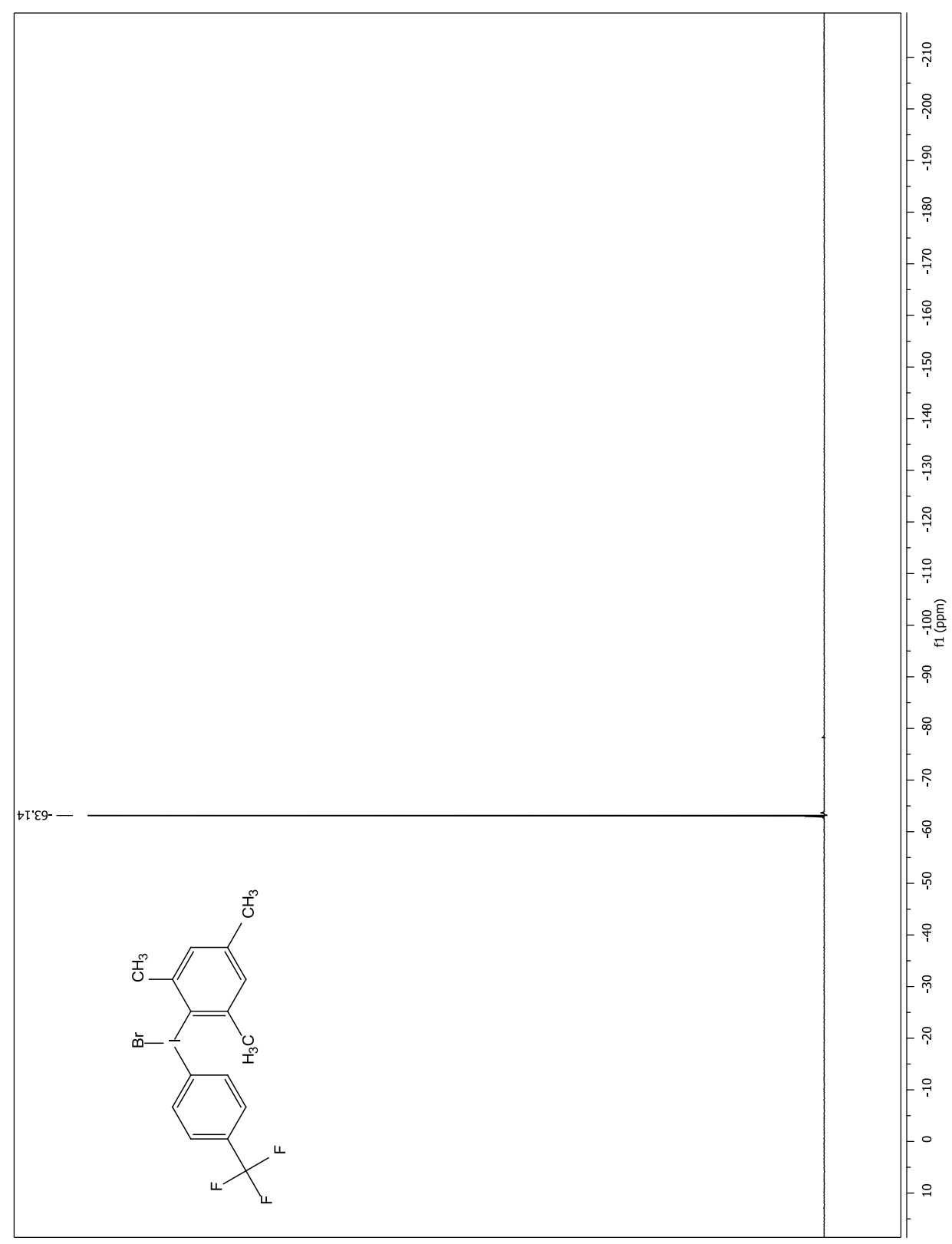




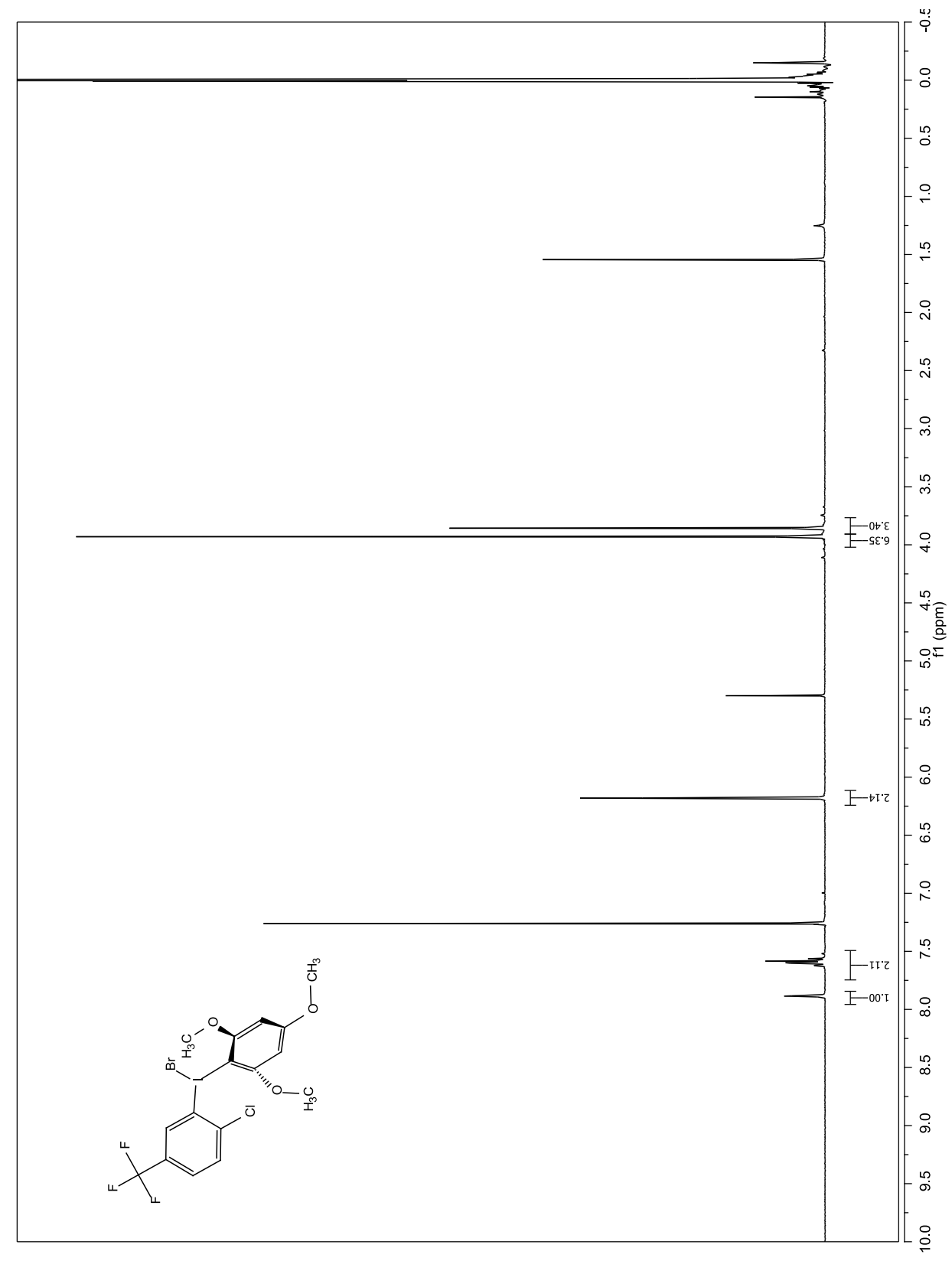




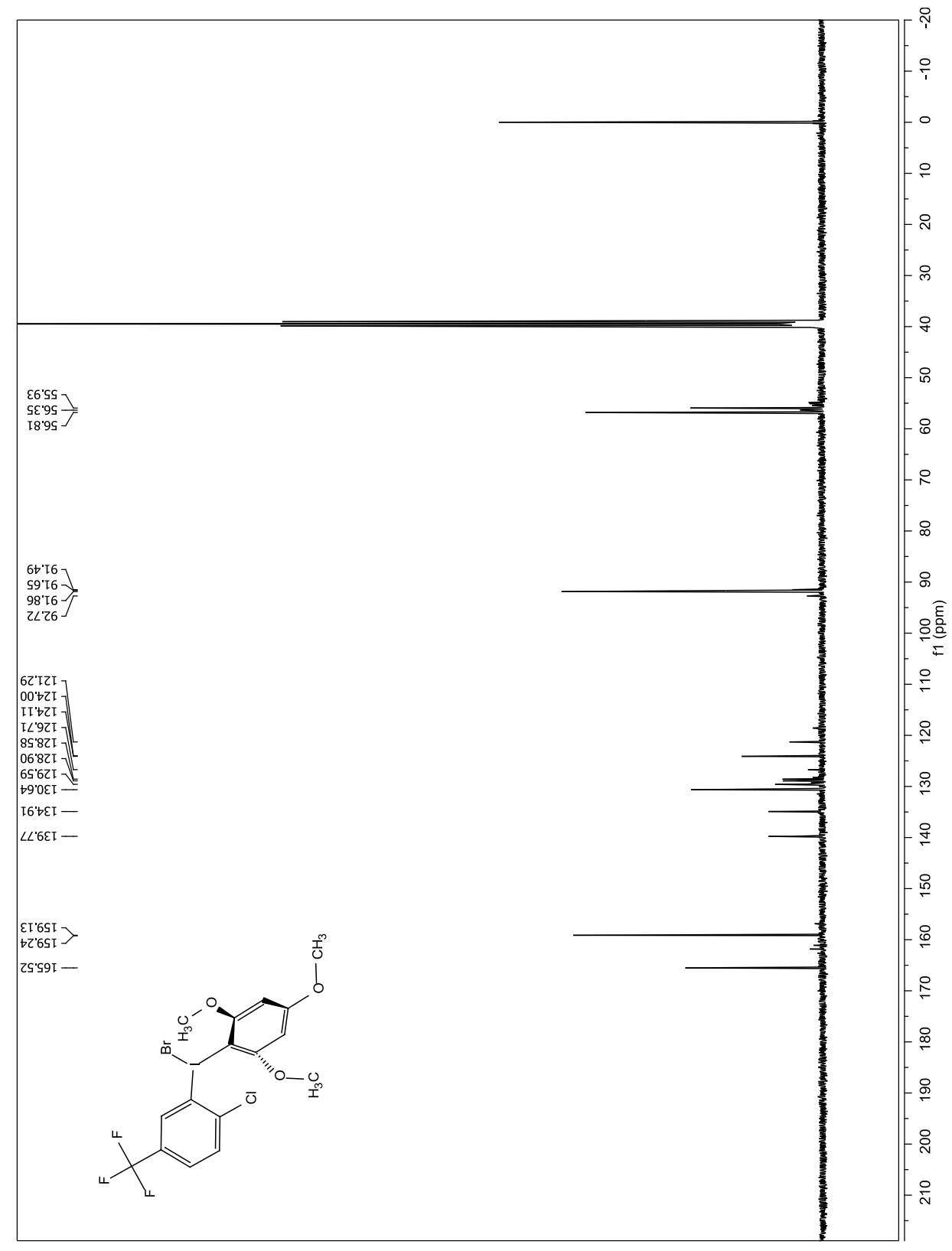




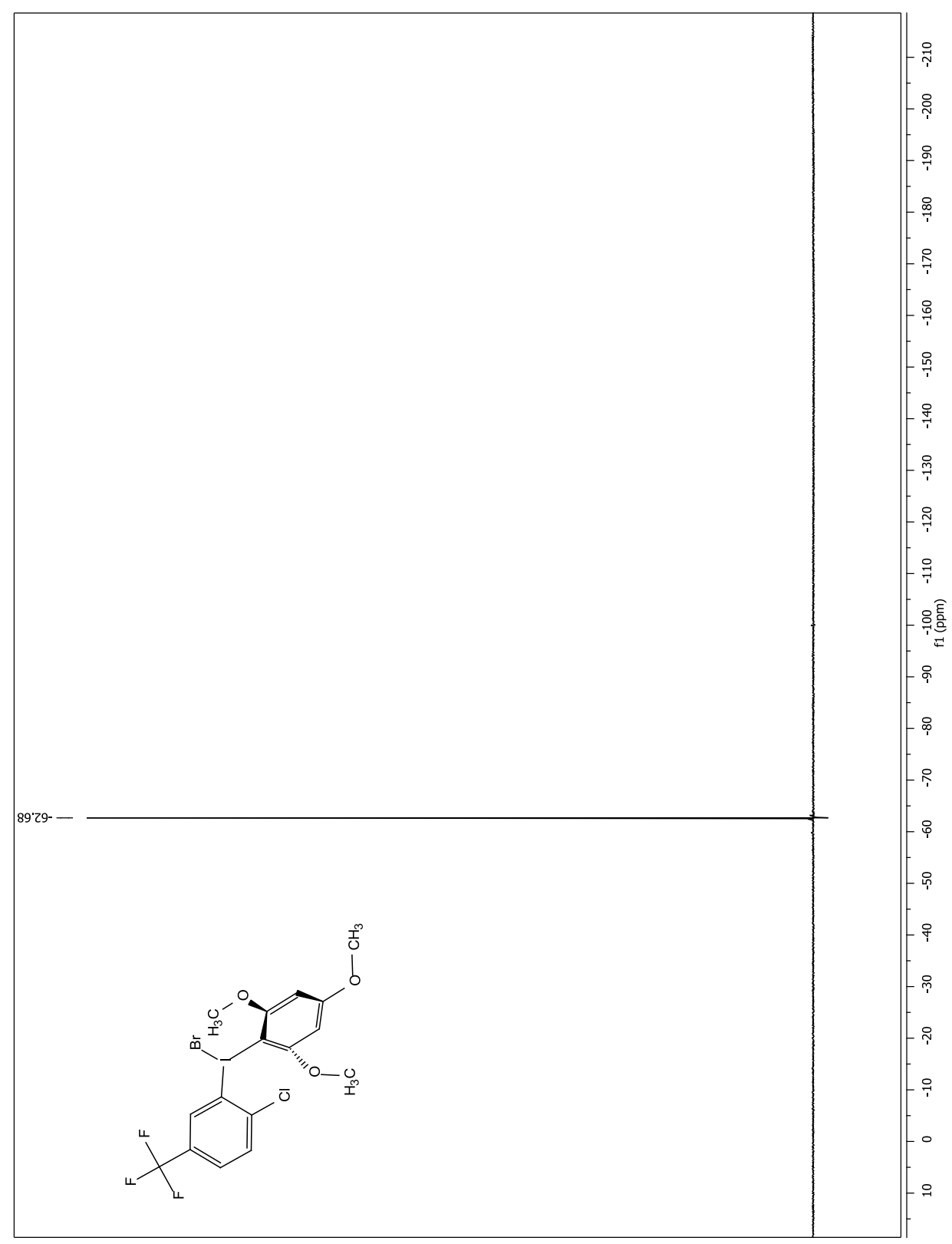




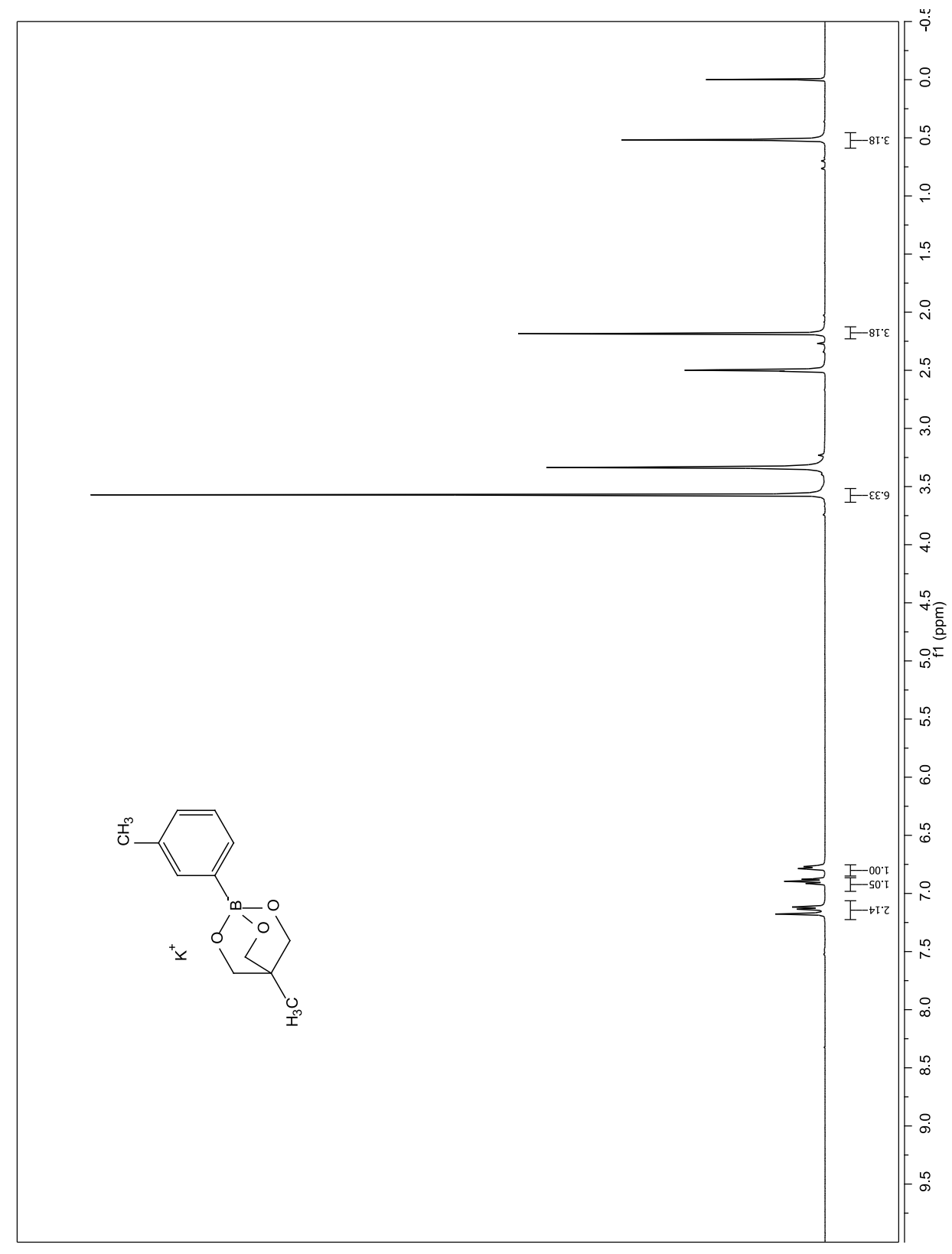




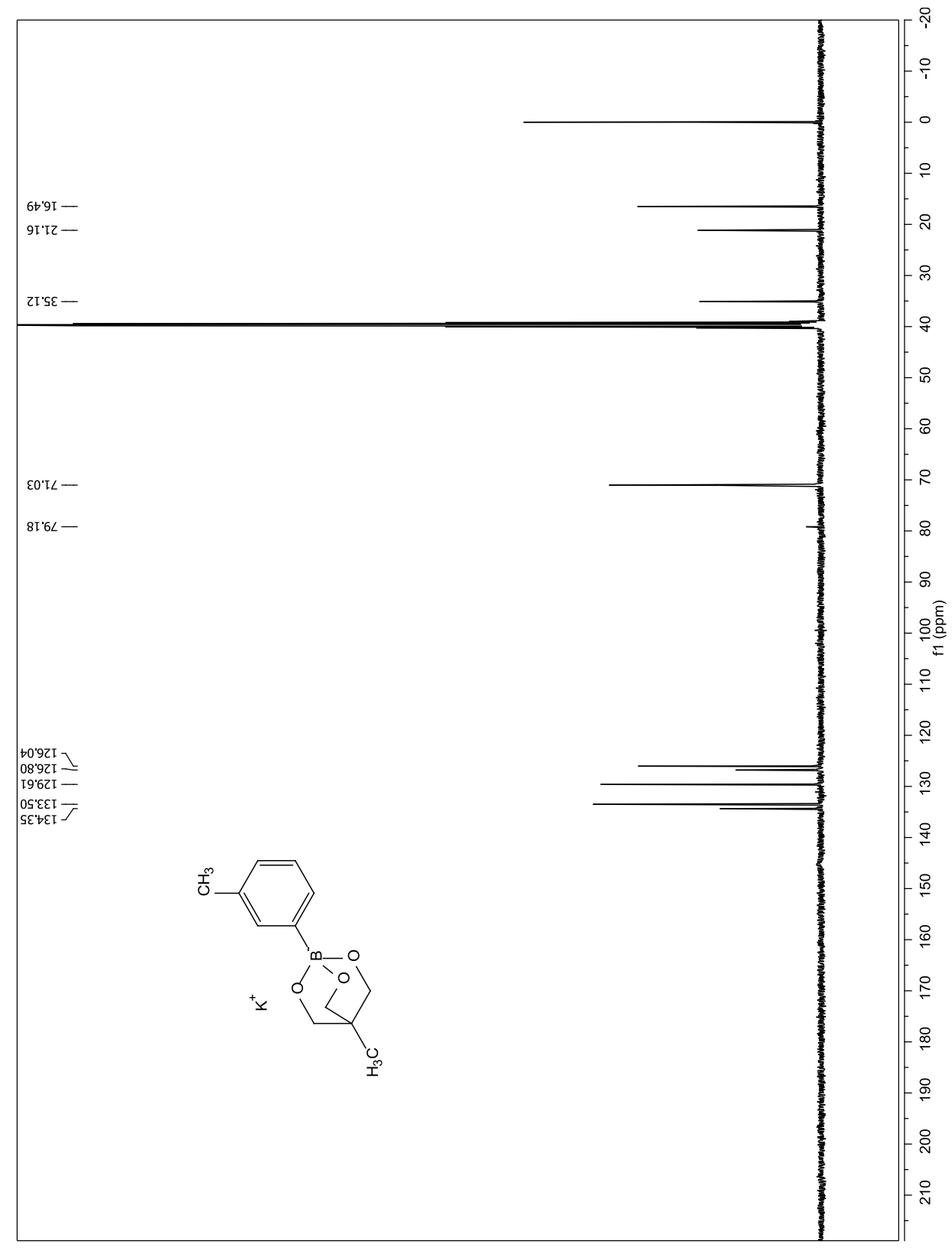




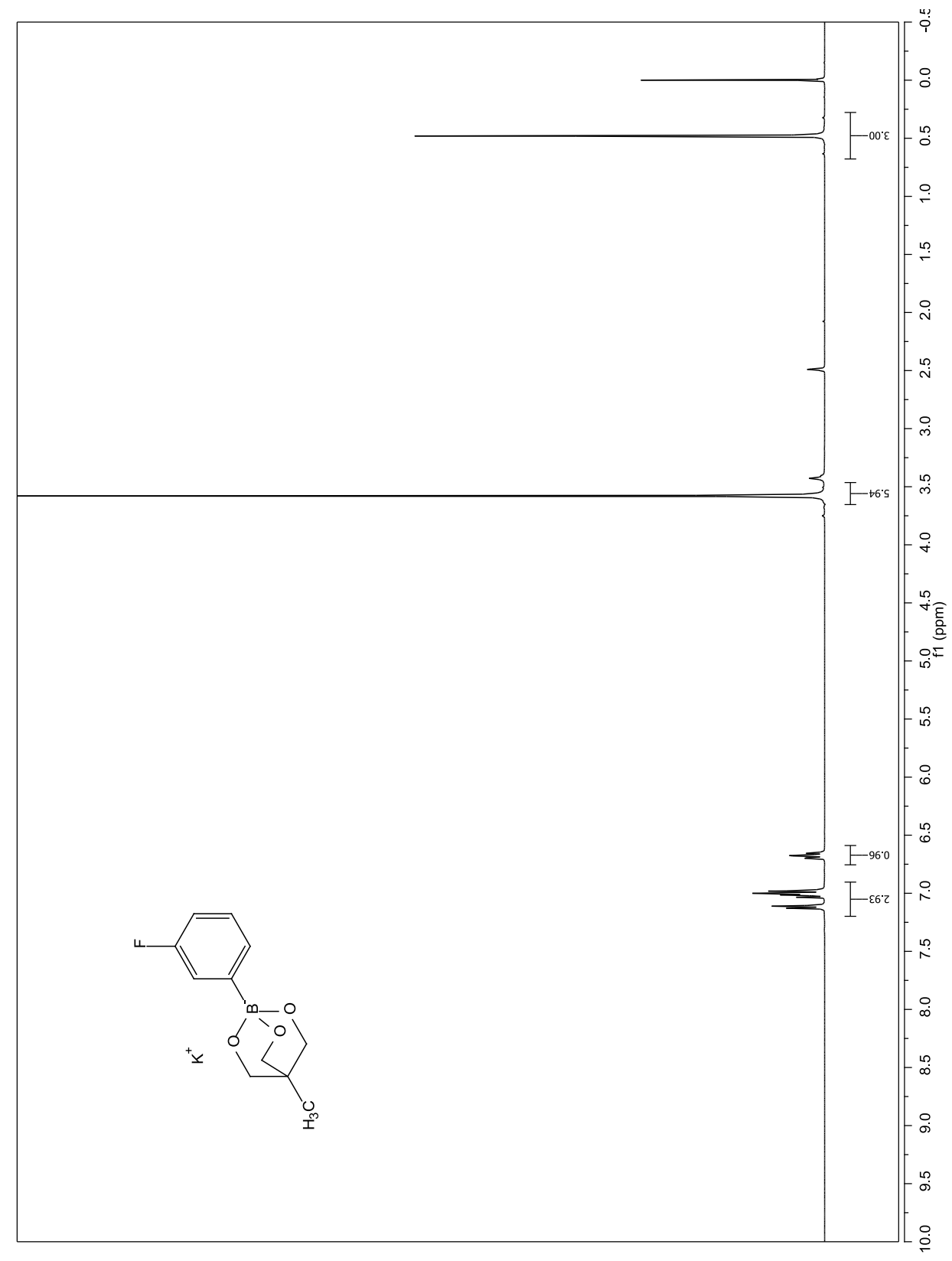




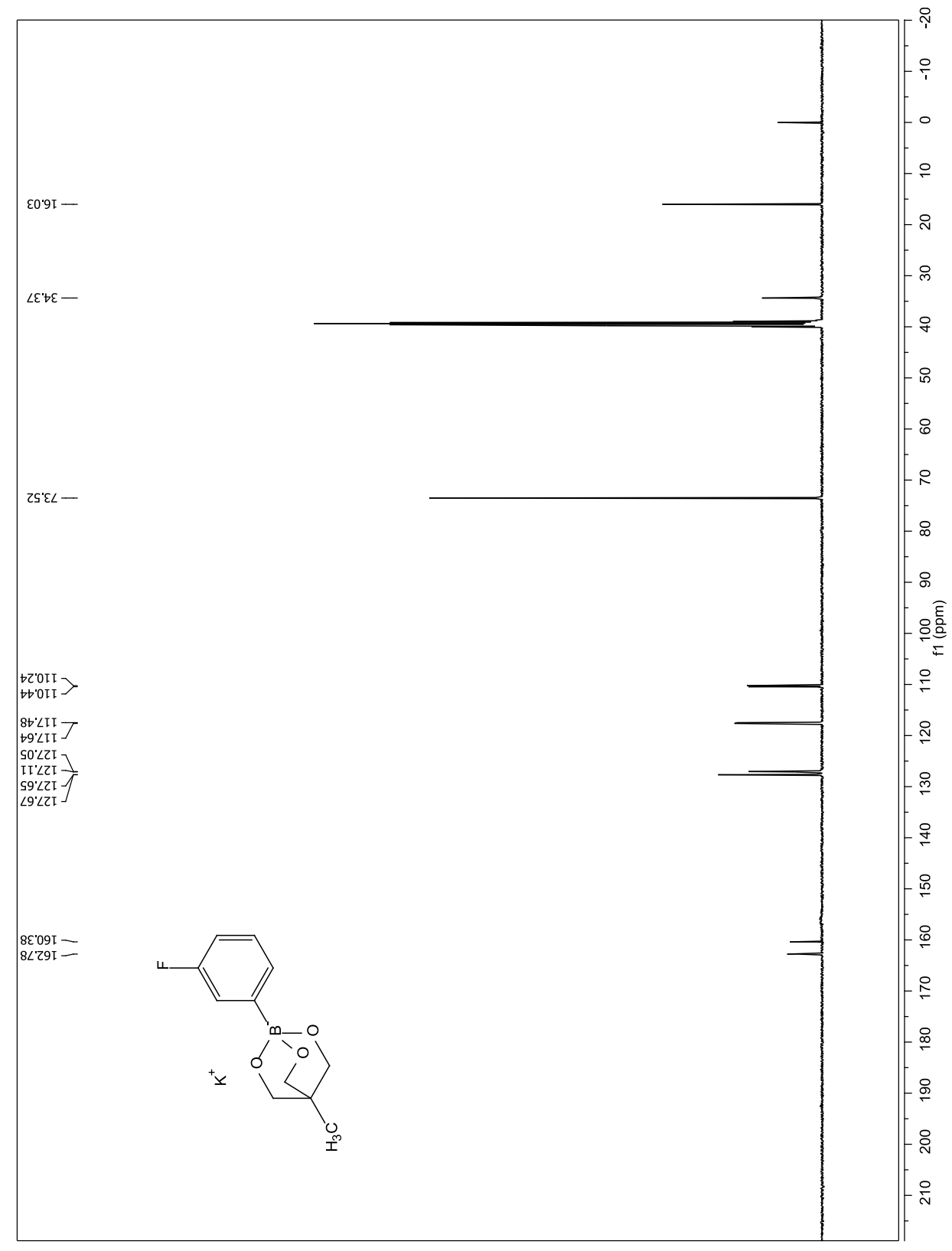




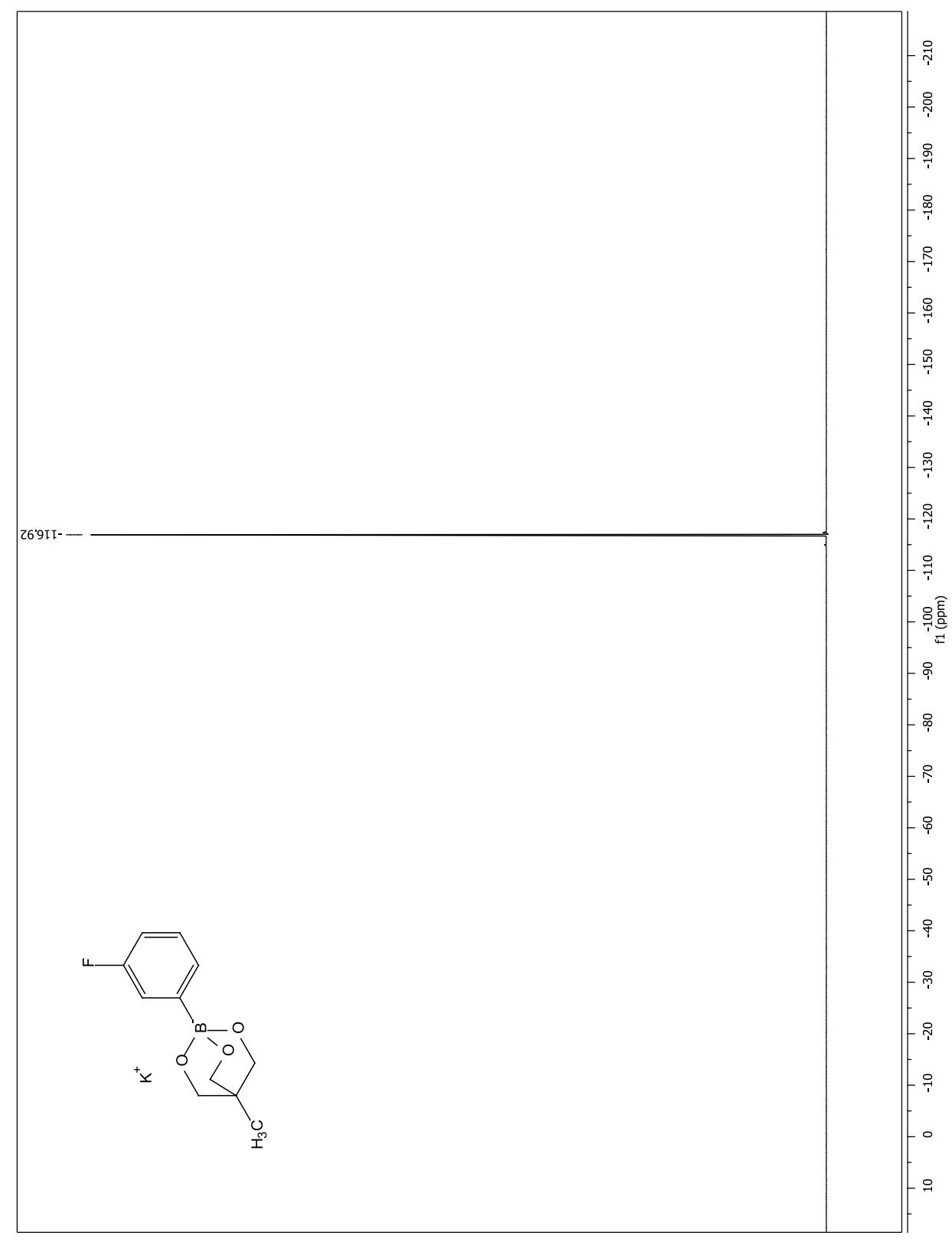




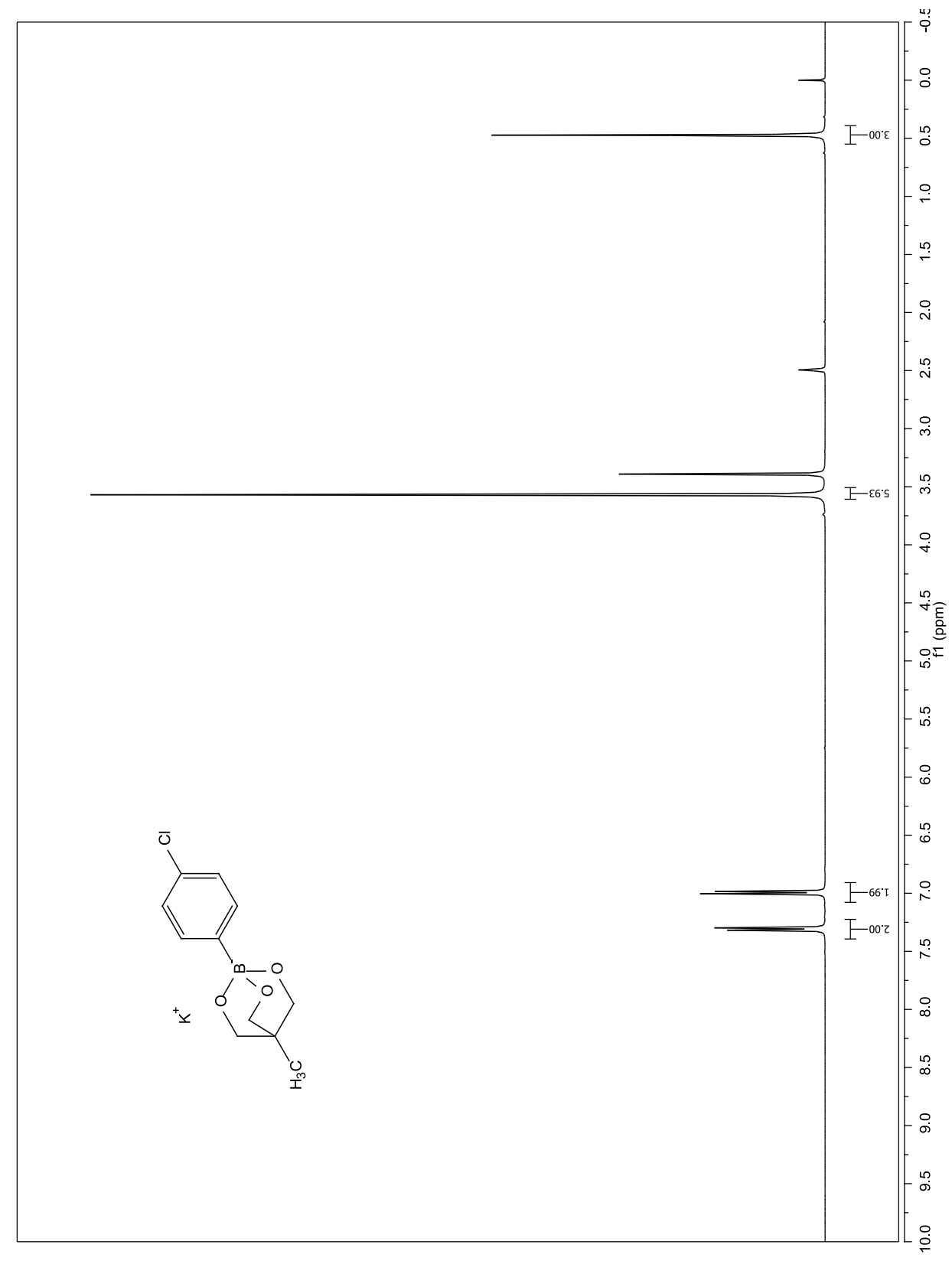




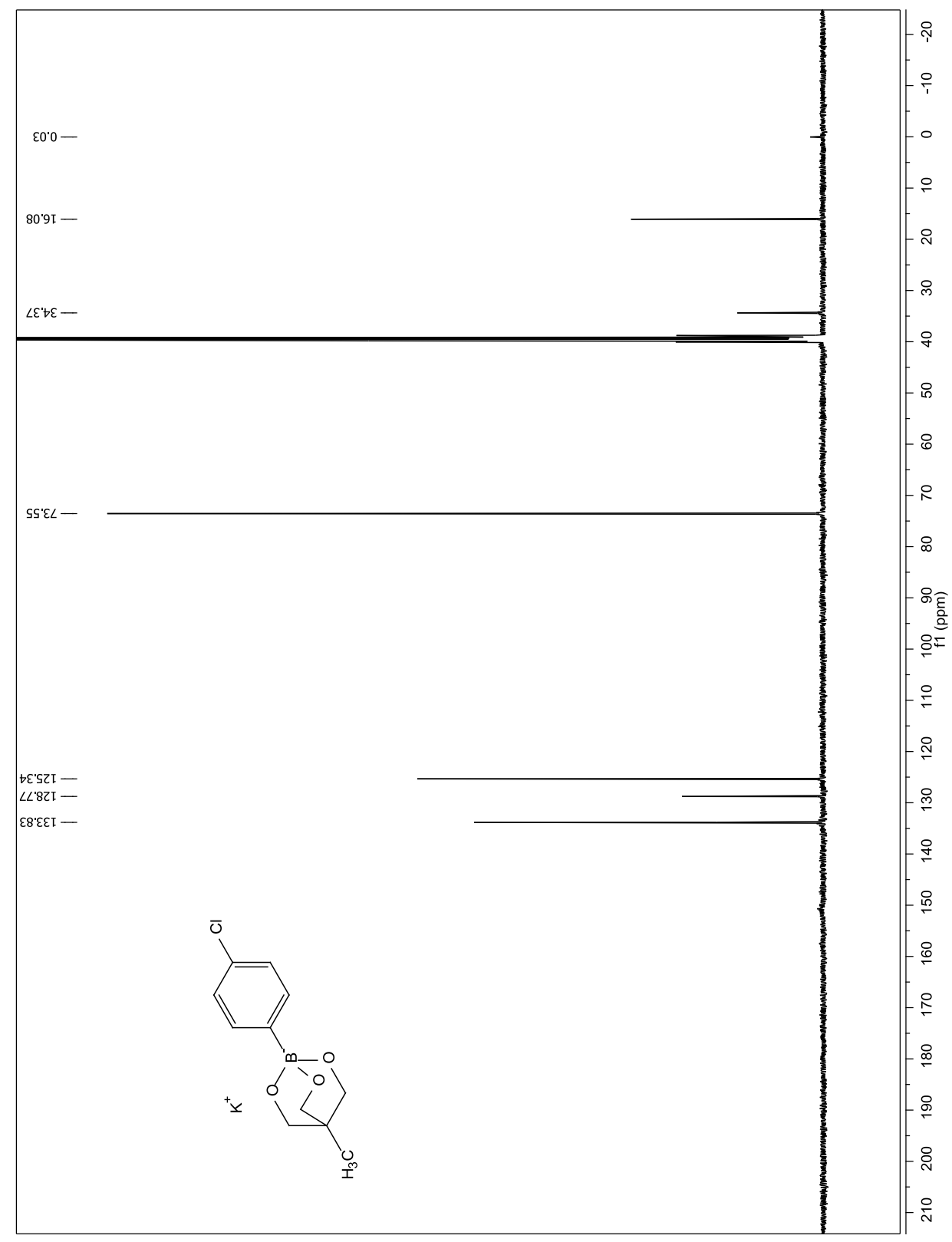




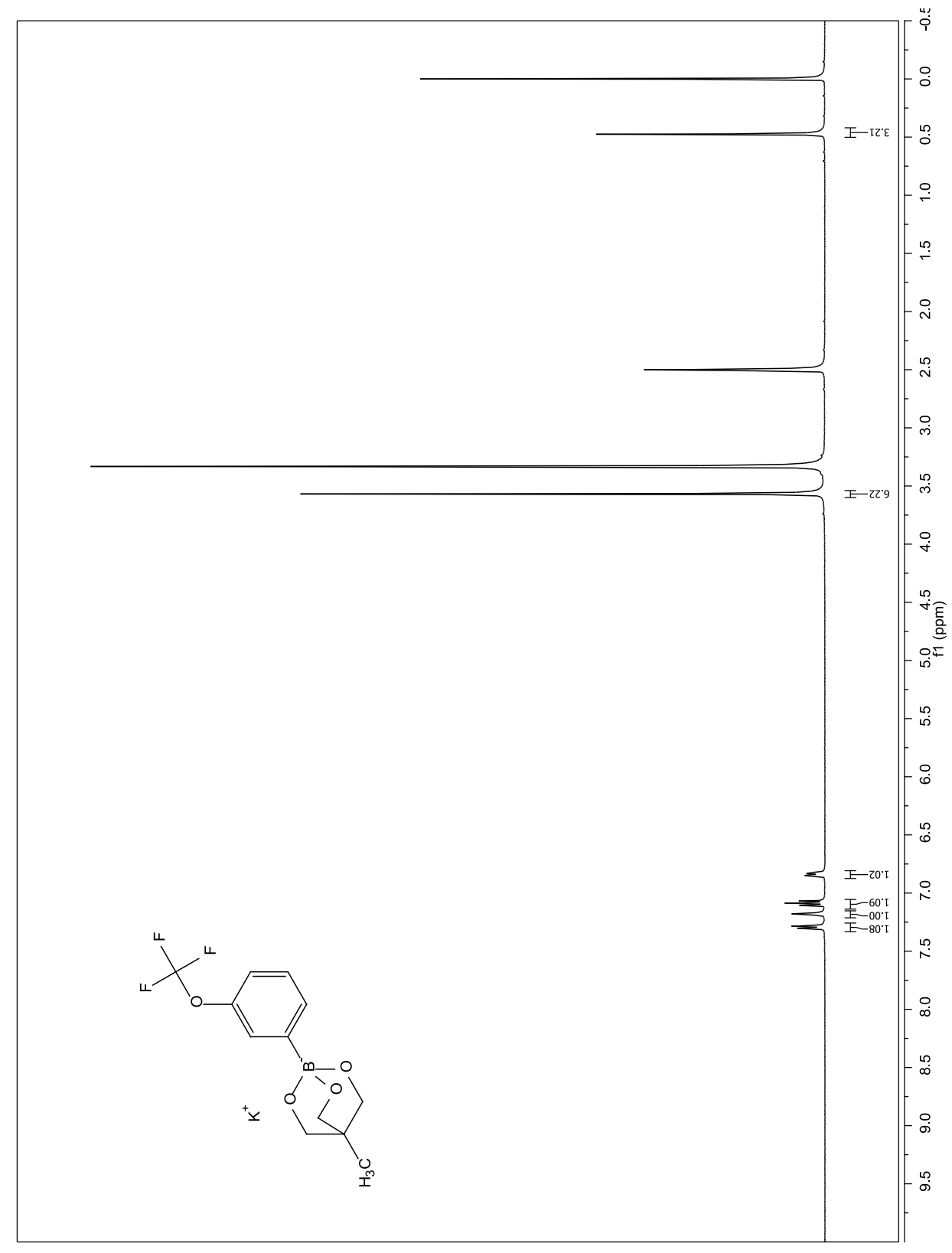




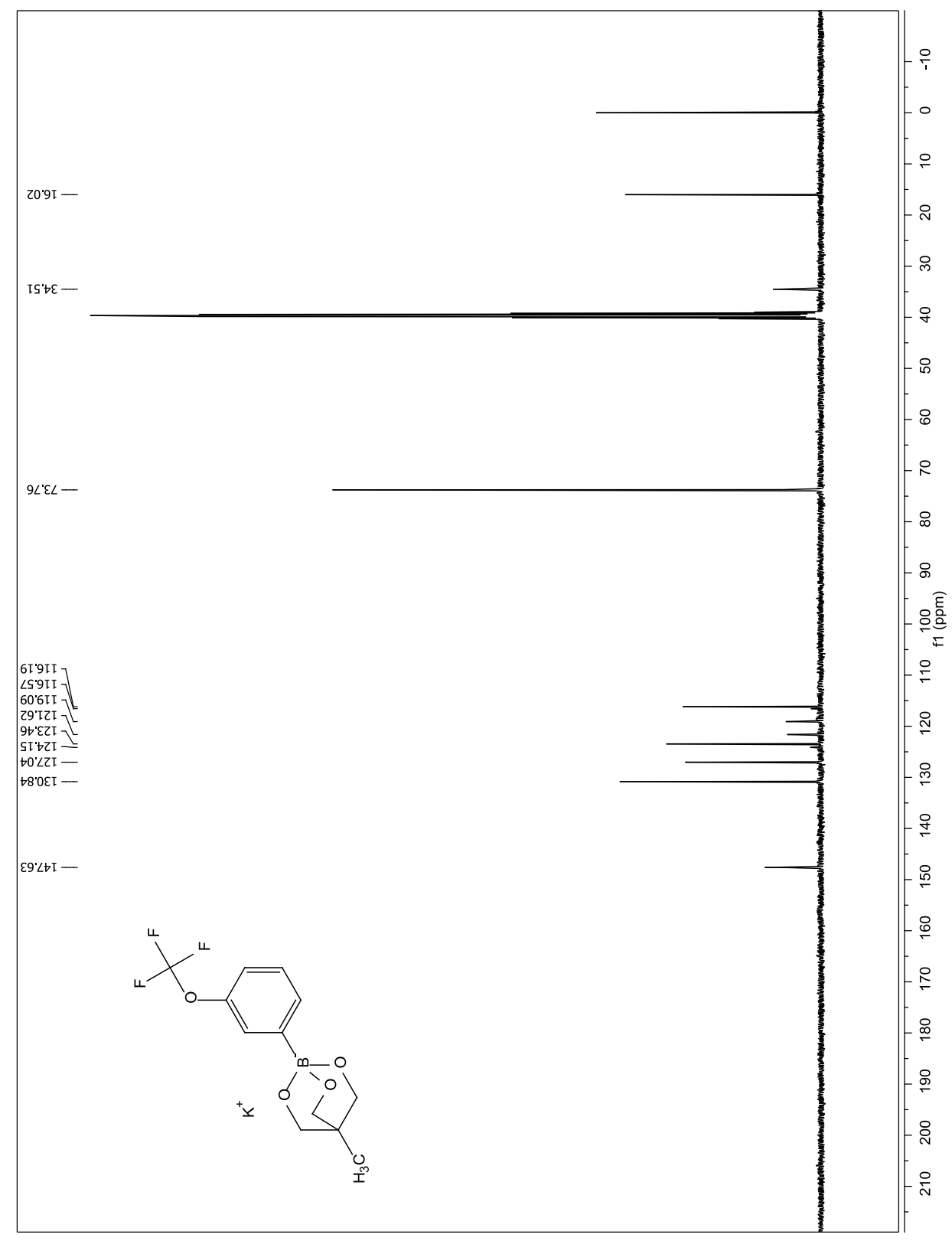




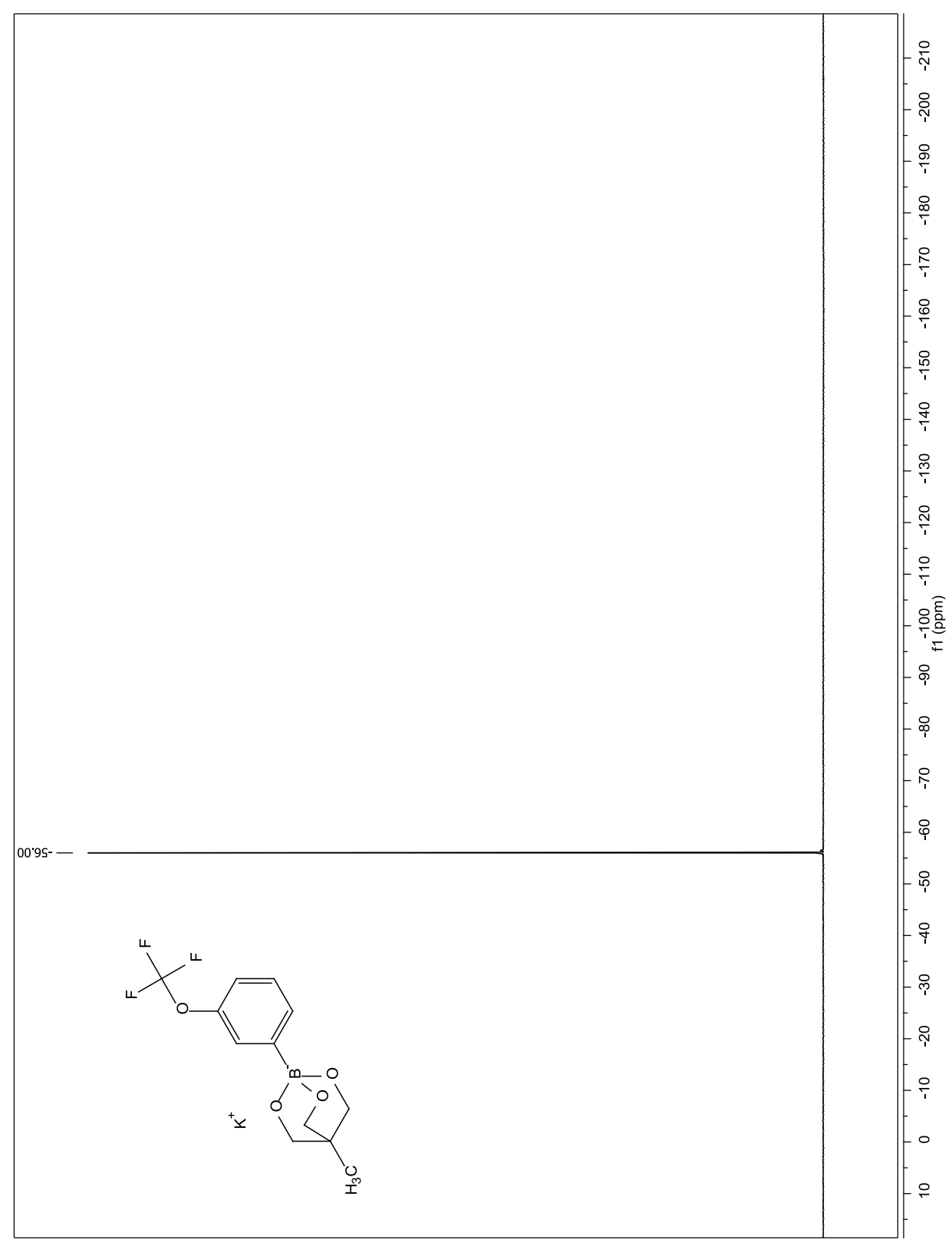

95 


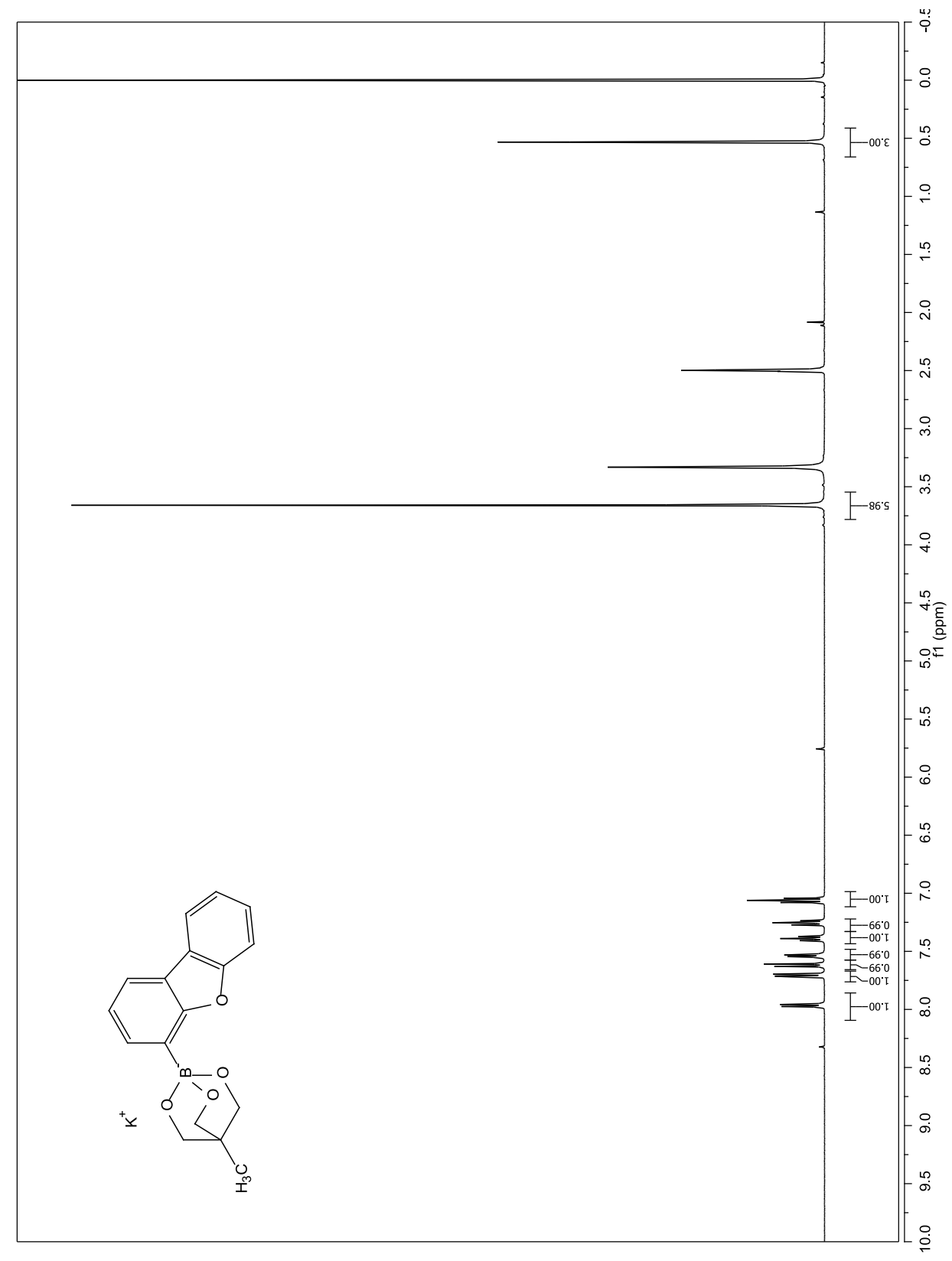




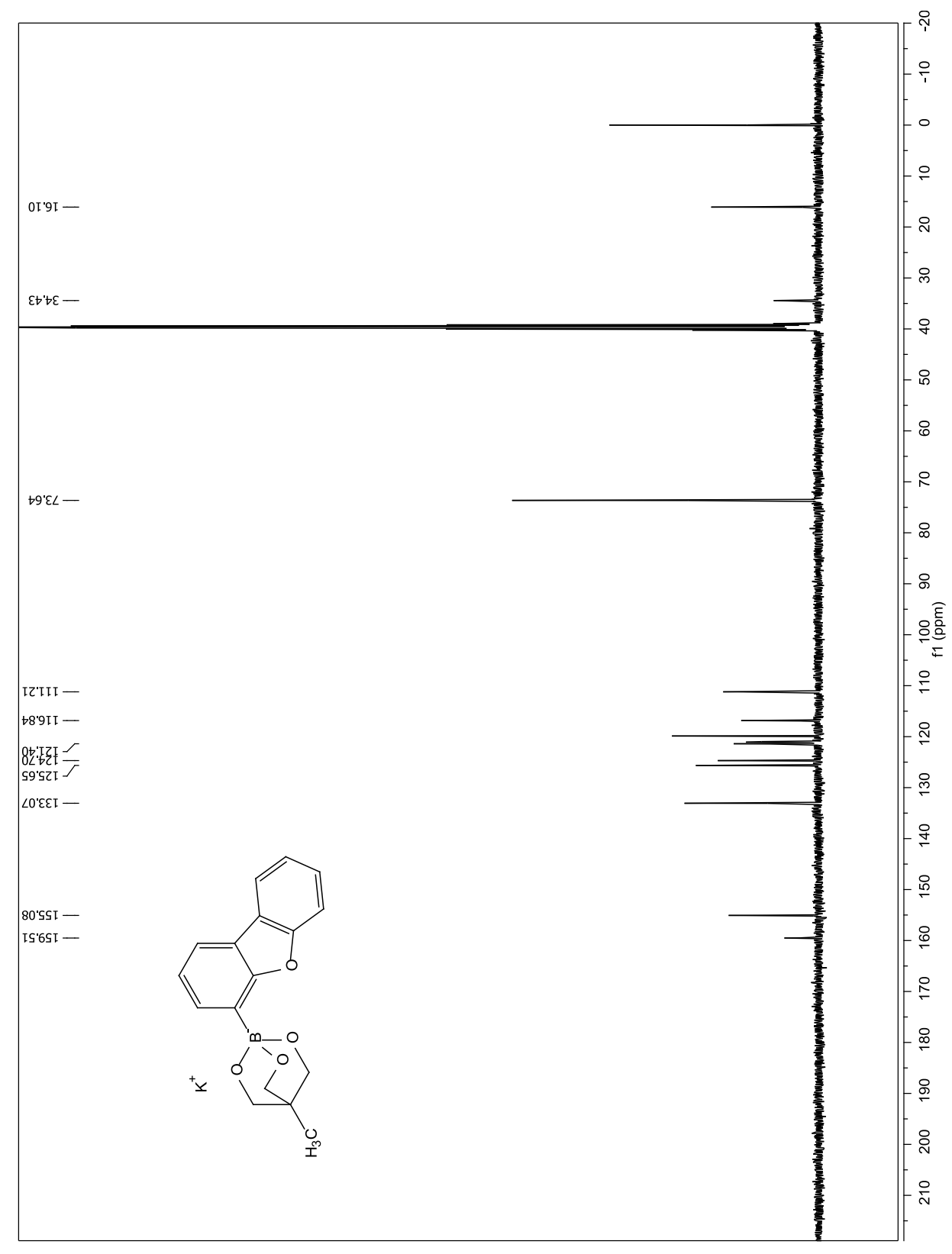




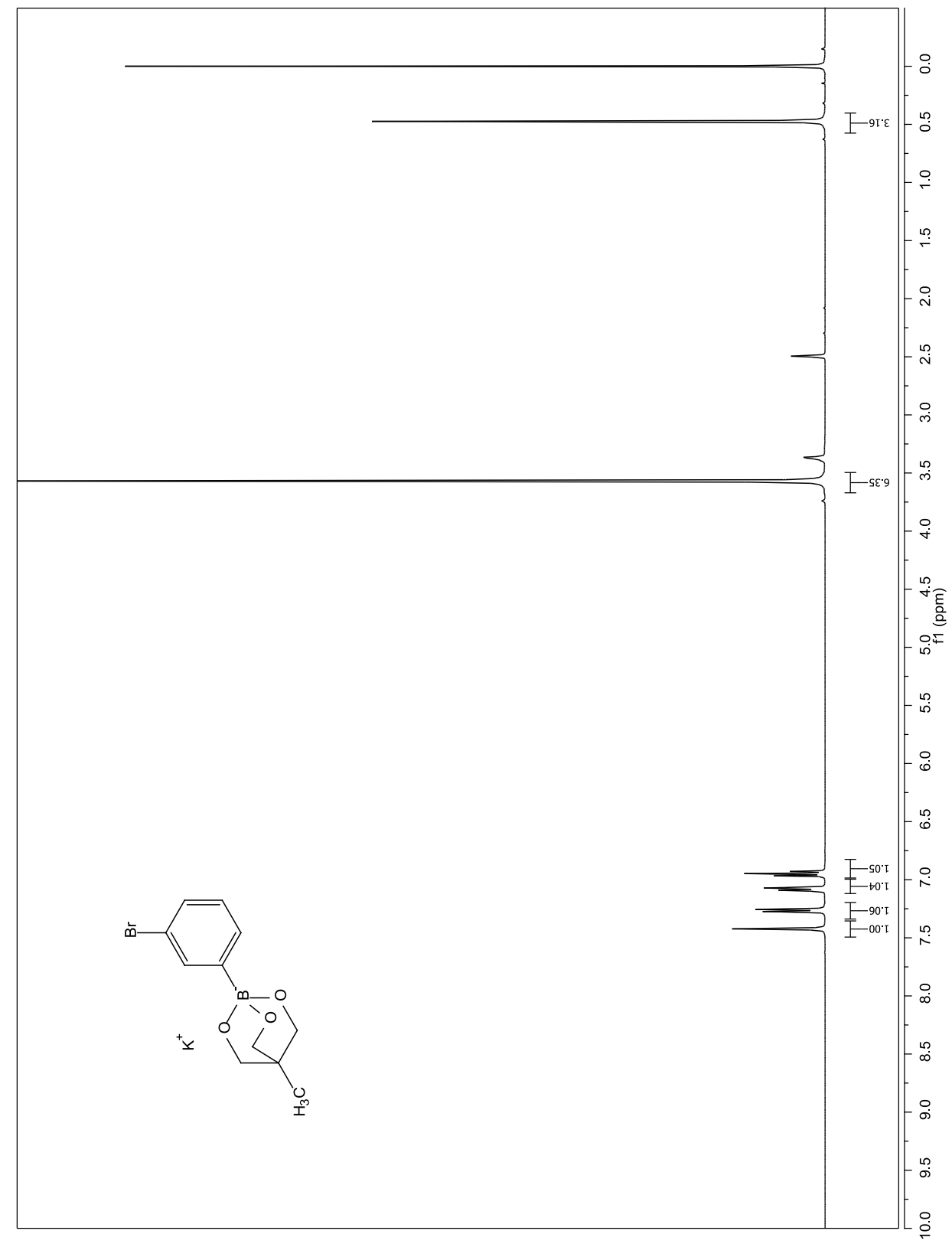




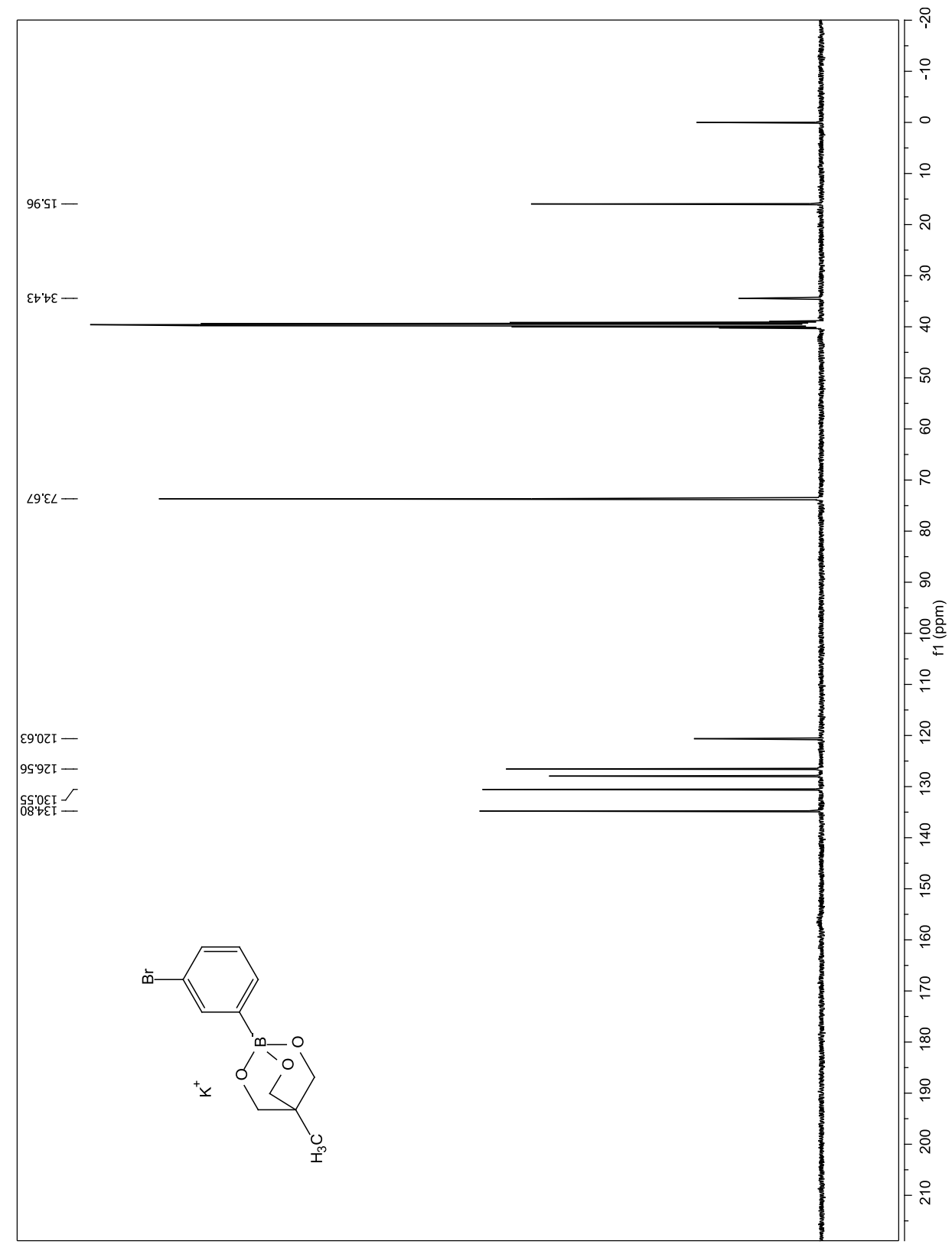




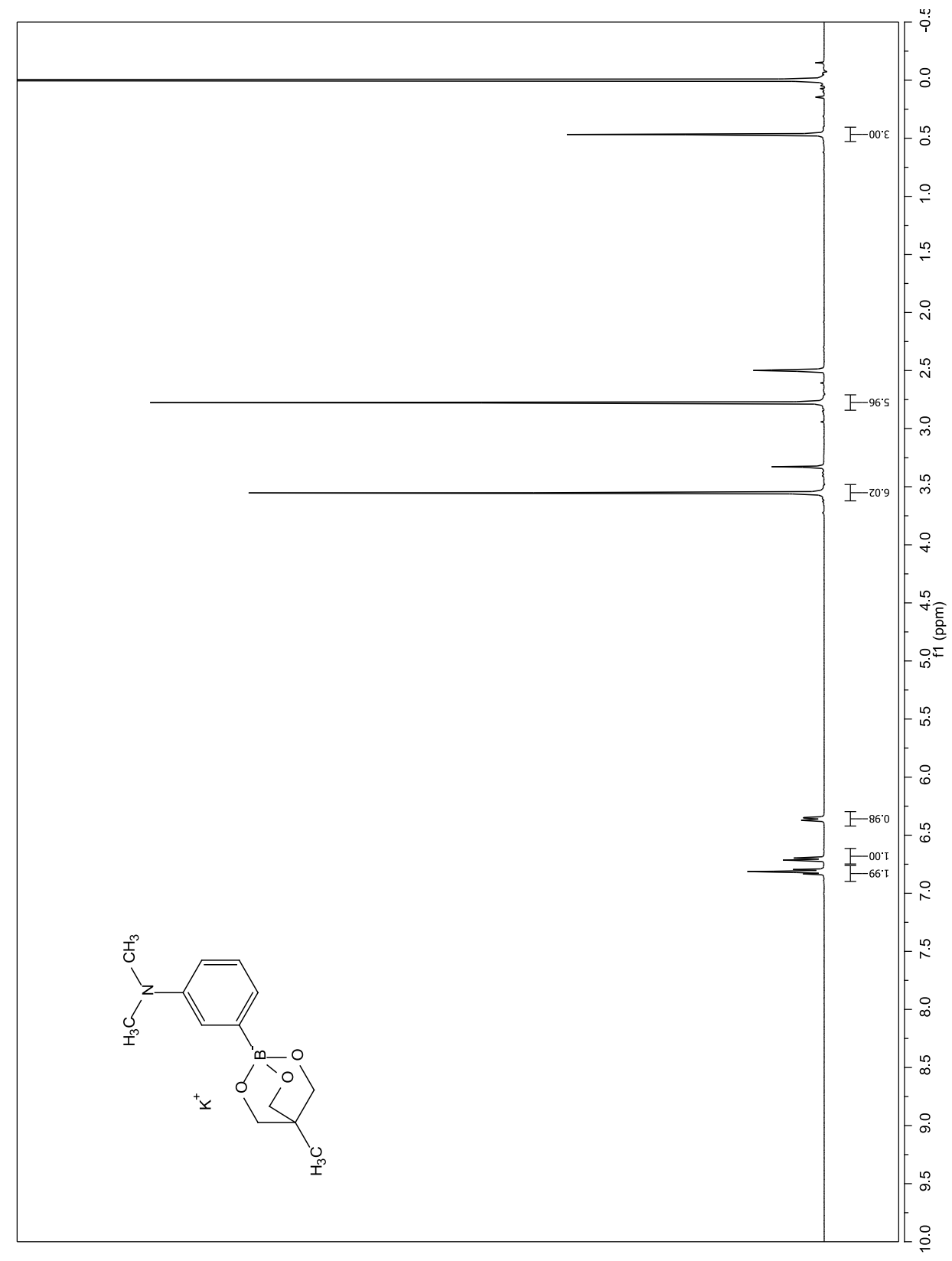




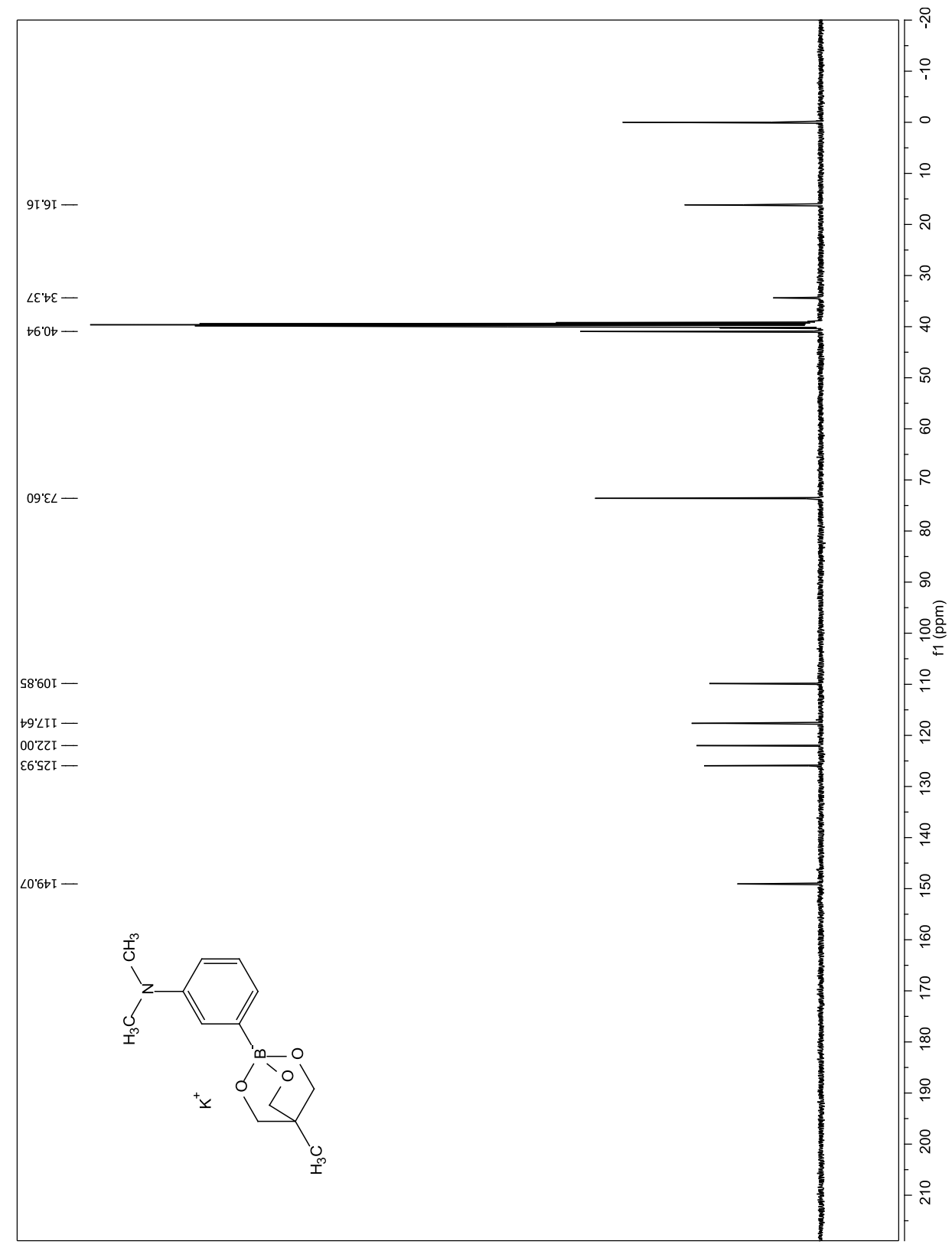




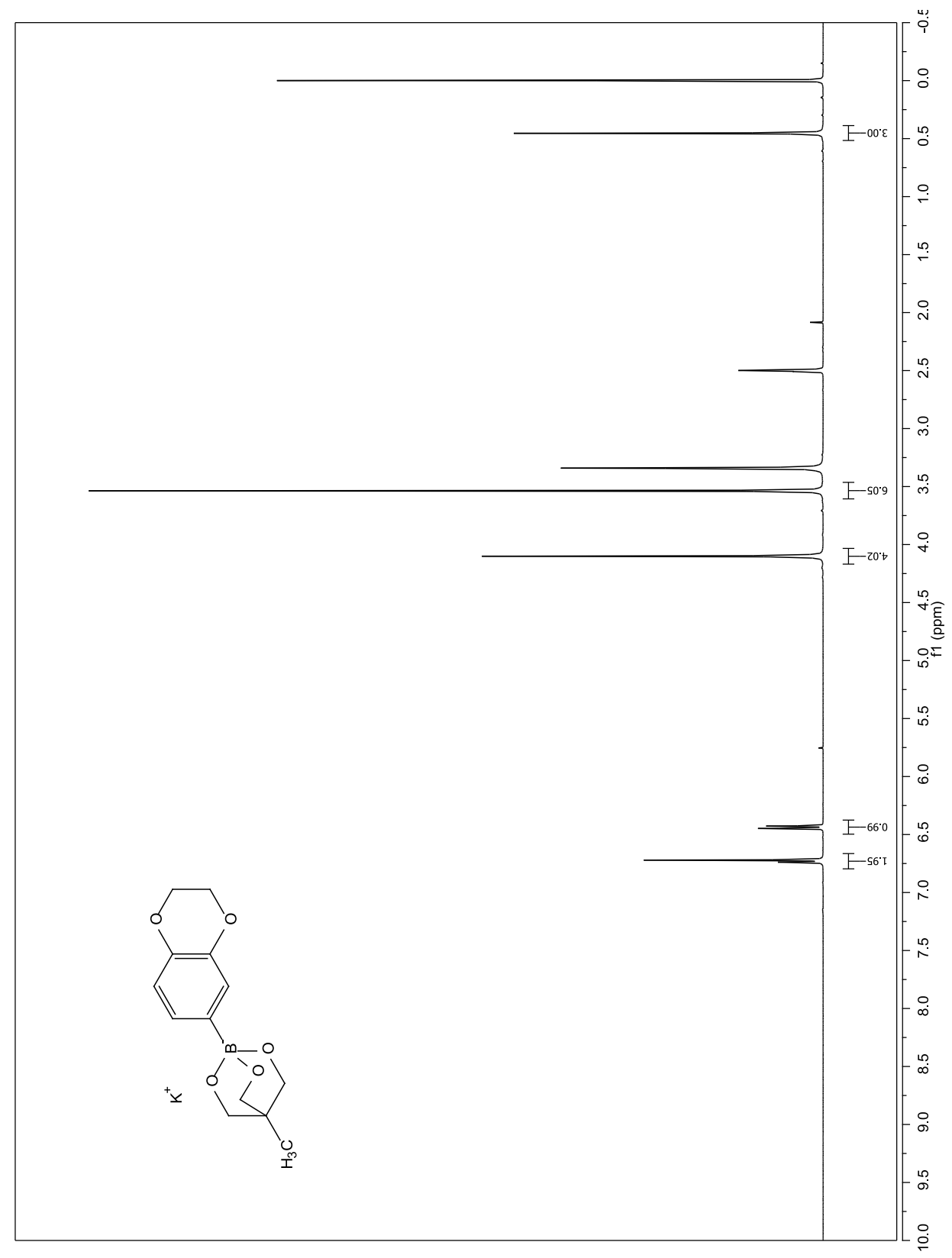




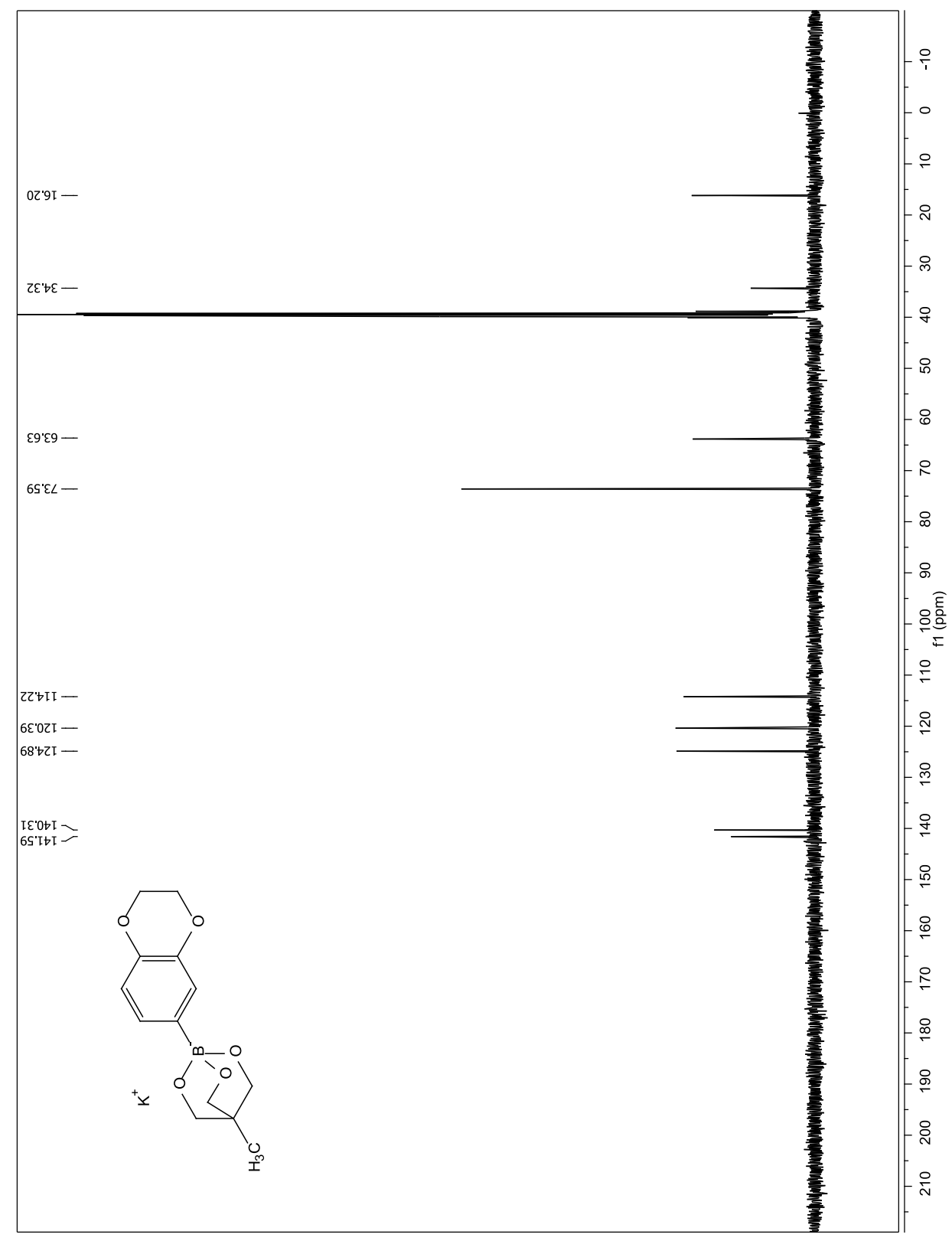




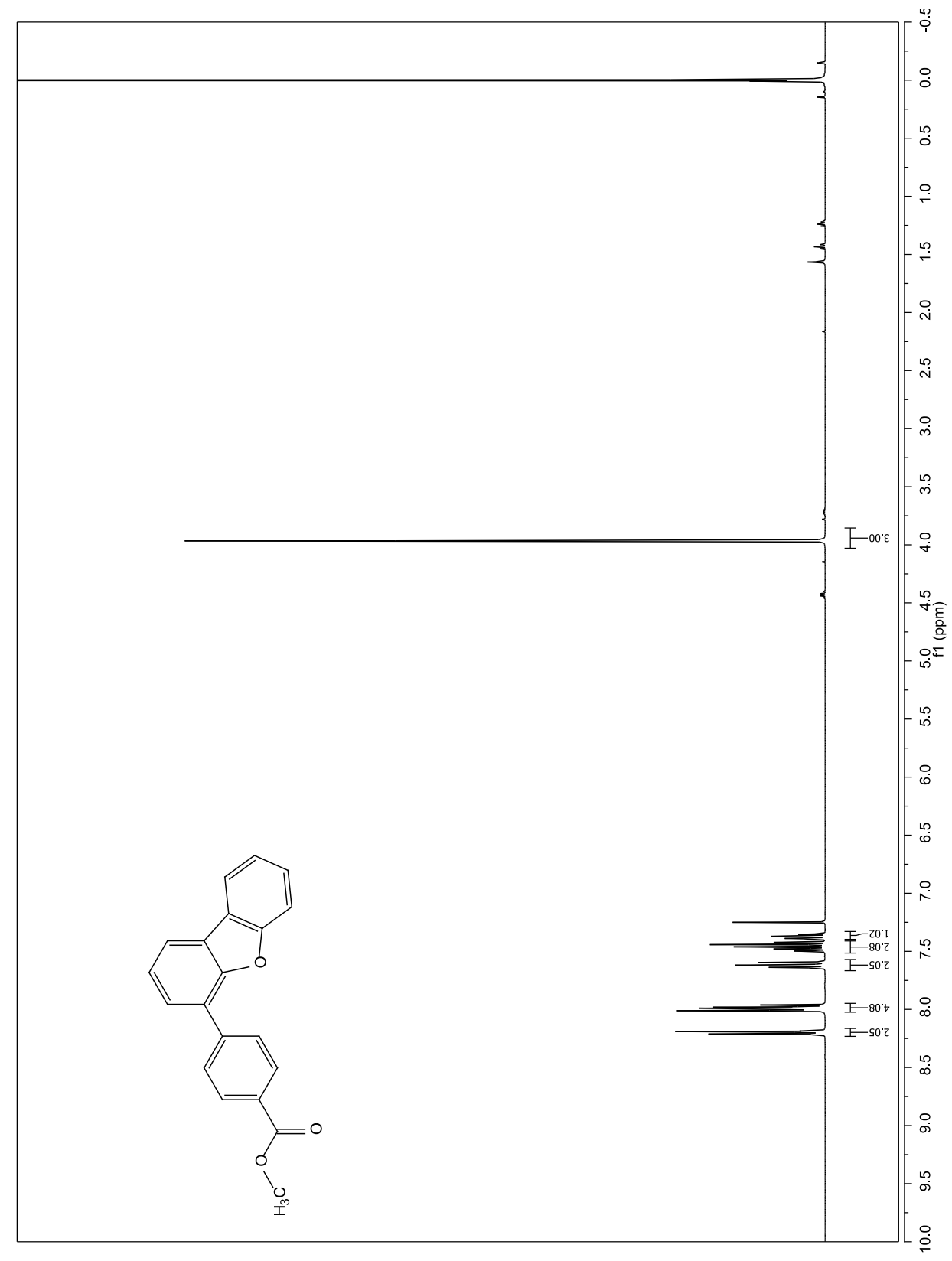




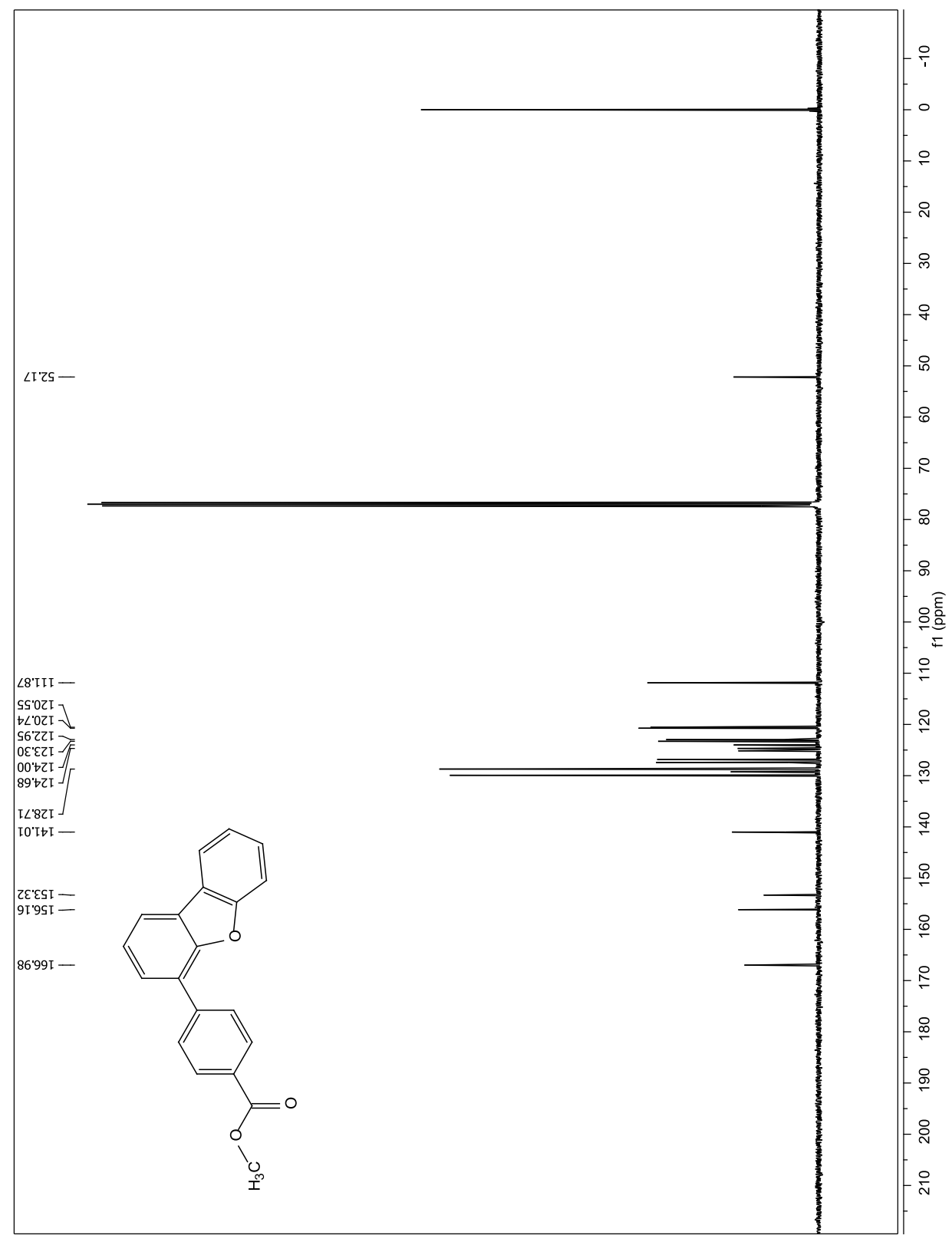




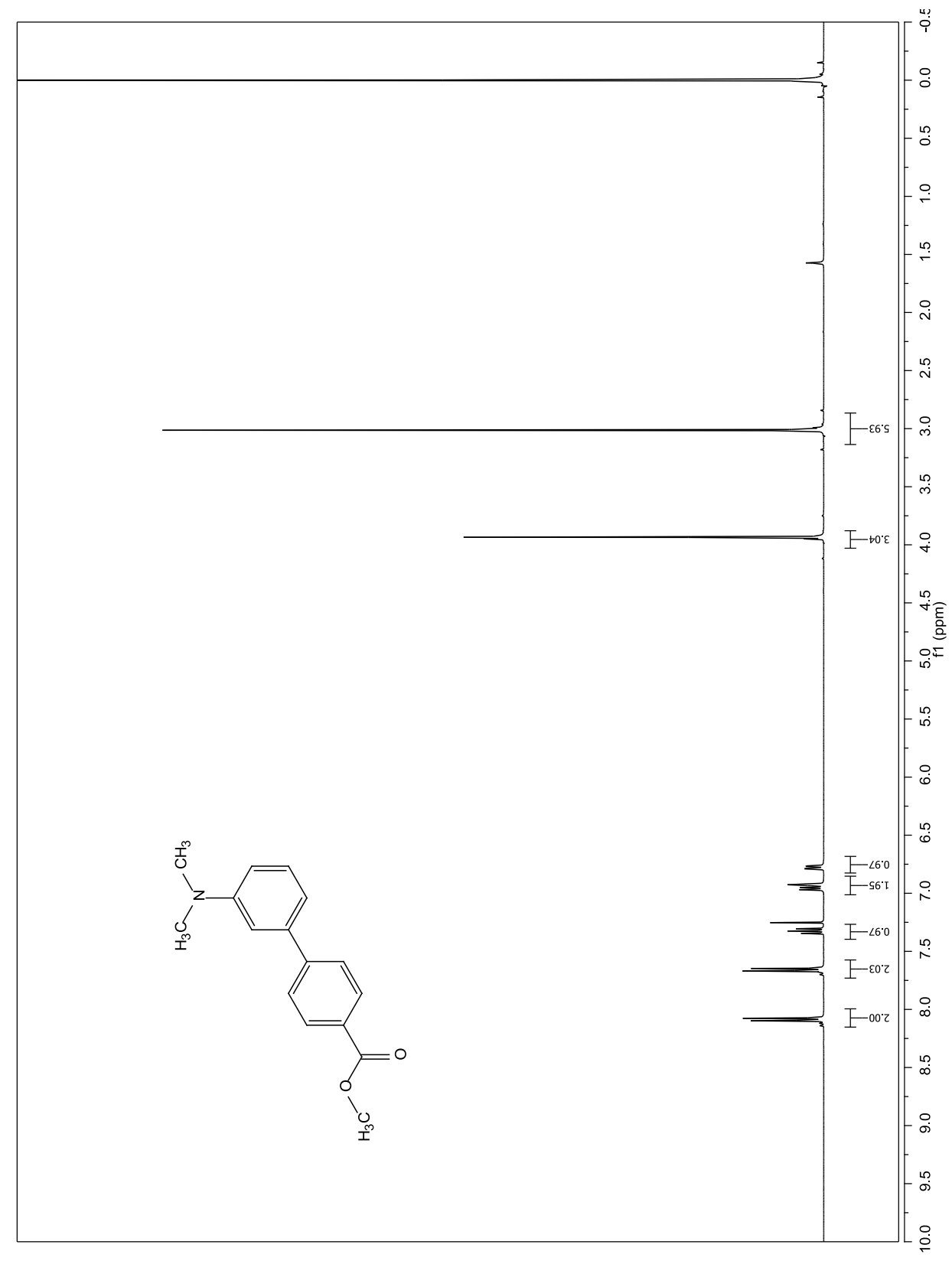




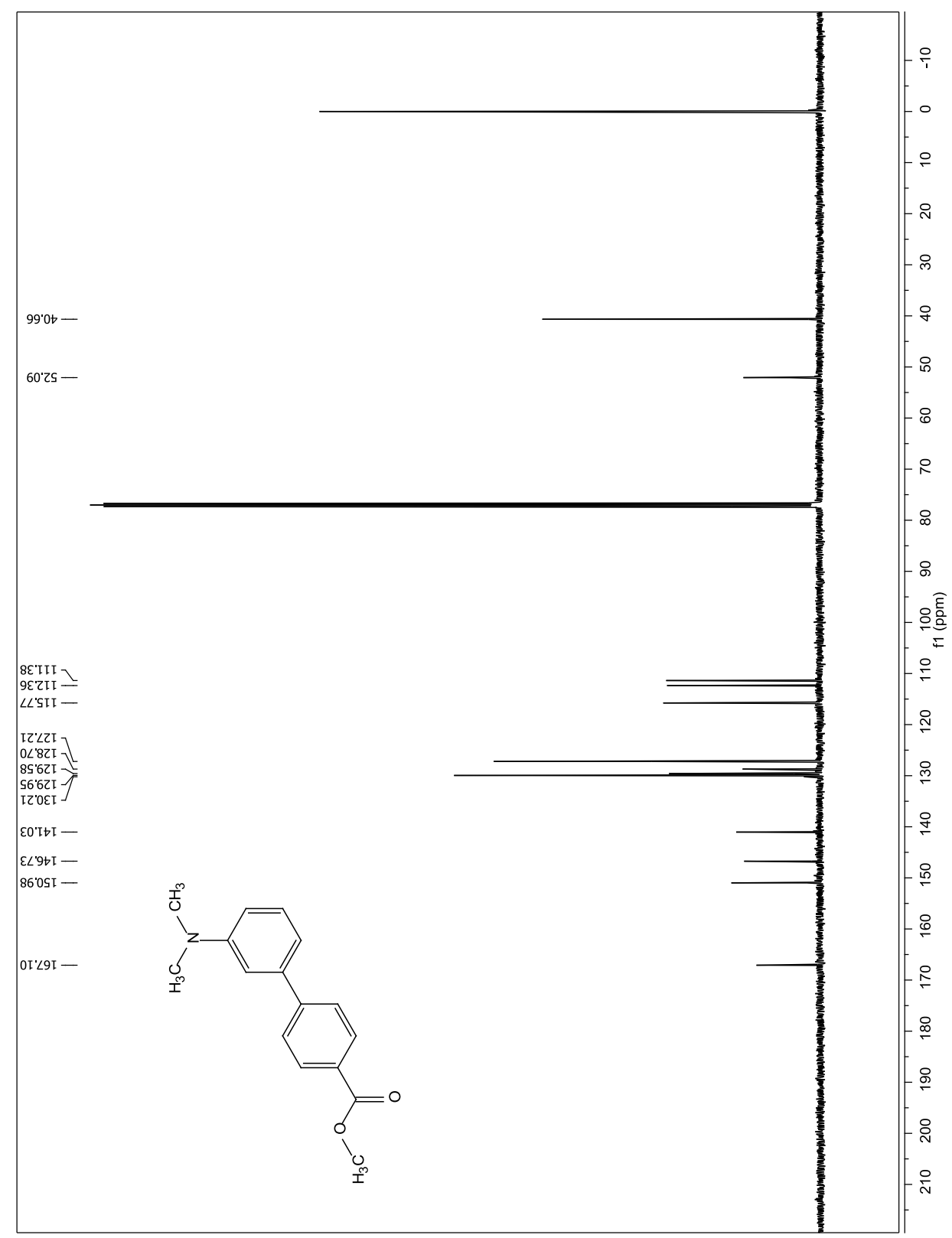




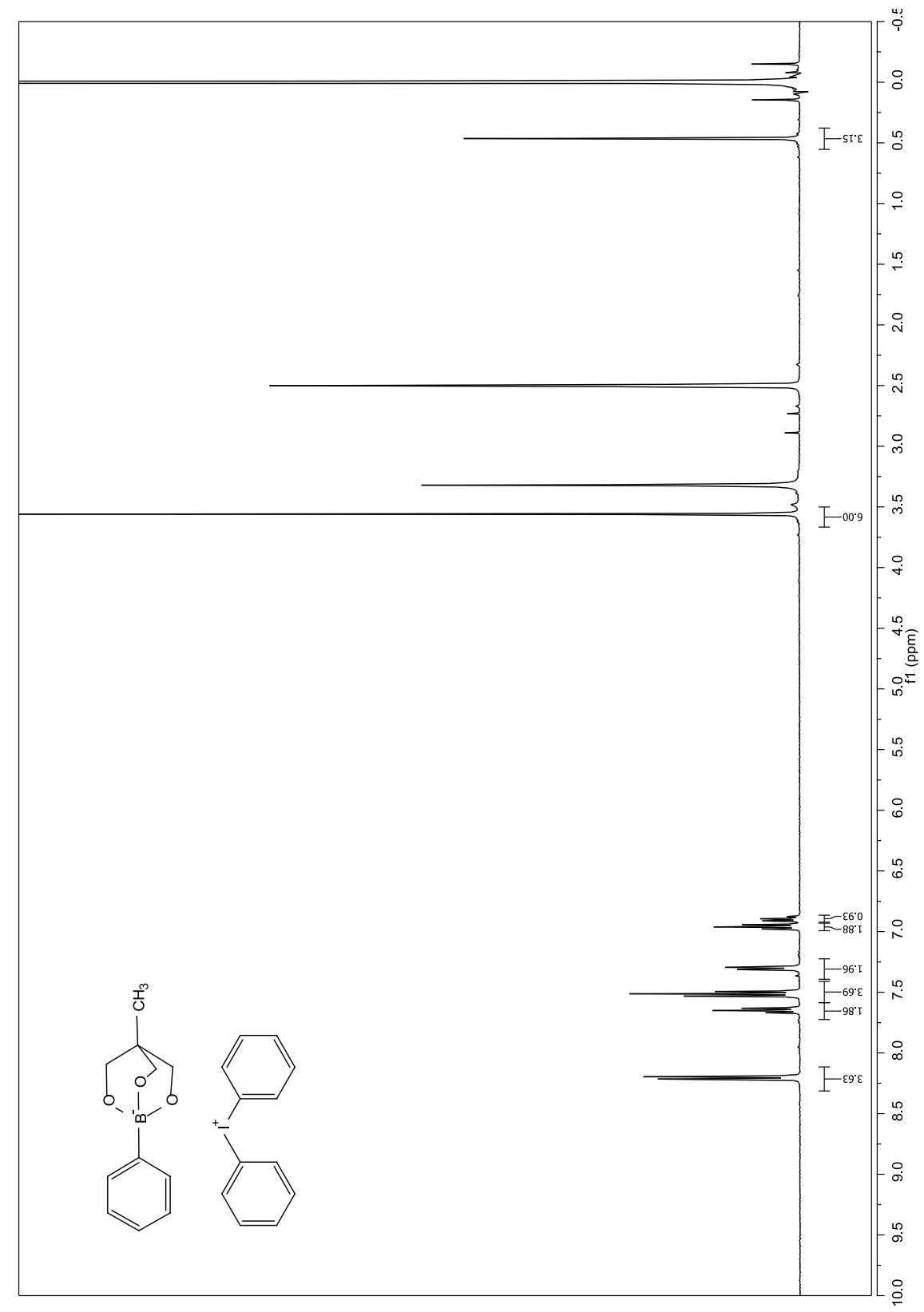

